\title{
Effective maxillary protraction: Hyrax expansion appliance vs. double-hinged expansion appliance
}

Thuy B. Do-deLatour

West Virginia University

Follow this and additional works at: https://researchrepository.wvu.edu/etd

\section{Recommended Citation}

Do-deLatour, Thuy B., "Effective maxillary protraction: Hyrax expansion appliance vs. double-hinged expansion appliance" (2009). Graduate Theses, Dissertations, and Problem Reports. 4456.

https://researchrepository.wvu.edu/etd/4456

This Thesis is protected by copyright and/or related rights. It has been brought to you by the The Research Repository @ WVU with permission from the rights-holder(s). You are free to use this Thesis in any way that is permitted by the copyright and related rights legislation that applies to your use. For other uses you must obtain permission from the rights-holder(s) directly, unless additional rights are indicated by a Creative Commons license in the record and/ or on the work itself. This Thesis has been accepted for inclusion in WVU Graduate Theses, Dissertations, and Problem Reports collection by an authorized administrator of The Research Repository @ WVU. For more information, please contact researchrepository@mail.wvu.edu. 


\title{
Effective Maxillary Protraction: \\ Hyrax Expansion Appliance vs. Double-hinged Expansion Appliance
}

Thuy B. Do-deLatour, DMD

Thesis submitted to the

School of Dentistry at West Virginia University

in partial fulfillment of the requirements

for the degree of

\author{
Master of Science \\ in \\ Orthodontics
}

\author{
Peter Ngan, D.M.D., Chairman \\ Chris Martin, D.D.S, M.S. \\ Thomas Razmus, D.D.S., M.S. \\ Department of Orthodontics
}

Morgantown, WV

2009

Keywords: maxillary protraction, double-hinged expander, hyrax expander, Alt-RAMEC 


\title{
ABSTRACT \\ Effective Maxillary Protraction: Hyrax Expansion Appliance vs. Double-hinged Expansion Appliance
}

\author{
Thuy B. Do-deLatour, DMD
}

Patients with a skeletal Class III malocclusion may have one of the following conditions: midface deficiency and/or mandibular hypertrophy/prognathism. If modification of the skeletal Class III growth pattern is not effectively accomplished at an early age via maxillary protraction, then orthognathic surgery would be required to help correct the skeletal Class III malocclusion. Some of the more serious risks associated with orthognathic surgery include parasthesia, bone and tissue necrosis, and possibly death. However, if one is able to effectively protract the maxilla, the need for anteriorposterior correction of the maxilla via orthognathic surgery will be minimized if not eliminated.

The purpose of this pilot study was to evaluate the quantitative difference, if any, between the conventional protraction technique using a one-time expansion and comparing it to a protraction protocol with the double-hinged expander as advocated by Liou. $^{1-3}$ The differences between the two techniques were evaluated on lateral cephalometric radiographs, in which the skeletal and dental changes with maxillary expansion and protraction were measured.

The results of this study found that both treatment groups experienced statistically significant sagittal changes as compared to the control group. But the primary reason for the improvement of the Class III malocclusion is related to the downward and backward rotation of the mandible. The Hyrax expansion group had more " $A$ " point forward movement; however, the success may have been attributed to the higher level of compliance in this group compared to the Double-hinged expansion group. Future studies reviewing the length of time that protraction forces are placed on the maxilla can help to clarify the results of protraction facemask therapy. Finally, more long-term studies are needed in order to evaluate the stability of the immediate success of maxillary expansion and protraction facemask therapy. 


\section{DEDICATION}

This thesis is dedicated to my family who have sacrificed so much for me to get to where I am today.

To my mother: Thank you for your unconditional love. You have sacrificed so much in order for me to have all that you did not have while growing up. Thank you for your dedication to helping me succeed and for taking care of my children. Because of your words of encouragement and your belief in me, I was able to achieve more than I thought was possible. I love you and will miss you always.

To my husband: Thank you for your loving support all of these years. You are my best friend and the best husband and father there is. Few men would be able to make the sacrifices that you have made. Thank you for taking such great care of me and helping me to attaining my career goals.

To my children: Thank you for your love and for making me so happy and blessed. You both are the love of my life. 


\section{ACKNOWLEDGEMENTS}

A special thanks are extended to the following individuals:

Dr. Peter Ngan for your kindness and generosity and for your mentorship.

Dr. Chris Martin for always being there to help me out.

Dr. Thomas Razmus for kindly serving as a member of my thesis committee.

Dr. Erdrogan Gunel for putting up with me and generating all of the statistics.

Rajia Sebbahi for your friendship and pep-talks.

Kolin and family for your friendship and morning commutes.

Michael Becht for being a great classmate.

The Residents for all of the great memories. 


\section{CONTENTS}

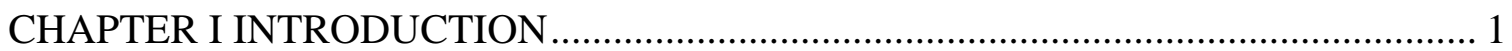

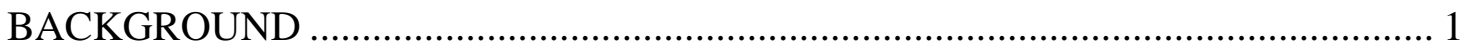

STATEMENT OF THE PROBLEM ….............................................................. 2

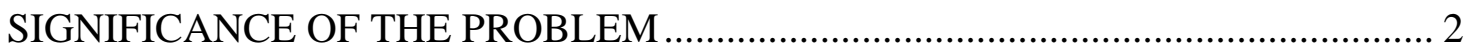

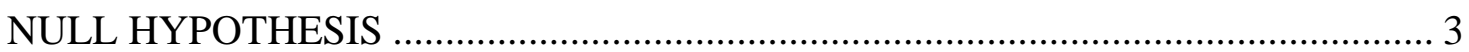

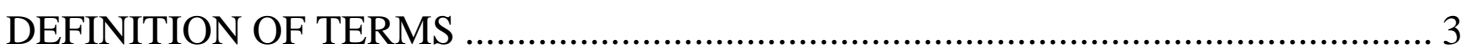

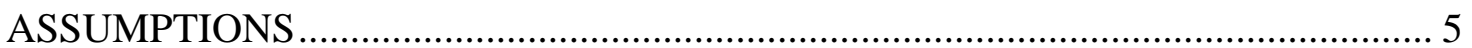

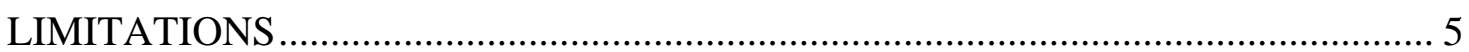

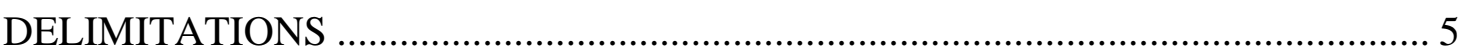

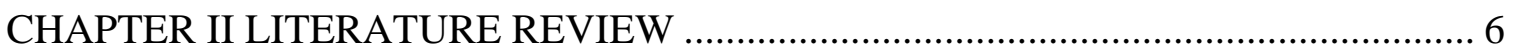

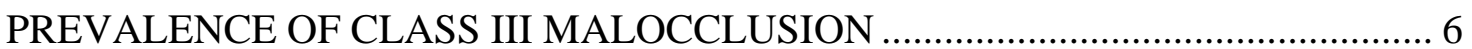

MORPHOLOGIC CHARACTERISTICS OF CLASS III MALOCCLUSION ............ 7

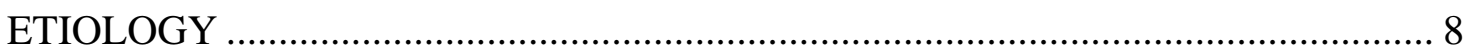

SKELETAL CLASS III GROWTH. ............................................................... 9

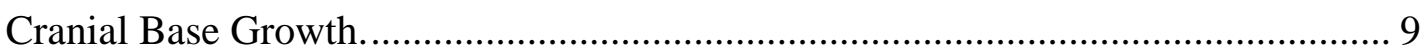

Nasomaxillary Complex. .............................................................................. 10

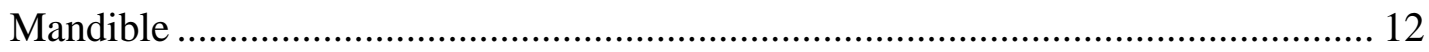

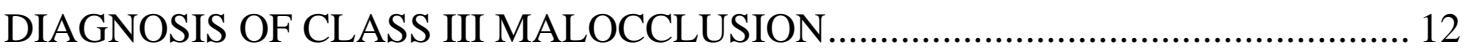

TREATMENT OF CLASS III MALOCCLUSION ................................................. 14

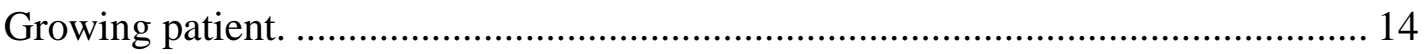

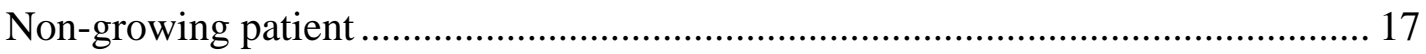

Methods of Early Treatment of Class III Malocclusion .......................................... 18

CHAPTER III MATERIALS AND METHODS ...................................................... 32

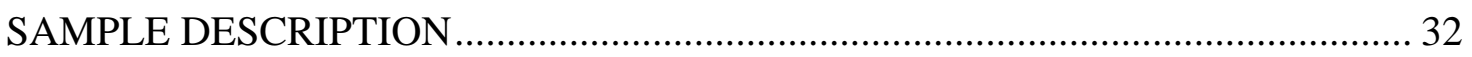

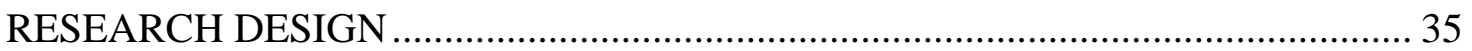

Appliance Design and Expansion Protocol............................................................ 35

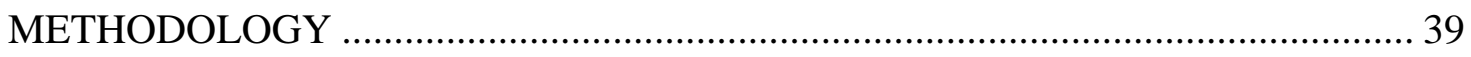

Reliability of Cephalometric Measurements .................................................... 40

Cephalometric Landmarks and Reference Planes................................................ 41

Measuring Procedure for Sagittal Changes......................................................... 43

Measuring Procedure for Vertical Changes.......................................................... 44

Measuring Procedure for Angular Changes......................................................... 45

Evaluation of Overjet and Molar Relationship Correction .................................... 46 
STATISTICAL TREATMENT ............................................................................ 47

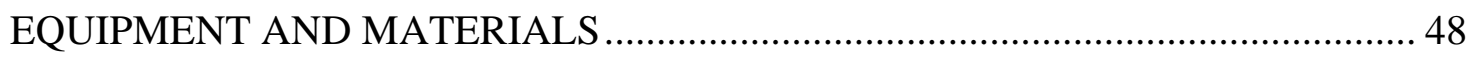

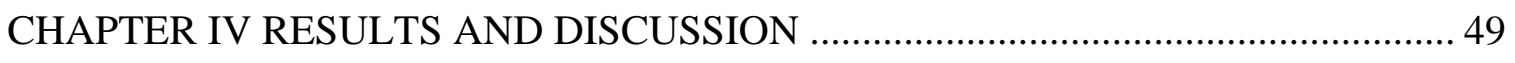

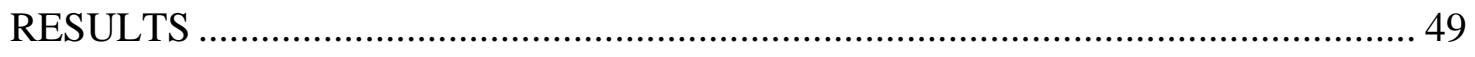

Reliability of Cephalometric Measurements .......................................................... 50

Statistical Significance Within the Treated Group ………………………………...... 53

Statistical Significance Within the Control Group ……………………………….... 59

Comparison of Treated and Control Groups............................................................. 62

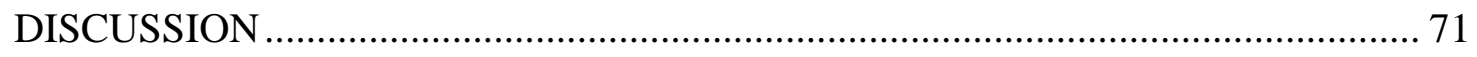

Reliability of Cephalometric Measurements ............................................................ 71

Comparison of All Groups................................................................................. 71

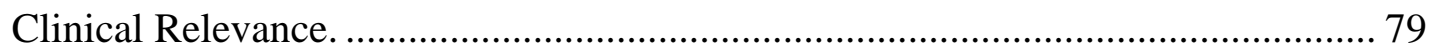

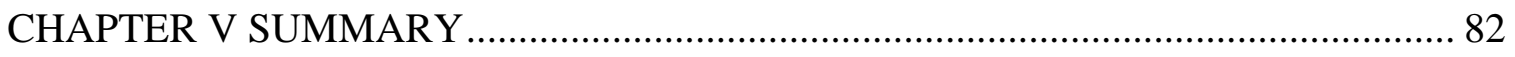

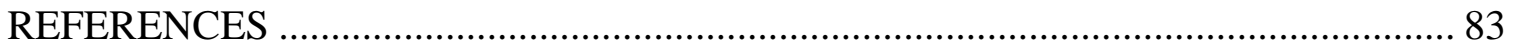

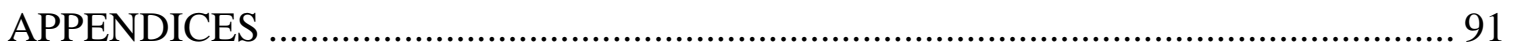

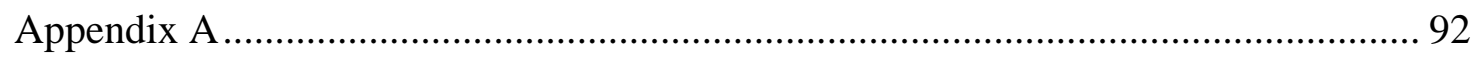

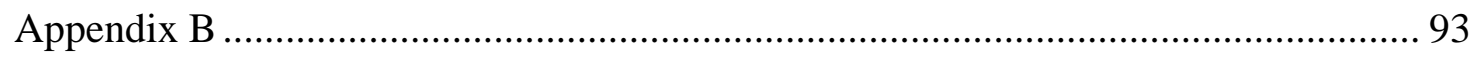

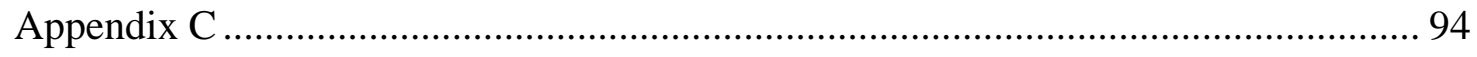

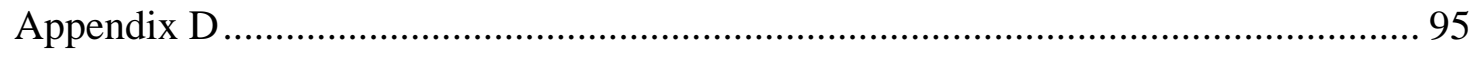

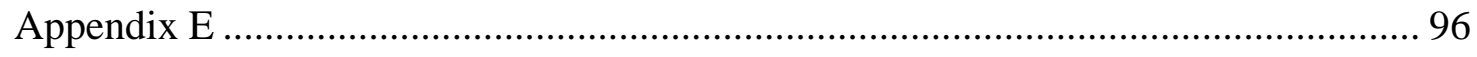

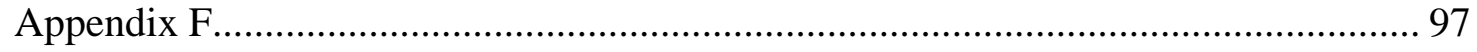

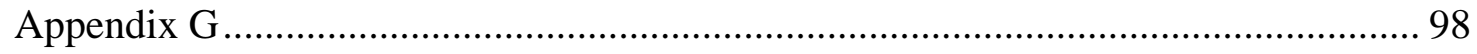

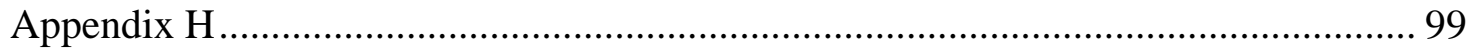




\section{LIST OF TABLES}

Table 1. Reported Incidence of Class III Malocclusion..................................................

Table 2. Prevalence of Maxillary and Mandibular Anterior-Posterior Deficiency.......8

Table 3. Maxillary Length Changes.........................................................................11

Table 4. Positive and Negative Factors Influencing the Decision for Early Treatment .......................................................................................14

Table 5. Symbols for the Different Time Intervals.....................................................32

Table 6. Chronologic Age Distribution of Treatment and Control Samples ...............33

Table 7. $\quad$ CVM of Treatment and Control Samples .........................................................34

Table 8. The Seventeen Skeletal and Dental Landmarks...........................................42

Table 9. Definition of the Reference Lines............................................................

Table 10. The Sagittal Measurements of Variables (1-9) ..............................................44

Table 11. The Vertical Measurements of Variables (10-16) ..........................................45

Table 12. The Angular Measurements of Variables (17-24) ..........................................46

Table 13. Calculation of Overjet and Molar Relationship Changes. ..............................46

Table 14. Intraclass Correlation Coefficient of Reliability for

Sagittal, Vertical, Angular Measurements, and Superimpositions ................51

Table 15. Sagittal Measurements at T1 and T2 in the Double-hinged Expander Group ......................................................................53

Table 16. Vertical Measurements at T1 and T2 in the Double-hinged Expander Group ....................................................................54

Table 17. Angular Measurements at T1 and T2 in the Double-hinged Expander Group .....................................................................55

Table 18. Sagittal Measurements at T1 and T2 in the Hyrax Expander Group ............................................................................56

Table 19. Vertical Measurements at T1 and T2 in the Hyrax Expander Group ...............................................................................57

Table 20. Angular Measurements at T1 and T2 in the Hyrax Expander Group 58

Table 21. Sagittal Measurements at $\mathrm{t} 1$ and t2 for the Control Group ............................60

Table 22. Vertical Measurements at $\mathrm{t} 1$ and $\mathrm{t} 2$ in Control Group..................................61

Table 23. Angular Measurements at t1 and t2 in Control Group....................................62

Table 24. Comparison of the Mean Difference Among all Groups................................63

Table 25. Mean Change in SNA Following Protraction Facemask Therapy..................78 


\section{LIST OF FIGURES}

Figure 1. Hyrax Expander with Protraction Hooks......................................................36

Figure 2. Double-Hinged Expander with Protraction Hooks ............................................36

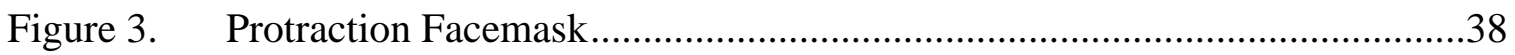

Figure 5. The Skeletal and Dental Landmarks ............................................................41

Figure 6. The Reference Grid (Ols and Olp) and Measuring Points Used in the Sagittal Cephalometric Analysis....................................................................43

Figure 7. The Reference Lines and Measuring Points Used in the Vertical Cephalometric Analysis ..................................................................44

Figure 8. The Reference Lines and Measuring Points Used for the Angular Cephalometric Analysis.................................................................45

Figure 9. Total Observation (Double Hinged): Sagittal Changes ...................................67

Figure 10. Total Observation (Hyrax): Sagittal Changes..................................................67

Figure 11. Total Observation (Double Hinged): Vertical and Angular Changes............69

Figure 12. Total Observation (Hyrax): Vertical and Angular Changes ..........................69 


\section{CHAPTER I}

\section{INTRODUCTION}

\section{BACKGROUND}

Patients having a Class III malocclusion may present with an anterior crossbite and/or a Class III molar relationship. Proclination of mandibular incisors and retroclination of maxillary incisors can cause posturing of the mandible in an anterior position due to incisal interference. This is a condition known as pseudo-Class III malocclusion and is really a Class I malocclusion. Individuals with a true skeletal Class III malocclusion present with one of the following conditions: midface deficiency and/or mandibular hypertrophy/prognathism. ${ }^{4}$ It has been reported that a significant percentage of the skeletal Class III malocclusion cases are due to maxillary retrusion ${ }^{5,6}$. The incidence of Class III malocclusion among American children is about $1 \%$ and is slightly higher in youths and adults ${ }^{7}$; whereas, the prevalence of Class III malocclusion in the Chinese and Japanese populations has been found to be as high as $14 \% .^{8,9}$ The etiology of Class III malocclusion can be genetic or environmental.

Early treatment using protraction facemask therapy in conjunction with rapid maxillary expansion appliance has been shown to be successful in correcting skeletal Class III malocclusions that are due primarily to deficient maxillary development. ${ }^{10-12}$ Rapid maxillary expansion is used to disarticulate the maxilla from the surrounding bones which are connected by circum-maxillary sutures. ${ }^{2}$ The goal of combining the rapid maxillary expansion appliance with the protraction face-mask is to provide a more effective protraction of the maxilla. ${ }^{13-16}$ However, studies have shown that the average 
amount of maxillary protraction is only about $1.5 \mathrm{~mm}$ - 3mm over a period of 8-12

months. ${ }^{17-19}$ Furthermore, the circum-maxillary sutures start to interlock or interdigitate during pubertal growth spurt making it difficult to protract in older patients. ${ }^{20}$ Liou et al. ${ }^{2}$ reported the use of a double-hinged expander as having a center of rotation around the tuberosity, which differs from the conventional Hyrax expander; therefore, the doublehinged expander will give a more forward movement of the maxilla during expansion. In addition, the repeated expansion and contraction of the maxilla seems to help in loosening the circum-maxillary sutures, allowing a more effective forward movement of the maxilla during protraction.

The purpose of this study is to evaluate the quantitative difference, if any, between the conventional protraction technique using the traditional Hyrax expander and the new protraction protocol with the double-hinged expander as advocated by Liou. The differences between the two techniques will be evaluated on lateral cephalometric radiographs, in which the skeletal and dental changes with maxillary expansion and protraction will be measured.

\section{STATEMENT OF THE PROBLEM}

Can multiple expansion and contraction of the maxilla using the double-hinged expander lead to a more effective protraction of the maxilla as compared to a one-time expansion technique using the Hyrax expander?

\section{SIGNIFICANCE OF THE PROBLEM}

A patient with a skeletal Class III malocclusion may have one of the following conditions: midface deficiency and/or mandibular hypertrophy/prognathism. If modification of the skeletal Class III growth pattern is not effectively accomplished at an 
early age via maxillary protraction, then the patient will require orthognathic surgery in order to correct his/her skeletal Class III malocclusion. Some of the more serious risks associated with orthognathic surgery include parasthesia, bone and tissue necrosis, and possibly death. However, if one is able to effectively protract the maxilla, then the need for anterior-posterior correction of the maxilla via orthognathic surgery will be minimized if not eliminated.

\section{NULL HYPOTHESIS}

No significant difference in the skeletal and dental changes when comparing onetime expansion using Hyrax expander and multiple expansion and constriction using a Double-hinged expander for maxillary protraction.

\section{DEFINITION OF TERMS}

1. Prognathic: Forward relationship of the mandible relative to the craniofacial skeleton.

2. Retrusion: Teeth and/or jaw posterior to their normal positions.

3. Facial concavity: A term applied to the analysis of a profile. The shape is described as an inwardly rounded curve from the forehead to the lips to the chin. A concave facial profile is often associated with a Class III malocclusion.

4. Class III malocclusion: Mesial (anterior) relationship of the lower first molar to the upper, a retruded relationship of the upper first molar to the lower, or a combination of the two. The mesiobuccal cusp of the upper first molar will typically occlude near the embrasure between the lower first and second molars. Also, a patient with a skeletal Class III malocclusion may have one of the following conditions: midface deficiency and/or mandibular hypertrophy/prognathism. 
5. Pseudo-Class III malocclusion: Proclination of mandibular incisors and retroclination of maxillary incisors can cause posturing of the mandible in an anterior position due to incisal interference.

6. Overbite: Vertical overlapping of upper teeth over lower teeth, usually measured perpendicular to occlusal plane.

7. Overjet: Horizontal projection of upper teeth beyond the lower teeth, usually measured parallel to the occlusal plane.

8. Rapid maxillary (palatal) expansion: Orthopedic widening of the two halves of the maxilla using the high load system.

9. Protraction facemask: An extra-oral protraction appliance used to exert a forward vector of force on the maxilla; for example, in maxillary deficiency problems.

10. Hyrax expander: This is the more commonly used type of banded rapid maxillary expansion appliance. Bands are placed on the maxillary first molars and first premolars. The expansion screw is located in the palate in close proximity to the palatal contour. Buccal and lingual support wires also may be added for rigidity.

11. Double-hinged expander: A 2-hinged rapid maxillary expander in which the expander is oriented perpendicular to the intermaxillary suture and is soldered to the molar and premolar bands. Two anterior expansion arms (0.051 inch stainless steel wires) extend bilaterally from the premolar bands toward central incisors.

12. Growth spurt: A rapid increase in height and weight, which typically occurs during puberty. 


\section{ASSUMPTIONS}

It was assumed that maxillary sutural separation will occur in the treated sample. Furthermore, it was assumed that the maxilla will move forward and downward with orthopedic force from protraction facemask therapy and that growth is constant (i.e., there is no growth spurt). The final assumption was that the lateral cephalograms for the treated and control groups were taken with the subjects in centric occlusion.

\section{LIMITATIONS}

1. Age differences amongst patients -- Growth spurts occurs at different times amongst patients

2. Gender differences amongst patients

3. Ethnicity differences amongst patients

4. Health history differences amongst patients

5. Cooperation differences amongst patients / parents

\section{DELIMITATIONS}

1. Only two types of RPE appliances were used
a. Double-hinged expander
b. Hyrax expander

2. CVM was used to match the experimental and control groups

3. Class III patients before growth spurt were utilized in this study to minimize growth differences among subjects. 


\section{CHAPTER II}

\section{LITERATURE REVIEW}

The review of related literature on Class III malocclusion was divided into five categories. These categories are listed below in order of presentation:

1. Prevalence of Class III malocclusion

2. Morphologic characteristics

3. Etiology

4. Diagnosis

5. Treatment of Class III malocclusion

\section{PREVALENCE OF CLASS III MALOCCLUSION}

The incidence of skeletal Class III malocclusion varies among different ethnic groups. The prevalence among Caucasian population is approximately 3-5 percent. ${ }^{21-27}$ In the United States, the Class III malocclusion is a less commonly observed clinical problem than Class II or Class I malocclusion and accounts for about $1 \%$ of the population. ${ }^{7}$ In U.S. studies of African American population groups, the incidence of Class III malocclusion was reported to be about 6.3 percent. ${ }^{28}$ Although few epidemiologic studies are available for other racial groups, there is reportedly a higher frequency of skeletal Class III malocclusion among the Oriental population. ${ }^{7}$ The prevalence of Class III malocclusion in Japan has been reported to be 4-13\%, and in populations of Chinese descent it has been reported to be as high as $14.51 \%$ of the 834 children who were surveyed. ${ }^{8,9,29,30}$ Table 1 lists reported incidences of Class III malocclusion. 
Table 1. Reported Incidence of Class III Malocclusion.

\begin{tabular}{|c|c|c|c|}
\hline Investigators & Date & Sample & Incidence \\
\hline Ainsworth $^{27}$ & 1925 & 4,170 (2-15 years) & $1.35 \%$ \\
\hline Huber \& Reynolds ${ }^{21}$ & 1946 & 500 (16-32 years) & $12.2 \%$ \\
\hline Bjork $^{31}$ & 1947 & 322 (boys 12 years) & $2.8 \%$ \\
\hline Enrich et al. ${ }^{32}$ & 1947 & 1,476 (12-14 years) & $3 \%$ \\
\hline Humphreys et al. ${ }^{22}$ & 1950 & 2,711 (2-5 years) & $1.52 \%$ \\
\hline Massler \& Frankel ${ }^{23}$ & 1951 & 2,758 (14-18 years) & $9.4 \%$ \\
\hline Hills et al. ${ }^{24}$ & 1959 & 4,251 (6-8 years) & $1 \%$ \\
\hline Altemus $^{33}$ & 1959 & 3,280 (12-16 years) & $5 \%$ \\
\hline Allwright \& Bundred ${ }^{30}$ & 1964 & 834 (6-11 years) & $14.51 \%$ \\
\hline Horowitz \& Doyle ${ }^{34}$ & 1970 & 410 (9-14 years) & $8.7 \%$ \\
\hline Garner \& Butt ${ }^{28}$ & 1985 & 445 (13-15 years) & $6.3 \%$ \\
\hline
\end{tabular}

\section{MORPHOLOGIC CHARACTERISTICS OF CLASS III MALOCCLUSION}

Patients with Class III malocclusion may present with various combinations of abnormal dental and skeletal patterns. Dentally, patients with a Class III malocclusion will tend to have the following characteristics: Angle Class III molars and canines, retroclined mandibular incisors, proclined maxillary incisors, and edge-to-edge incisor relationship or negative overjet. Patients with a skeletal Class III pattern, however, typically present with a concave-appearing profile where the tip of the chin and the lower lip will be in front of a vertical line drawn from nasion, perpendicular to the Frankfort horizontal. Table 2 presents the various combinations of skeletal components of a Class III malocclusion, as reported by Ellis and McNamara. ${ }^{6}$ 
Table 2. Prevalence of Maxillary and Mandibular Anterior-Posterior Deficiency

\begin{tabular}{|c|c|c|c|}
\hline Group & Maxilla & Mandible & \% \\
\hline I & Retrusive & Protrusive & 30.1 \\
\hline II & Retrusive & Neutral & 19.5 \\
\hline III & Neutral & Protrusive & 19.2 \\
\hline IV & Protrusive & Protrusive & 14.9 \\
\hline V & Retrusive & Retrusive & 7.9 \\
\hline VI & Neutral & Neutral & 4.6 \\
\hline VII & Neutral & Retrusive & 1.6 \\
\hline VIII & Protrusive & Neutral & 1.6 \\
\hline IX & Protrusive & Retrusive & 0.33 \\
\hline
\end{tabular}

Based on the results found in Table 2, a retrusive maxilla and protrusive mandible was the most prevalent skeletal combination in Class III malocclusion. A study conducted by Guyer and colleagues ${ }^{5}$ reported similar results in that $25 \%$ of the 144 Michigan children, who were between the ages of 5 and 15 years and had a Class III malocclusion with a retrusive maxilla and a protrusive mandible.

\section{ETIOLOGY}

The few human studies that focus on the role of genetics with regards to Class III malocclusion support the belief that the growth and size of the mandible is predetermined by hereditary. ${ }^{35,36}$ Other studies have found that Class III malocclusion also has an environmental etiology. Rakosi and Schilli ${ }^{37}$ reported that individuals who mouthbreathes or have mandibular postural habits may present with a Class III type of malocclusion because the tongue tends to be flat and anteriorly displaced which then results in the widening of the mandibular arch laterally and anteriorly. Discontinuation of the habit allows for the malocclusion to self-correct. Rakosi and Schilli also noted that interferences in occlusal function, such as reverse overjet, can alter the direction of 
mandibular growth and the shape of the mandible. Early correction of a pseudo-Class III malocclusion creates a more favorable development of the maxilla and mandible. ${ }^{37}$

\section{SKELETAL CLASS III GROWTH.}

Although functional disturbances play a small role in the number of Class III malocclusions, it can definitely accentuate a Class III growth tendency. However, the more severe Class III cases tend to be the result of genetics and can be worsened by environmental factors. ${ }^{7}$ Therefore, to have a better understanding of the Class III skeletal pattern it is important to review the growth of the cranial base, the nasomaxillary complex, and the mandible.

\section{Cranial Base Growth.}

The cranium primarily grows by the following processes: (1) deposition on the outer cortex; (2) resorption of the inner cortex; and (3) deposition in the spheno-occipital synchondrosis. According to Enlow, ${ }^{38}$ the spheno-occipital synchondrosis is a major growth center and enlarges by endochondral growth. Also, the spheno-occipital synchondrosis has a pressure-adaptive growth mechanism that displaces bones as it grows bi-directionally.

Many studies have focused on the relationship between the cranial base and facial skeleton. Singh ${ }^{39}$ have found that the posterior cranial base length represented by Pc-Bo (posterior clinoid process-Bolton point) was consistently and significantly shorter in prepubertal Class III subjects. This provides support for the contention that the development within the petro-occipital complex account for elongation of the posterior cranial fossa. Thus, a developmental deficiency of the posterior cranial base could be 
associated with the development of Class III malocclusion because of a prognathic cranio-mandibular articulation. ${ }^{39}$

In addition, Hopkin ${ }^{40}$ and Jarvinen ${ }^{41}$ reported that Ar-SN (Articulare-SellaNasion) angle was smaller in skeletal Class III patients as compared to skeletal Class II patients. There have been many reports that an acute cranial base angle was correlated with skeletal Class III malocclusion. ${ }^{40-43}$ In 2001, Hong ${ }^{44}$ demonstrated that subjects with flexion of the cranial base tend to have a maxillary counterclockwise rotation in which there was more vertical growth of the posterior maxilla, anterior rotation of the anterior maxilla, and proclination of the upper incisors. According to Hong, the maxillary rotational growth can affect the glenoid fossa and could consequently bring about changes in the mandibular position.

The morphology of the cranial base is therefore an important factor in establishing the antero-posterior relationship of the jaws. Class III individuals tend to have an anterior cranial base that is wider and shorter, thereby establishing a foreshortened but wider palate and maxillary arch. Also, the middle cranial fossa is aligned backward and upward which then places the nasomaxillary complex in a more retrusive position and creates the brachiocephalic facial form.

\section{Nasomaxillary Complex.}

Growth of the nasomaxillary area is a result of active growth at the maxillary sutures and nose and passive, forward displacement of the maxilla created by growth in the cranial base. ${ }^{7}$ As the maxilla moves downward and forward, the space at the sutures is filled in by bone proliferation. Growth in the synchondroses decreases with the completion of the neural growth around 7 years of age, and passive displacement of the 
maxilla decreases as well. Active growth accounts for most of the forward movement of the maxilla between ages 7 to 15 as seen in Table 3 .

Table 3. Maxillary Length Changes. (From University of Michigan Center for Human Growth)

\begin{tabular}{|c|c|c|c|c|}
\hline AGE & \multicolumn{2}{|c|}{$\begin{array}{c}\text { Total forward movement of the } \\
\text { maxilla (mm) (basion-ANS } \\
\text { increment) }\end{array}$} & $\begin{array}{c}\text { Forward displacement of the maxilla } \\
\text { (mm) (basion-PNS increment) }\end{array}$ \\
\hline & Male & Female & Male & Female \\
\hline 7 & 1.3 & 2.1 & 0.0 & 0.8 \\
\hline 8 & 1.5 & 1.8 & 0.9 & 1.1 \\
\hline 9 & 1.6 & 0.4 & 0.4 & 0.4 \\
\hline 10 & 1.8 & 2.0 & 0.8 & 0.2 \\
\hline 11 & 1.9 & 1.0 & 0.2 & 0.2 \\
\hline 12 & 2.0 & 1.3 & 0.4 & 1.1 \\
\hline 13 & 2.1 & 1.2 & 1.0 & -0.1 \\
\hline 14 & 1.1 & 1.5 & 0.3 & 0.1 \\
\hline 15 & 1.2 & 1.1 & 0.4 & 0.8 \\
\hline
\end{tabular}

Profitt $^{7}$ and McNamara ${ }^{45}$ have reported normal growth of the maxilla is usually 1-2 $\mathrm{mm}$ per year, and there is a linear relationship with respect to the effective maxillary length (Co-A point) as compared to the effective mandibular length (Co-Gn). Many studies have reported that Class III skeletal malocclusions are due to a deficient maxillary corpus length. ${ }^{31,46}$ Maxillary growth in the sagittal, vertical, and transverse dimensions occurs at the fronto-maxillary, palato-maxillary, and midpalatal sutures. Any developmental aberration will invariably affect the midfacial complex and result in maxillary hypoplasia and midfacial retrusion. In turn, the dento-alveolar regions alone or the entire midface can be affected. Singh found that the variability of the midfacial complex in Class III malocclusions is due to developmental deficiency at the transverse palatine suture and that acute angulation of the maxillary incisor acts as a compensatory occlusal mechanism for the shorter maxilla relative to the longer mandible. ${ }^{39}$ 


\section{Mandible}

Mandibular growth involves bone deposition and resorption in a posterior and superior direction. The condyle grows toward the glenoid fossa and displaces the entire mandible in a forward and downward position. ${ }^{7}$ A hyperdivergent skeletal Class III open-bite pattern exists when the following features are present: (1) a steeper mandibular occlusal plane; (2) an increased gonial angle; (3) an increased mandibular plane angle; (4) a more downward and backward location of the mandibular ramus; and (5) an increased total anterior facial height and lower facial height. ${ }^{6}$ On the other hand, if the ascending ramus is shorter and the gonial angle is more obtuse, then there exists a hypodivergent or horizontal growth pattern of the jaw. ${ }^{47,48}$

Battagel $^{48}$ found that the primary reason for a Class III incisor relationship was because the lower jaw had an increase body length and because its articulation was more ventrally located. Another common feature of Class III malocclusions is a more anteriorly positioned condyle. ${ }^{49}$ Although an increased mandibular length is commonly found in Class III malocclusions, the mandible's position is responsible for most of its prominence rather than its length.

\section{DIAGNOSIS OF CLASS III MALOCCLUSION}

Differential diagnosis of the skeletal Class III malocclusion is important in attaining treatment success. However, the prognosis is obscure until growth is completed. Furthermore, variations in magnitude and expression of the Class III malocclusion can make diagnosing difficult. In order to differentiate the underlying cause of a Class III malocclusion, a systematic approach should be employed. Several authors have made the following recommendations in the assessment of Class III 
patients. $^{50-52}$ First and foremost, a thorough family history must be obtained because the Class III malocclusion has a strong genetic component. Any facial (skeletal and dental) characteristics that are shared among siblings, parents, and relatives, should be noted.

Next, perform a clinical exam and make note of the patient's overall facial proportions, chin position, midface profile, and assess the patient's occlusion. An examination of the occlusion should involve both a clinically judgment and a visual analysis of high quality orthodontically trimmed study models. Components of the occlusal exam should include: incisor relationship, overjet and overbite, maxillary and mandibular incisor inclinations, buccal segment relationships, arch alignment (e.g., crowding, spacing, and rotations), crossbites, supernumerary/missing teeth, and dental anomalies. Be sure to check for the presence of a functional shift by placing the patient in centric relation (CR) and observing if the patient slides into centric occlusion (CO). If the $\mathrm{CO} / \mathrm{CR}$ discrepancy is due to an anterior functional shift, then the patient is considered to have a pseudo-Class III malocclusion. In other words, this patient will present with a Class I skeletal pattern, normal facial profile, and Class I molar relation in centric relation, but in centric occlusion he/she will present as a Class III skeletal and dental pattern. In this case, early treatment will benefit the patient and provide a favorable maxillary and mandibular growth environment.

Following the clinical exam, one needs to quantitatively assess the severity of the Class III malocclusion via cephalometric analysis (e.g., Wits appraisal, SNA, SNB, and linear measurements of Condylion to A point, and Condylion to Gnathion). This will help to determine the underlying cause of the jaw discrepancy. Finally, summarize the diagnosis and include the nature of the malocclusion, the location of crowding or spacing, 
and the severity of the skeletal pattern. A prioritization of the problem list will help in strategically planning the sequence of treatment for the Class III malocclusion.

\section{TREATMENT OF CLASS III MALOCCLUSION}

\section{Growing patient.}

The goal of early orthodontic treatment is to provide a favorable environment for dentofacial development and to prevent a more severe malocclusion in late

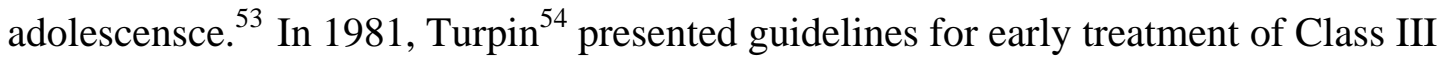
malocclusions. He presented the positive and negative factors that may influence the orthodontist's decision of whether or not to start early treatment, and these factors are listed in Table 4. Turpin also recommended that patients be made aware of the fact that surgery is not to be ruled out, even though they may have a successful early treatment phase.

Table 4. Positive and Negative Factors Influencing the Decision for Early Treatment.

\begin{tabular}{|l|l|}
\hline \multicolumn{1}{|c|}{ Positive Factors } & \multicolumn{1}{c|}{ Negative Factors } \\
\hline Convergent facial type & Divergent facial type \\
\hline Anterior-posterior functional shift & No anterior-posterior shift \\
\hline Symmetrical condylar growth & Asymmetrical growth \\
\hline Young, with remaining growth & Growth complete \\
\hline Mild skeletal disharmony & Severe skeletal disharmony \\
\hline Good cooperation expected & Poor cooperation expected \\
\hline No familial prognathism & Familial pattern established \\
\hline Good facial esthetics & Poor facial esthetics \\
\hline
\end{tabular}

\section{$\underline{\text { Stages of Early Treatment for Class III Malocclsuion }}$}

Class III treatment in the growing patient can be categorized into the stages of dental development (i.e., deciduous dentition, early mixed dentition, late mixed dentition, and early permanent dentition) in order to help in deciding the appropriate treatment (e.g., 
non-extraction/camouflage treatment, an extraction/camouflage treatment, and functional orthopedic appliances).

Deciduous Dentition. Because of the nature of the skeletal maturation at this stage, anterior and posterior crossbites may be effectively treated in the primary dentition. ${ }^{4}$ However, there has been little evidence to suggest that any orthodontic intervention during the deciduous dentition stage can prevent or slow the development of a Class III malocclusion. Thus, it may be better to wait until the patient is in the early mixed dentition stage before considering orthodontic treatment to correct the malocclusion, especially since ages six through nine years tend to provide the best patient cooperation.

Early Mixed Dentition. Besides the advantage of patient cooperation, orthodontic intervention during early mixed dentition can be beneficial for certain cases. For example, early treatment should be provided for a patient who presents with a Class III incisor relationship and a mandibular shift that is due to a premature contact. Treatment of the functional shift may help prevent temporomandibular joint dysfunction in adulthood. ${ }^{52}$

A shift caused by premature contacting deciduous canines can be treated by enameloplasty of the cuspal interferences. If the shift is caused by premature contacting of permanent incisors (i.e., a pseudo-Class III malocclusion), then a viable treatment option would be the proclination of the incisors utilizing orthodontic brackets on the four maxillary incisors and the maxillary first molars (2 x 4 ) or utilizing an upper removable appliance incorporating either Z-springs or a screw-section if there is insufficient anterior retention. $^{52}$ Note that posterior bite planes may be incorporated into the treatment in 
order to free the occlusion in cases where the overbite is deep. As with all treatment of anterior crossbites, it is important to attain adequate overbite and to use retention in order to successfully maintain the corrected incisor position.

Late Mixed Dentition. During late mixed dentition, it is important to provide treatment for a patient who presents with a deep overbite (i.e., underbite) and a mild-tomoderate skeletal Class III relationship where the maxillary and mandibular incisors are proclined. However, because of the nature of the skeletal Class III malocclusion growth modification is unpredictable especially where mandibular and/or vertical excess is present. In the past, the Frankel III and chin-cup appliances were the treatment of choice for the pubertal class III patient, but they lack long-term stability. ${ }^{55,56}$ Although protraction facemask/RPE therapy is most effective during pre-pubertal growth, it is currently considered to be the most appropriate treatment for patients with a retrusive maxilla during the late mixed dentition stage. ${ }^{57}$ Moreover, rapid maxillary expansion should be used in order to maximize the skeletal change when using protraction headgear.

Early Permanent Dentition. The goal of treatment in the early permanent dentition stage is to produce a Class I incisor relationship and to attempt to compensate for the underlying skeletal discrepancy. However, the clinician must be sure that skeletal growth will not negate the treatment outcome, and the clinician should determine the whether or not the patient has a severe skeletal discrepancy in which orthodontic treatment would not be successful. Adolescents with a mild Class III skeletal discrepancy may be treated effectively by proclining the maxillary incisors so as to create positive overjet. For patients with a moderate skeletal discrepancy, proclination of the 
upper incisors should be combined with retroclination of the lower incisors so as to prevent an unstable and potentially traumatic occlusion.

If crowding is present, then extractions of the first premolars in mandibular arch may be necessary. The maxillary arch crowding can sometimes be resolved by proclining the incisors or via rapid palatal expansion. If crowding cannot be eliminated in the maxillary arch, then extraction of the second premolars would be the treatment of choice. ${ }^{28}$ Finally, it should be noted that if pre-treatment dentoalveolar compensation has already occurred, further treatment is often limited.

\section{Non-growing patient}

Once the patient has no remaining growth, treatment options are limited. The treatment options that are available for Class III non-growing patients include nonextraction/camouflage treatment, extraction/camouflage treatment, or surgery.

Sometimes a compromised treatment option may be employed because of the severity of the skeletal discrepancy and if extraction or surgery is not an option. In these cases, an alignment of the teeth may be achieved, but the occlusion will not be ideal. That is, a fair amount of negative overjet may still persist due to skeletal discrepancies between the maxilla and mandible.

Often, extractions are recommended to treat the malocclusion, mainly because it will allow resolution of the crowding and because it will allow camouflaging of a moderate skeletal discrepancy in which orthopedic correction is not possible. In addition, extractions will allow the reduction in negative overjet which helps to camouflage the skeletal discrepancy. Extraction patterns may vary depending on the amount of crowding and/or the skeletal discrepancies in an adult patient. ${ }^{52}$ 
Orthognathic surgery is another option that is available for the non-growing Class III patient. Although this treatment alternative will lead to the most ideal relationship of the maxilla and mandible in severe malocclusions, it is also the most invasive and expensive option. On the other hand, in cases of moderate or severe Class III anteroposterior skeletal discrepancies where a vertical or transverse skeletal discrepancy is present, surgery may be the only viable treatment option. Pre-surgical orthodontic treatment necessitates both alignment and decompensation of the axial inclination of the incisors. According to McIntyre ${ }^{52}$ the maxillary incisors are retroclined and the mandibular incisors are proclined to approximately $109^{\circ}$ and $90^{\circ}$, respectively to the maxillary and mandibular planes. A short period of orthodontic treatment (about 6 months) is often required following surgery to finish and detail the occlusion.

\section{Methods of Early Treatment of Class III Malocclusion}

As previously discussed, there are more treatment options available for correcting the Class III malocclusion in a growing patient as opposed to non-growing patients. The following discussion explains some of the available methods of early treatment for Class III malocclusions.

2x4 Appliance. In 2004, Hagg, Tse, Bendeus, and Rabi, conducted a study in which 25 patients (mean age of 10.2 years) with a pseudo-Class III malocclusion were treated with $2 \times 4$ appliance. ${ }^{58}$ These patients were observed for five years posttreatment. Of the 25 patients, only 5 patients had subsequent full comprehensive orthodontic treatment to correct crowding. The researchers found that young patients treated early with 2 x 4 appliance were able to attain long-term stability overjet correction. 
Frankel III (FR-3). Only a few articles published on the Frankel III appliance (FR-3) provided scientific basis on which treatment results were claimed. The Frankel III appliance is designed to counteract the muscle forces acting on the maxillary complex. ${ }^{59}$ The upper portion of the appliance has vestibular shields in the depths of the sulcus that placed away from the alveolar buccal plates of the maxilla in order to allow the maxilla to develop anteriorly. In contrast, the vestibular shield is fitted closely to the mandibular alveolar process so as to hold or redirect growth posteriorly. Robertson ${ }^{56}$ monitored 12 Class III patients (mean age was 9.4 years) who were treated with FR-3 for 2 years. These patients experienced overjet correction primarily through dentoalveolar changes in (i.e., crown tipping).

A study by Loh and Kerr ${ }^{60}$ reviewed the lateral cephalometric radiographs of 20 patients treated with FR-3. There was not a control group, and the mean treatment time was 3.1 years $+/-1.9$ years. The results of the study indicated that the FR-3 appears to have proclined the upper incisors and retroclined the lower incisors. Also, the mandible repositioned in downward and backward direction which in turn increased the facial height. There were minimal skeletal changes with respect to the maxilla. The authors concluded that the best indication for using a FR-3 would be in a young, early mixed dentition patient with Class III malocclusion and an overbite of 4-5 mm.

In a study by Ulgen and Firatli ${ }^{61}$, 20 patients with functional Class III malocclusions were treated with FR-3. These patients showed a significant increase in the ANB angle as compared to the 20 untreated subjects in the control group who also had functional Class III malocclusion. The patients in both groups were able to reposition their mandible backward into an anterior edge-to-edge position. The 
significant increase in the treatment group’s ANB angle was mostly due to a decrease in SNB as the mandible rotated downward and backward. No significant changes in SNA were reported. The authors claim that the treatment period in this study was shorter compared to others and that there was poor patient cooperation.

In conclusion, the use of the FR-3 may not be the ideal choice for treatment of patients who present with maxillary anteroposterior deficiency as the primary etiology. However, this appliance may have some clinical application, particularly in patients who present with any existing hyperactivity in the muscles associated with the maxilla. ${ }^{59}$ Petit $^{62}$, McNamara ${ }^{63}$ and Brudon ${ }^{45}$ recommended the use of FR-3 for retention after protraction headgear therapy.

Chin Cup Therapy. The use of appliances resembling chin cups to help reduce a prognathic mandible was reported as early as the 1800 's. Graber ${ }^{64}$ attempted to explain that the failure associated with the early trials of chin-cup therapy was because of the lack of complete understanding of facial growth which lead to an unsuitable amount of force to be used or to the use of the chin cup after the skeletal growth has been completed. In 1977, Graber treated 30 skeletal Class III Caucasian children, averaging six years of age, with chin cup therapy for a period of three years. He compared this treated group to an untreated Class III control group and found that the treated group had a posterior rotation of the mandible, a decrease gonial angle, a restriction in vertical condylar growth, and a "clockwise rotation" of the maxilla. Mitani and Sakamoto ${ }^{65}$ reported similar results to the Graber's study. The authors followed three Japanese females treated with the chin cup and found that the mandibular growth was altered to a downward and backward direction for all three patients. 
In 1986, Mitani and Fukazawa ${ }^{66}$ evaluated growth changes in the mandible when orthopedic force is applied during the pubertal period in 26 Japanese females. The patients were examined in the pre-peak, peak, and post-peak pubertal growth periods. Also, the treatment group was compared to a control group of Class I subjects around the same age. There findings of this study were interesting, especially the fact that subjects all exhibited some incremental growth of the mandible during use of the chin cup in all three stages, especially during the peak stage. Thus, the authors concluded that orthopedic force does not alter the innate growth of the mandible.

A study by Ritucii and Nanda ${ }^{67}$ in 1986 focused on the effects of using the chin cup on the maxilla and the cranial base. The treated and control sample sizes were small in that there were only 10 treated Class III patients and 7 untreated Class I control. The authors reported significant inhibition of anterior and posterior vertical maxillary growth and a clockwise rotation of the maxilla. They explained that the maxillary clockwise rotation occurred because the inhibition of posterior vertical development was greater than the anterior.

In 1990, Sugawara et al. ${ }^{55}$ found similar results to the aforementioned study in which they concluded chin cup has no effect on the anteroposterior growth of the midface. The skeletal profile showed great improvement during the initial stages of chin cup therapy, but the patients later had a mandibular displacement in a forward and downward direction before growth was completed. Therefore, chin cup therapy does not necessarily guarantee correction of skeletal profile after completion of growth.

In 1993, Allen and colleagues ${ }^{68}$ found that the overjet correction that resulted from the use of chin cup is attributed to proclination of upper incisors, retroclination of 
lower incisors, and downward movement of the mandible. A significant change of the ANB angle was not noted. Consequently, the authors questioned whether the chin cup brings about a change in the anteroposterior jaw relationship.

In summary, among the published studies chin cup therapy have shown varying results in the attempts to restrict mandibular growth. According to Sugawara et al. ${ }^{55}$ clinicians should not overestimate the effects of a chin cap appliance to correct skeletal facial profiles. For patients who present with skeletal Class III malocclusion due primarily to maxillary anteroposterior deficiency, the chin cup therapy would not address the underlying problem. ${ }^{55,67}$

Protraction Facemask Therapy. In the past few decades, protraction facemask therapy increased in popularity largely due to the awareness of the role that maxillary deficiency has in contributing to the skeletal Class III malocclusion ${ }^{5,6,40}$. One of the first people to have mentioned the clinical effects of maxillary protraction was Dr. Albin Oppenhein in 1944, when he presented three cases in which the Class III patients were treated using a chin cup with spurs to which a maxillary lingual arch was attached via elastics. $^{69}$

In the 1960s, Delaire introduced a modification to the chin cup which included a forehead support and an interlabial bow with spurs for elastic attachment. ${ }^{70}$ Around the same time that Delaire introduced the facial mask, Haas reported the use of maxillary expansion alone can move the maxilla forward and downward, resulting in a mandibular downward and backward rotation. ${ }^{15}$ Protraction facemask therapy used in conjunction with rapid maxillary expansion appliance has been shown to be successful in correcting skeletal Class III malocclusions that are due to deficient maxillary development and /or 
mandibular prognathism. ${ }^{9-12,30,71,72}$ In the 1970s, several primate studies showed dramatic skeletal changes and helped to explain the anatomical effects of continuous forces on maxillary protraction. ${ }^{73-76}$

Animal Studies. In 1973, Dellinger ${ }^{76}$ conducted a study on anterior maxillary displacement using two Macaca speciosa monkeys. He used rapid maxillary expansion and connected it to a spring device that delivered an anterior force of six pounds on the maxilla. A significant amount (2.0 $\mathrm{mm}$ and $2.8 \mathrm{~mm})$ of maxilla anterior displacement was noted in seven days.

In 1977, Kambara $^{74}$ studied the possible effects of extra-oral forward force on the growth of the dentofacial group of five monkeys; however, no maxillary expansion device was employed. An intermittent force of 300 grams was applied to the maxilla bilaterally for 15 hours per day. The results were significant changes in the circummaxillary sutures with a small degree of counterclockwise rotation of the maxilla. Histologic preparations showed that the significant changes may have resulted from an opening of the suture, stretching of sutural connective tissue fibers, and new bone deposition along the stretched fibers. Sutural width was maintained through homeostasis. Kambara concluded that further studies are needed to evaluate post-treatment relapse.

In a 1978 study on six Macaca mulatta monkeys with three controls, Nanda ${ }^{75}$ noted that the extra-oral forces helped to displace the maxilla anteriorly. An anterior force of 500 grams was delivered for 81-95 days to a bar that extended anteriorly from a splint fastened to the maxillary arch. Furthermore, Nanda found that maxillary movement was related to the direction of force. With the exception of one treated monkey, the maxilla's angle of rotation directly correlated to line-of-force angle. For 
instance, as the line-of-force became more parallel to the occlusal plane, less maxillary rotation occurred in which a relatively more horizontal movement was noted.

However, the results from the 1979 study conducted by Jackson et al. ${ }^{73}$ contradict Nanda's findings. They found that a steeper line-of-force to the occlusal plane produced a greater amount of maxillary rotation and vertical displacement. Jackson, Kokich and Shapiro performed the study on four Macaca nemestrina monkeys with no control group, and they documented that when the anterior extra-oral traction was applied parallel to the occlusal plane the maxillary complex had significant anterior positioning with a slight amount of counter-clockwise rotation. In addition, the authors noted a substantial degree of relapse due to reorientation of the maxillary complex after active treatment was completed. Therefore, a period of stabilization following the application of force to the maxilla may be necessary to minimize the amount of post-treatment relapse.

Human Studies. Protraction headgear effects in humans have been reported by many investigators ${ }^{10-12,62,70,71,77-79}$ However, the person mainly responsible for reviving the interest in the protraction headgear technique was Delaire. ${ }^{70}$ Later, Petit ${ }^{62}$ modified the Delaire's basic concepts by increasing the amount of time that the facemask is worn and the amount of force generated by the appliance, thus attaining dramatic results within a shorter time period.

Since 1970 when Haas ${ }^{15}$ showed downward and forward maxillary displacement with the use of palatal expansion, many clinical studies have noted that the use of a palatal expander in conjunction with protraction headgear enhanced maxillary protraction. ${ }^{10-12,71,77}$ Palatal expansion helps to disarticulate the maxilla and initiates cellular response in the suture, allowing a more positive reaction to protraction forces. ${ }^{15}$ 
In 1980, Nanda ${ }^{77}$ demonstrated the use of modified protraction headgear in patients prior to their adolescent growth spurt. Rapid palatal expansion and/or the use of the chin cup was often combined with the use of the protraction headgear, and the author reported favorable results after 4 to 8 months of protraction headgear treatment. The maxilla and dentition displaced anteriorly about 1-3 mm and 1-4mm, respectively.

In 1987, Wisth and colleagues ${ }^{78}$ evaluated lateral cephalograms of 22 children, between 5-10 years of age, who presented with a Class III malocclusion and were treated with the protraction facemask for 3-12 months. These patients placed on an observation period of 6-48 months. The researchers compared the before, during, and after treatment results to that of a control group of individuals with normal occlusion and found that 18 of the 22 children had a significant decrease in mandibular prognathism with overjet correction. The changes observed during retention were found to be comparable to the control groups. The authors concluded that maxillary protraction had a normalizing effect not only on the negative overjet but also on the general face morphology.

McNamara ${ }^{10}$ and Turley $^{11}$ reported similar findings with the use of the maxillary protraction appliance. Treatment results included forward and downward movement of the maxilla along with anterior and downward maxillary tooth movement. They also found that the mandible moved downward and rotated backwards, thus increasing lower facial height and creating an overall improvement of soft tissue contour.

In a 1992 preliminary study by Ngan and co-workers ${ }^{12}$, ten Class III patients who treated with protraction headgear and fixed palatal expansion appliance were found to have had significant overjet and molar corrections after six months of treatment. The correction of the Class III malocclusion was primarily due to the maxilla's forward and 
downward movement and the mandible's downward and backward rotation. From this study, the authors concluded that a long-term follow-up study is needed to assess the stability of this treatment modality.

A year later, Takada and colleagues ${ }^{79}$ conducted a study in which they treated Japanese female children using a modified maxillary protraction headgear and chin cup. The treatment group was divided into three categories according to their age: prepubertal (7-10 years), mid-pubertal (10-12 years), and late pubertal (12-15 years) and the average treatment time was 1.1, 1.0, and 1.4 years, respectively. There was a significant increase in maxillary length for the pre-pubertal and mid-pubertal groups, but results were not as significant in the late pubertal group.

Ngan and colleagues ${ }^{71}$ found similar results in their 1996 study in which 30 Chinese Class III patients who were treated with protraction headgear and rapid palatal expansion. The patients showed a change in overjet which went from a negative value to a positive value of approximately $6.2 \mathrm{~mm}$ after six months of treatment. The results are partly due to the anterior movement of the maxilla and the posterior rotation of the mandible. There was also a one degree counter-clockwise rotation of the maxilla that occurred as a result of the 30 degree downward elastic pull from the occlusal plane.

In 1998, Nartallo-Turley ${ }^{80}$ examined 21 females between the ages of 3.9 to 10.8 years of age who were treated with palatal expansion and facemask therapy for an average of 11 months and found that the facemask therapy produced a statistically significant anterior movement of the maxilla (SNA angle increased by 2.4 degree and ANB angle increased by 3.7 degrees). The mandible had a significant downward movement when measured at Menton, and the occlusal plane analysis showed that the 
maxilla contributed more to the correction than did the mandible. There were also dental changes that contributed to the molar and overjet correction in that the upper molars and incisors moved forward by $1.7 \mathrm{~mm}$ and $1.8 \mathrm{~mm}$, respectively. Overall, the palatal expansion with facemask therapy produced both skeletal and dental changes that contributed to the Class III correction.

A 2002 study conducted by Keles et al. ${ }^{81}$ examined the effect of varying the force and direction of the maxillary protraction. A total of 20 patients with Class III malocclusion due to a retruded maxilla were randomly divided into two groups. Both groups had a rapid palatal expander that was activated twice a day for 10 days and then protraction facemask therapy was initiated. Group 1 had a unilateral 500 gram force that was applied forward and downward in a direction 30 degrees angle relative to the occlusal plane; whereas, group 2 had the same amount of force applied extraorally but at $20 \mathrm{~mm}$ above the maxillary occlusal plane. Both groups had effective maxillary protraction; however, the maxilla advanced forward with a counter-clockwise rotation in group 1 and had only an anterior translation without rotation in group 2 . The dental effects in both groups were also different in that the maxillary incisors were slightly proclined in group 1 but were retroclined and extruded in group 2. The authors concluded that counter-clockwise rotation can be prevented if the force application is near the center of resistance of the maxilla. This would be especially useful for patients who present as Class III malocclusion along with an anterior open bite.

Miniplates for Anchorage During Maxillary Protraction. Most orthopedic appliances use the teeth for anchorage which yields unwanted dental side effects such as dental anchorage loss or maxillary counter-clockwise rotation. In the past, it was shown 
that forces can be applied to ankylosed teeth or implants to help prevent dental anchorage loss during maxillary protraction. ${ }^{5,82}$ The more recent studies on the subject of protraction facemask therapy involve the use of osseo-integrated implants/screws and mini-plates for anchorage during maxillary expansion and protraction.

The use of osseo-integrated implants as skeletal anchorage has been successful in several studies. In 1998, Smalley et al. ${ }^{83}$ were able to gain significant disarticulation of the circum-maxillary sutures and remodeling of the bony surfaces in monkeys via the use of osseo-integrated implants as anchorage for protraction of the maxillofacial complex. Movassaghi et al. ${ }^{16}$ also did an animal study but used skeletally immature rabbits. They were able to distract the nasal bones of these rabbits from the frontal cranial segment and induced bone formation across the frontonasal suture. In 2000, Singer et al. ${ }^{84}$ placed titanium implants in the zygomatic buttress area in a 12-year and 1-month-old female patient with a Class III malocclusion secondary to repair of a unilateral cleft lip and palate defect. The implants were allowed to osseo-integrate for 6 months then customized abutments that projected into the buccal sulcus were placed. Elastic force of $400 \mathrm{~g}$ per side was applied from a facemask to the implants at 30 degrees to the occlusal plane for 14 hours per day for 8 months (ages 12 years and 10 months to 13 years and 6 months). The results were the downward and forward maxilla movement of $4 \mathrm{~mm}$ along with an anterior maxillary rotation which in turn rotated the mandible open. In addition, there was an increase in nasal prominence as the maxilla advanced which contributed to the increase in facial convexity. The researchers were able to avoid the unwanted dental changes frequently seen in standard facemask therapy, and the anterior maxillary displacement was stable for 1 year post-treatment. 
In the late 1990s and early 2000, titanium mini-plates became popular primarily as an alternative to orthognathic surgery for treating openbites, especially because the miniplates assisted in intruding molars. ${ }^{83,85,86}$ In 2005, Beyza et al. ${ }^{87}$ presented a case report in which titanium mini-plates were used as skeletal anchorage for orthopedic protraction in an 11-year-old girl who presented with severe maxillary hypoplasia and hypodontia. The mini-plates were placed on the lateral nasal wall of the maxilla to serve as anchorage for facemask protraction, and intraosseous titanium screws were placed on the palatal bone near the alveolar crest in order to provide anchorage for palatal expansion. After $7 \mathrm{~mm}$ of expansion, protraction facemask therapy was initiated. The patient experienced 8mm of anterior maxillary movement with an increase in SNA of $7^{\circ}$ and a decrease in SNB of 3 degrees. The mandible did rotate posteriorly and the palatal plane angle rotated $2^{\circ}$ counterclockwise. Beyza et al. stated that by using the miniplates, they were able to take advantage of the sutural growth potential because the orthopedic forces were directed to the sutural sites. Furthermore, the researchers attributed their success to the location of the mini-plate anchorage because the lateral nasal wall is anterior to all of the sutures joining the maxilla to the cranial base and because its location was anterior to the center of resistance of the maxilla.

Effective Maxillary Protraction. As previously discussed, effective maxillary protraction is dependent upon many variables, especially overcoming resistance of the circum-maxillary sutures. Maxillary expansion aids in the disarticulation of the maxilla. Recall that Haas reported the use of maxillary expansion alone can move the maxilla forward and downward, resulting in a mandibular downward and backward rotation. ${ }^{15}$ Furthermore, protraction facemask therapy used in conjunction with rapid maxillary 
expansion appliance has been shown to be successful in correcting skeletal Class III malocclusions related to deficient maxillary development and /or mandibular prognathism. ${ }^{9-12,30,71,72}$ However, most protraction techniques use the teeth for anchorage and result in unwanted dental side effects. Moreover, traditional protraction facemask therapy has only produced about 1.5 - 3mm of protraction per year. ${ }^{17,18,88}$

Despite the other studies results, Liou and Tsai ${ }^{1}$ have been able to achieve an average of 5.8mm of maxillary advancement (horizontal movement at A point) using only toothborne devices. They attribute their success partly to the use of a new doublehinged rapid maxillary expander which is designed to expand and rotate each half of the maxilla outward, allowing greater anterior displacement with a reduced risk of bone resorption in the tuberosity area. ${ }^{1-3}$ In his 2005 report, Liou and Tsai ${ }^{1}$ described the use of the double-hinged expander along with an Alternate Rapid Maxillary Expansion and Constrict (Alt-RAMEC) protocol in which the maxilla is expanded $1 \mathrm{~mm}$ per day for one week and then constricted $1 \mathrm{~mm}$ per day for the following week. This protocol lasted for a period of seven to nine weeks. Afterwards, instead of using a protraction facemask, a pair of fixed, toothborne 0.036” TMA helical springs along with mandibular anchorage from a 0.036” TMA lingual holding arch is used to protract the maxilla. Although protraction facemask can be used, the intra-oral protraction springs eliminate the reliance on patient cooperation. Liou and Tsai concluded that the most important element to their success is the Alt-RAMEC protocol because it helped to loosen the maxillary suture and therefore allowed for the maxilla to be orthopedically protracted without significant unwanted dental side-effects. 
In March 2009, Wang, Chang, and Liou ${ }^{89}$ reported the results of their animal study in which they attempted to quantitatively analyze the opening of the circummaxillary suture after the Alt-RAMEC protocol. Twelve cats were randomly grouped into two groups of six in which group 1 was expanded for one week and group two had five weeks of alternating expansion and constriction. The double-hinged expander was used in both groups. The animals were sacrificed at the end of the experiment and the nasomaxillary complexes were preserved in $10 \%$ formalin in order to examine the circum-maxillary suture opening. The researchers conclude that Alt-RAMEC opens the sutures both sagitally and coronally more than the conventional rapid maxillary expansion technique. Furthermore, the sutures that ran sagittally were opened significantly more than the sutures that ran coronally, whether or not they were connected to the maxilla directly.

Given the success that Liou et al. ${ }^{1-3,89}$ have been able to achieve with the doublehinged expander, this study will compare the quantitative difference, if any, between the conventional protraction technique that uses the traditional Hyrax expander and the new protraction protocol with the double-hinged expander as advocated by Liou. The skeletal and dental changes with maxillary expansion and protraction will be measured. Finally, the differences between the two techniques will be evaluated on lateral cephalometric radiographs. 


\section{CHAPTER III}

\section{MATERIALS AND METHODS}

\section{SAMPLE DESCRIPTION}

All patients included in this study were between the ages of 6 to 12 years old and have a Class III malocclusion with no craniofacial anomaly. The stage of dental development varied from early to late mixed dentition, and all subjects had an overjet ranging from $-5.6 \mathrm{~mm}$ to $+3.9 \mathrm{~mm}$ prior to the start of the treatment. The treated sample had lateral cephalograms taken before treatment and after 6 months of protraction facemask therapy in order to evaluate treatment changes. Table 5 illustrates the symbols used to represent the different time intervals at which lateral cephalograms were taken. Note that the mean treatment time was 9 months \pm 3 months. A Frankel III appliance was given to patients following treatment to help maintain Class III correction. Table 6 reports the chronological age distribution of both treated groups and the control group.

TABLE 5. Symbols for the different time intervals.

\begin{tabular}{|l|l|}
\hline \multicolumn{1}{|c|}{ Symbol } & \multicolumn{1}{c|}{ Definition } \\
\hline t1 & $\begin{array}{l}\text { Control subject's radiograph taken at an age corresponding to double- } \\
\text { hinged expansion patient's before treatment age }\end{array}$ \\
\hline t2 & Control subject's radiograph taken 6 months the first radiograph (t1) \\
\hline T1 & Treated subject's radiograph taken before treatment \\
\hline T2 & $\begin{array}{l}\text { Treated subject's radiograph taken } 6 \text { months after the start of protraction } \\
\text { facemask therapy }\end{array}$ \\
\hline
\end{tabular}


Table 6. Chronologic Age Distribution of Treatment and Control Samples

\begin{tabular}{|l|c|c|c|c|c|c|c|c|c|}
\hline & \multicolumn{3}{|c|}{$\begin{array}{c}\text { Double-Hinged } \\
\text { Expander Group }\end{array}$} & \multicolumn{3}{c|}{$\begin{array}{c}\text { Hyrax } \\
\text { Expander Group }\end{array}$} & \multicolumn{3}{c|}{$\begin{array}{c}\text { Control } \\
\text { Group }\end{array}$} \\
\hline (Years) & Female & Male & Mean & Female & Male & Mean & Female & Male & Mean \\
\hline T1 or t1 & 8.6 & 8.3 & 8.5 & 8.6 & 8.7 & 8.6 & 8.5 & 8.4 & 8.4 \\
& \pm 0.9 & \pm 1.0 & \pm 1.2 & \pm 0.7 & \pm 1.5 & \pm 1.2 & \pm 1.0 & \pm 1.3 & \pm 1.1 \\
\hline \multirow{3}{*}{ T2 or t2 } & 9.6 & 9.5 & 9.5 & 9.6 & 9.3 & 9.4 & 9.5 & 9.4 & 9.4 \\
& \pm 1.5 & \pm 1.2 & \pm 1.1 & \pm 0.5 & \pm 1.1 & \pm 1.2 & \pm 1.6 & \pm 1.4 & \pm 1.5 \\
\hline
\end{tabular}

The Double-hinged expander group consisted of seven Caucasians, one Chinese, and one African-American, subjects. Of these subjects, there were four females and five males who presented with Class III skeletal malocclusion and were treated at the West Virginia University School of Dentistry Department of Orthodontics. At the start of treatment, the average age of the female patients were $8.6 \pm 0.9$ years of age, and the average age for the male patients was $8.3 \pm 0.9$ years of age. A lateral cephalogram was taken prior to treatment. Then, these patients were treated with maxillary expansion using a Double-hinged expander along with the alternating expansion and constriction (Alt-RAMEC) protocol as described by Liou et al. ${ }^{1-3}$ Following maxillary expansion, protraction facemask therapy was prescribed for approximately 9 months for 10-12 hours of wearing time per night.

The Hyrax expander group consisted of lateral cephalometric radiographs of nine Chinese subjects who were closely matched in age, sex, and pretreatment skeletal morphology to the Double-hinged expansion treatment group. These patients were treated with maxillary expansion and protraction facemasks in the Department of Children's Dentistry and Orthodontics, Faculty of dentistry, University of Hong Kong. After 6 
months of protraction facemask therapy, a new lateral cephalometric radiograph was taken on the Hyrax expander subjects to assess treatment effects.

The control group consisted of nine Chinese subjects who were closely matched in age, sex, and pretreatment skeletal morphology to the Double-hinged expansion treatment group. Serial lateral cephalometric radiographs were taken on untreated patients with a Class III malocclusion in order to monitor their growth. Note that the control group subjects were eventually treated with rapid palatal expansion and protraction facemask therapy. However, the lateral cephalometric radiographs selected for this study were both taken before treatment and are six months apart. The radiographs are denoted as (t1) and (t2).

For this study, the cervical vertebra maturation level was reviewed in all treated and control group subjects in order to assess the subjects' skeletal age and to account for any differences in treatment outcome that may be due to the pubertal growth spurt. Table 7 illustrates the CVM levels of all patients in this study.

Table 7. CVM of Treatment and Control Samples

\begin{tabular}{|c|c|c|c|c|c|c|c|}
\hline $\begin{array}{l}\text { CVM } \\
\text { (Stage 1-5) }\end{array}$ & \multicolumn{2}{|c|}{$\begin{array}{c}\text { Double-Hinged } \\
\text { Expander Group }\end{array}$} & \multicolumn{2}{|c|}{$\begin{array}{c}\text { Hyrax } \\
\text { Expander Group }\end{array}$} & \multicolumn{2}{|c|}{$\begin{array}{c}\text { Control } \\
\text { Group }\end{array}$} & Sig. \\
\hline Time & Mean & SD & Mean & SD & Mean & SD & \\
\hline T1 or t1 & 1.22 & 0.44 & 1.33 & 0.50 & 1.44 & 0.53 & N.S. \\
\hline T2 or t2 & 1.56 & 0.73 & 1.67 & 0.50 & 2.00 & 0.71 & N.S. \\
\hline
\end{tabular}

NS = not significantly different

* = significantly different at $\mathrm{p}<0.05$. 
The cervical maturation assessment used in this study was based on the new Cervical Vertebral Maturation (CVM) method developed and employed by Baccetti, Franchi, and McNamara. ${ }^{90}$ It should be noted that at the start of treatment, all subjects were at the CVM stage 1-2, and at the end of treatment all subjects were at CVM stage 23. Therefore, all subjects have not undergone a pubertal growth spurt during treatment. Table 6 displays the mean CVM stage in the treated groups and control group at times T1 and T2.

\section{RESEARCH DESIGN}

\section{Appliance Design and Expansion Protocol}

Hyrax Rapid Palatal Expander.

The Hyrax rapid palatal expander is an orthopedic appliance that widens the maxillary halves (Figure 1). In fabricating the Hyrax rapid palatal expander bands were fitted on the posterior teeth. In the primary dentition, the bands were fitted on the maxillary deciduous first and second molars. In the mixed dentition, bands were fitted on the second deciduous molars and on the permanent first molars. After the bands were fitted, a maxillary alginate impression was made. The bands were soldered to heavy wires (0.045 inch) which were connected to a jackscrew that is centered along the midline of the maxillary palate. Bilaterally, 0.045 inch wire was soldered to the buccal aspects of the molar bands, and extended anteriorly to the canine area. This buccal wire has a curve at the canine area so that elastics can be used to connect the appliance to a protraction facemask. The patient activated the appliance two times per day (once in the morning and once at night with each turn being $0.25 \mathrm{~mm}$ ) for 1 week. Patients with a narrow maxilla activated the expansion screw for 2 weeks. 


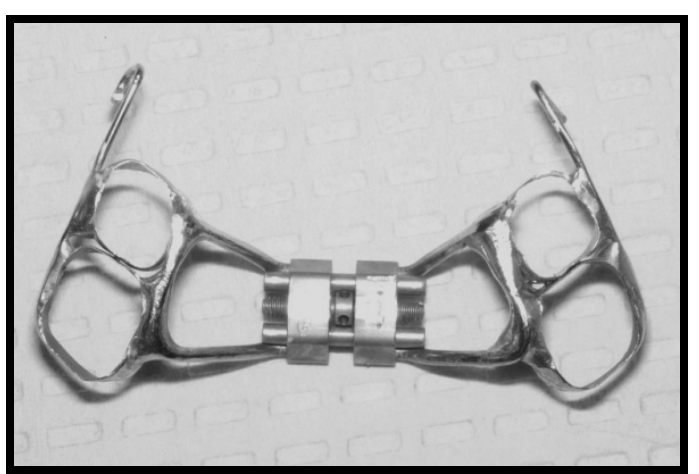

Figure 1. Hyrax expander with protraction hooks

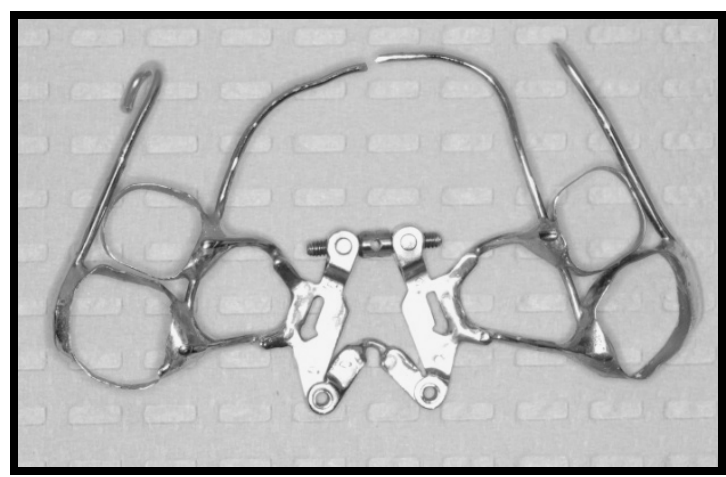

Figure 2. Double-hinged expander with protraction hooks.

\section{Double-Hinged Expander}

The double-hinged expander (Figure 2) is an orthopedic appliance that was designed for greater anterior displacement of maxilla. The double-hinged expander consists of 2 rotational hinges in the posterior, a jackscrew in the center, and 0.051 inch wires attached to the expander. ${ }^{3}$ When activated, the double-hinged expander rotates each half of the maxilla outward through the two hinges. This allows for expansion that entails forward rotation of maxilla with a decreased likelihood of bone resorption behind the maxillary tuberosities. ${ }^{1-3}$ Similar to the fabrication of the Hyrax expander, the teeth that were used as anchorage for the double-hinged expander were the posterior teeth. That is, in the primary dentition the bands were fitted on the maxillary deciduous first and second molars; whereas, in the mixed dentition bands were fitted on the second deciduous molars and on the permanent first molars. After the bands were fitted, a compound impression of the banded teeth and a maxillary alginate impression were made. The impression with the fitted bands was poured in silky rock stone and sent to a lab for the fabrication of the double-hinged expander. 
The expander is soldered to the molar bands and positioned perpendicular to the intermaxillary suture. Bilaterally, 0.045 inch wire was soldered to the buccal aspects of the molar bands, and extended anteriorly to the canine area. This buccal wire has a curve at the canine area so that elastics can be used to connect the appliance to a protraction facemask. In some cases, a lingual wire (0.045 inch wire) was soldered to the molar bands and was extended to the cingulum of the maxillary incisors to increase anchorage control, if needed. The bands are sandblasted prior to cementation. On the day of cementation, the double-hinged expander is activated according to the Alt-RAMEC as listed below. ${ }^{1,2}$

\section{Alternate Rapid Maxillary Expansions and Constrictions (Alt-RAMEC).}

Alt-RAMEC is a protocol in which the maxilla is rapidly expanded and constricted on an alternating weekly basis ${ }^{1,2}$ According to Liou et al, it takes seven to nine weeks to loosen the maxilla. For this study, a seven-week protocol was used. The weekly protocol is as follows: (1) $7 \mathrm{~mm}$ of expansion, (2) $7 \mathrm{~mm}$ of constriction, (3) $7 \mathrm{~mm}$ of expansion, (4) $7 \mathrm{~mm}$ of constriction, (5) $7 \mathrm{~mm}$ of expansion, (6) $7 \mathrm{~mm}$ of constriction, and (7) $7 \mathrm{~mm}$ of expansion. The maxilla is expanded or constricted $1 \mathrm{~mm}$ per day (two turns in the morning and two turns at night). Patients were recalled after the first week, the second week, the fifth week, and finally the seventh week. The maxilla must be loosened before proceeding for maxillary protraction. The maxilla could be clinically examined for mobility by holding patient's head with one hand and rocking the expander with maxilla up and down with another hand. At the seventh week, protraction facemask therapy was begun, and the patient was recalled six weeks after the start of protraction facemask therapy. 


\section{Protraction Facemask.}

The Petit-Delaire protraction facemask is a one-piece construction with adjustable forehead padding, adjustable chin cup, and an adjustable anterior bar (Figure 3). The adjustable components of the protraction facemask allows for proper positioning of the chin cup for comfort upon opening and closing and of the proper position of the anterior bar to which elastics were attached to both left and right sides. To avoid an opening of the bite as the maxilla is protracted, the elastics were attached near the maxillary canines with a downward and forward pull of 30 degrees to the occlusal plane. Maxillary protraction generally requires 300 to 600 grams of force per side, depending on the patient. In this study, a Correx Haag-Streit Bern gauge was used to measure the elastic force on the Double-hinged expander patients in order to ensure that approximately 380 grams of force was generated on each side. Patients were instructed to wear the protraction facemask for 10-12 hours a day, which includes nighttime wear. The Hyrax expander patients were instructed to wear the protraction face for 12 hours per day. Like the Double-hinged expander group, the elastics were gauged to produce 380 grams of force per side.
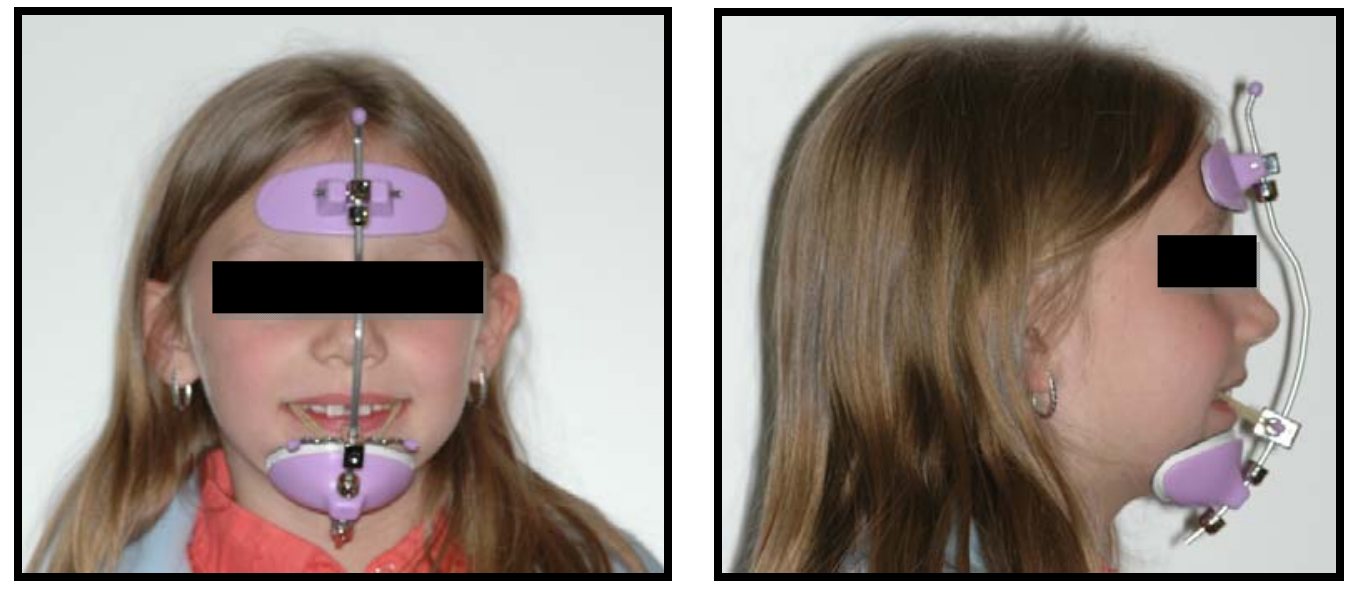

Figure 3. Protraction Facemask 


\section{METHODOLOGY}

Lateral cephalometric radiographs were taken at the following time periods:

before treatment (T1) and 6 months of treatment with protraction (T2). All radiographs

were taken in the same cephalostat with the teeth in habitual occlusion, the lips in repose.

Tracing of the lateral cephalograms were performed on 0.003 inch matte acetate tracing

film with a $0.75 \mathrm{~mm}$ mechanical \#2 lead pencil. The researcher traced all radiographs

with the use of a lighted 12 1/4” x 11 1/2” x 2 1/4” cephalometric viewbox. The midpoint

bisecting the two images was used where cephalometric landmarks had right and left images.

Measurements of each variable were performed twice with the use of a cephalometric protractor or a Fowler-Sylvac Ulta-Cal Mark III electronic caliper as shown in Figure 4. The caliper was calibrated to zero before each measurement, and the average of the two measurements was recorded. Sagittal and vertical measurements were recorded to the nearest $0.01 \mathrm{~mm}$, and angular measurements were reported to the nearest 0.1 degree.

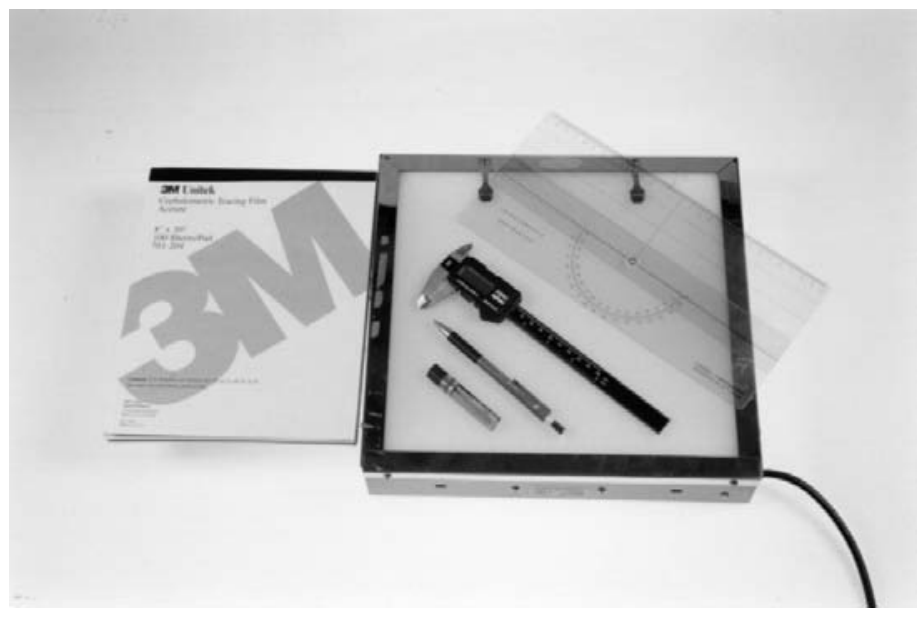

Figure 4. Acetate Tracing paper, lighted viewbox, cephalometric protractor, electronic caliper, mechanical pencil, and lead. 


\section{$\underline{\text { Reliability of Cephalometric Measurements }}$}

This part of the study analyzed the error in locating, superimposing, and measuring the changes of the different landmarks by one examiner (intra-examiner error). Lateral cephalograms at $\mathrm{t} 1$ and $\mathrm{t} 2$ of nine subjects in the control group and lateral cephalograms at T1 and T2 of the nine subjects in each treatment group were used for this part of the analysis. Each series of cephalograms of the total twenty-seven subjects were recorded independently at two separate occasions, two weeks apart. While tracing the radiographs, the examiner was aware of when the cephalograms were taken (e.g., at $\mathrm{T} 1$ or T2). Calculations were made to determine the differences between the independent repeated measurements of each cephalometric variable at T1 and T2 (or t1 and t2). Any measurement with more than $1.00 \mathrm{~mm}$ or 1.0 degree difference between the first and second measurement was eliminated from the database, and the cephalometric variable was then measured again twice to get more accurate and precise measurements. Also, the superimposition error was calculated to show the treatment changes of the twenty-seven subjects. Other data recorded include the arithmetic mean, standard deviation (S.D.), and minimum and maximum of each cephalometric variables. These calculations are listed in Appendix A through $\mathrm{H}$. 


\section{Cephalometric Landmarks and Reference Planes}

The cephalometric landmarks described by Bjork ${ }^{91}$ and Pancherz ${ }^{92}$ were used in this study and are defined in Table 8 and Figure 5. The reference lines used are defined in Table 9 and Figure 6. Sagittal, vertical, and angular measurements were performed on each lateral cephalogram tracing.

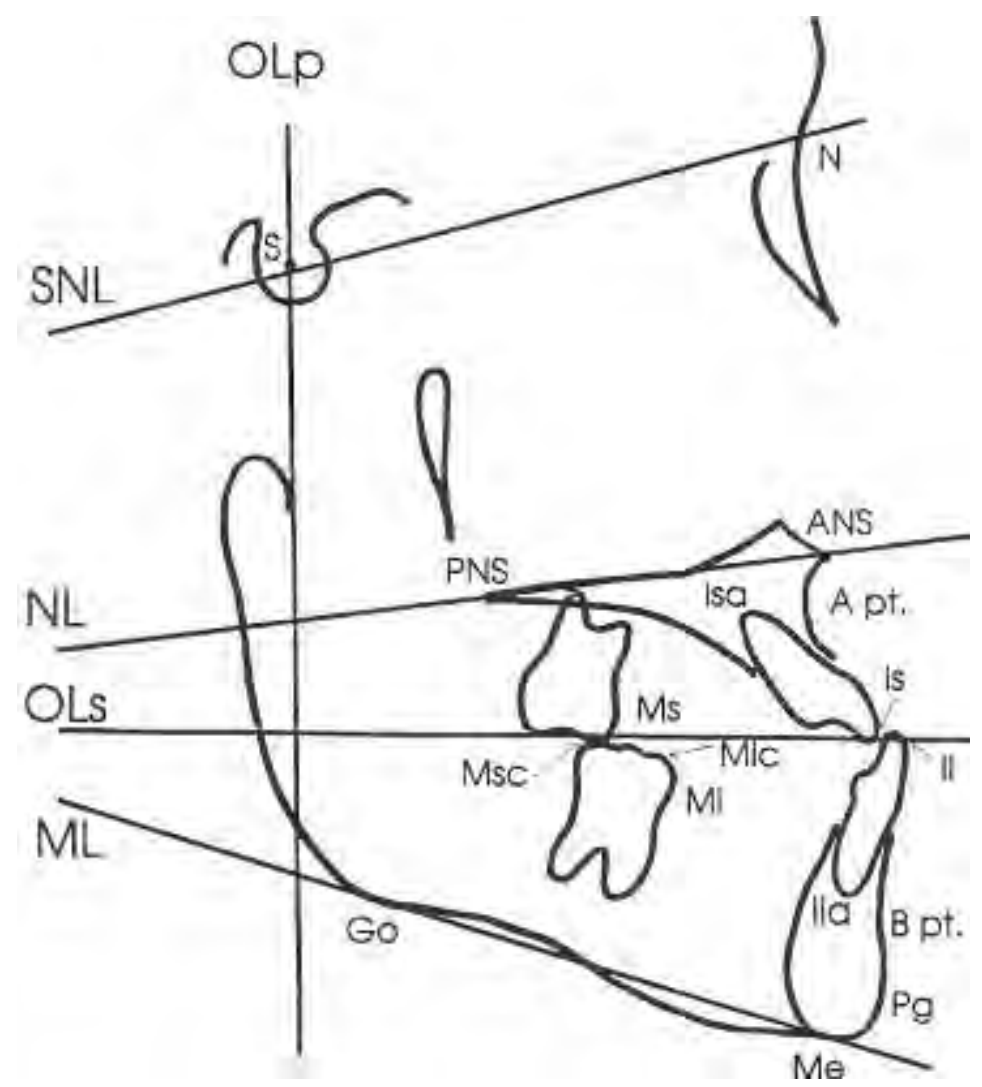

Figure 5. The skeletal and dental landmarks (see Table 7 for definitions). 
Table 8. The seventeen skeletal and dental landmarks.

\begin{tabular}{|c|c|c|}
\hline Name & Symbol & Definition \\
\hline Sella & $\mathrm{S}$ & The center of the sella turcica \\
\hline Nasion & $\mathrm{N}$ & The most anterior point of the naso-frontal suture \\
\hline Anterior nasal spine & ANS & The apex of the spina nasalis anterior \\
\hline Posterior nasal spine & PNS & $\begin{array}{l}\text { The most posterior point on contour of the palate in the } \\
\text { midsagittal plane }\end{array}$ \\
\hline Subspinale & A pt. & $\begin{array}{l}\text { The deepest point in the concavity of the anterior } \\
\text { maxilla between the ANS and the alveolar crest }\end{array}$ \\
\hline Supramentale & B pt. & $\begin{array}{l}\text { The deepest point in the concavity of the anterior } \\
\text { mandible between the alveolar crest and pogonion }\end{array}$ \\
\hline Pogonion & Pg & The most prominent point on the chin \\
\hline Menton & $\mathrm{Me}$ & The deepest point of the mandibular symphysis \\
\hline Gonion & Go & $\begin{array}{l}\text { The lowest point of the bony contour of the angle of the } \\
\text { mandible }\end{array}$ \\
\hline $\begin{array}{l}\text { Maxillary incisor } \\
\text { apex }\end{array}$ & Isa & $\begin{array}{l}\text { The root apex of the most prominent maxillary central } \\
\text { incisor }\end{array}$ \\
\hline $\begin{array}{l}\text { Maxillary incisor } \\
\text { edge }\end{array}$ & Is & $\begin{array}{l}\text { The incisal point of the most prominent maxillary } \\
\text { central incisor }\end{array}$ \\
\hline $\begin{array}{l}\text { Mandibular incisor } \\
\text { apex }\end{array}$ & Iia & $\begin{array}{l}\text { The root apex of the most prominent mandibular central } \\
\text { incisor }\end{array}$ \\
\hline $\begin{array}{l}\text { Mandibular incisor } \\
\text { edge }\end{array}$ & Ii & $\begin{array}{l}\text { The incisal point of the most prominent mandibular } \\
\text { central incisor }\end{array}$ \\
\hline $\begin{array}{l}\text { Molar superius } \\
\text { mesial cusp }\end{array}$ & Msc & $\begin{array}{l}\text { The mesio-buccal cusp tip of the maxillary second } \\
\text { primary molar or first permanent molar }\end{array}$ \\
\hline Molar superius & Ms & $\begin{array}{l}\text { The mesial contact point of the maxillary primary } \\
\text { second molar or permanent first molar }\end{array}$ \\
\hline Molar inferius & Mic & $\begin{array}{l}\text { The mesial-buccal cusp tip of the mandibular primary } \\
\text { second molar or permanent first molar }\end{array}$ \\
\hline Molar inferius & Mi & $\begin{array}{l}\text { The mesial contact point of the mandibular primary } \\
\text { second molar or permanent first molar }\end{array}$ \\
\hline
\end{tabular}

Table 9. Definition of the reference lines.

\begin{tabular}{|l|l|l|}
\hline \multicolumn{1}{|c|}{ Name } & \multicolumn{1}{|c|}{ Symbol } & \multicolumn{1}{c|}{ Definition } \\
\hline Sella-Nasion plane & SNL & Reference line joining Nasion and Sella \\
\hline Maxillary plane & NL & $\begin{array}{l}\text { Reference line joining anterior nasal spine and } \\
\text { posterior nasal spine }\end{array}$ \\
\hline Occlusal plane & OLs & $\begin{array}{l}\text { Reference line joining maxillary incisal edge and the } \\
\text { molar superious mesial cusp tip }\end{array}$ \\
\hline Mandibular plane & ML & Reference line joining menton and gonion \\
\hline $\begin{array}{l}\text { Occlusal plane } \\
\text { perpendicular }\end{array}$ & OLp & $\begin{array}{l}\text { Reference line produced by dropping a } \\
\text { perpendicular line from sella to the occlusal plane }\end{array}$ \\
\hline
\end{tabular}




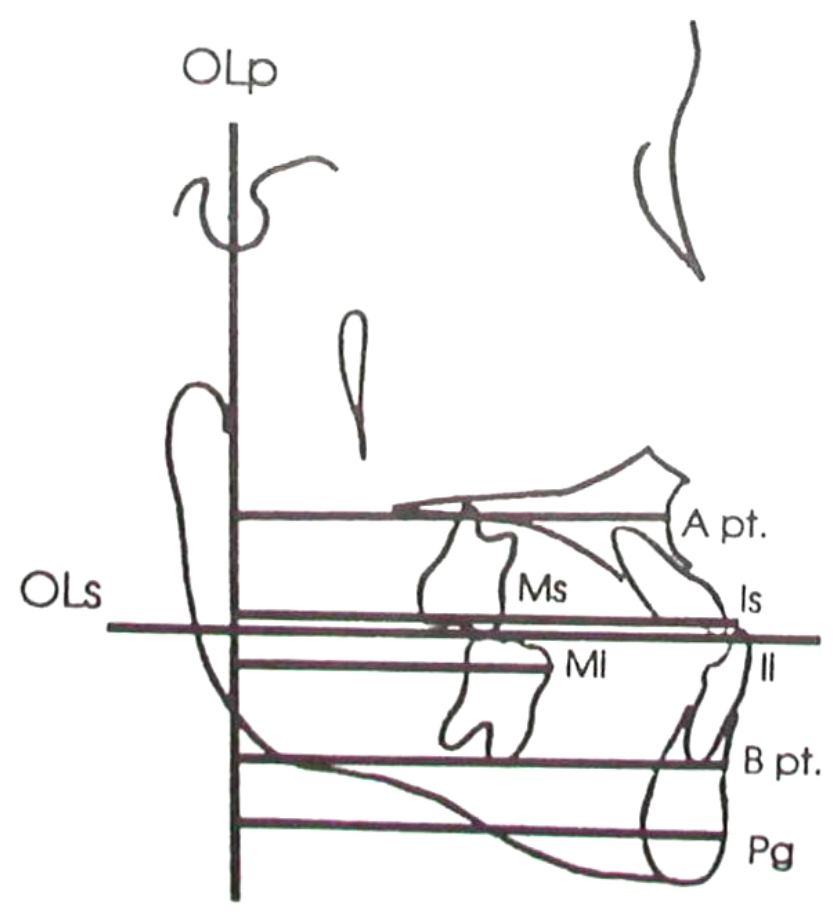

Figure 6. The Reference Grid (OLs and OLp) and Measuring Points Used in the Sagittal Cephalometric Analysis.

\section{Measuring Procedure for Sagittal Changes.}

The occlusal plane (OLs) and the occlusal plane perpendicular (OLp) from the tracing of $\mathrm{T} 1$, the before treatment lateral cephalogram, formed the reference grid. This reference grid was used for all the sagittal skeletal and dental measurements which analyzed the distance between the OLp and the cephalometric landmarks as shown in Figure 6. The grid was then transferred to T2, the 6-month post-protraction facemask therapy lateral cephalogram. Note that the T1 tracing was superimposed on the T2 tracing using the sella-nasion line (NSL) and along the anterior cranial base structure. The distance between OLp and the cephalometric landmarks on the T2 tracing were measured. The reference grid was only used for sagittal measurements on the superimpositions. The nine sagittal variables are listed in Table 10. 
Table 10. The Sagittal Measurements of Variables (1-9).

\begin{tabular}{|l|l|}
\hline \multicolumn{1}{|c|}{ Variable (mm) } & \multicolumn{1}{c|}{ Definition } \\
\hline Skeletal measuring points: & \\
\hline 1. OLp - A pt. & Position of maxillary base \\
\hline 2. OLp - B pt. & Position of mandibular base \\
\hline 3. OLp - Pg & Position of mandibular chin \\
\hline Dental measuring points: & \\
\hline 4. Is/OLp & Position of maxillary central incisor \\
\hline 5. Ii/OLp & Position of mandibular central incisor \\
\hline 6. Overjet & Is/OLp minus Ii/OLp \\
\hline 7. Ms/OLp & Position of maxillary second primary or first permanent molar \\
\hline 8. Mi/OLp & Position of mandibular second primary or first permanent molar \\
\hline 9. Molar Rel & Molar relationship: Ms/OLp minus Mi/OLp \\
\hline
\end{tabular}

\section{Measuring Procedure for Vertical Changes.}

Figure 7 illustrates the reference line and planes used in vertical measurements, and the seven vertical measuring points are listed in Table 11 .

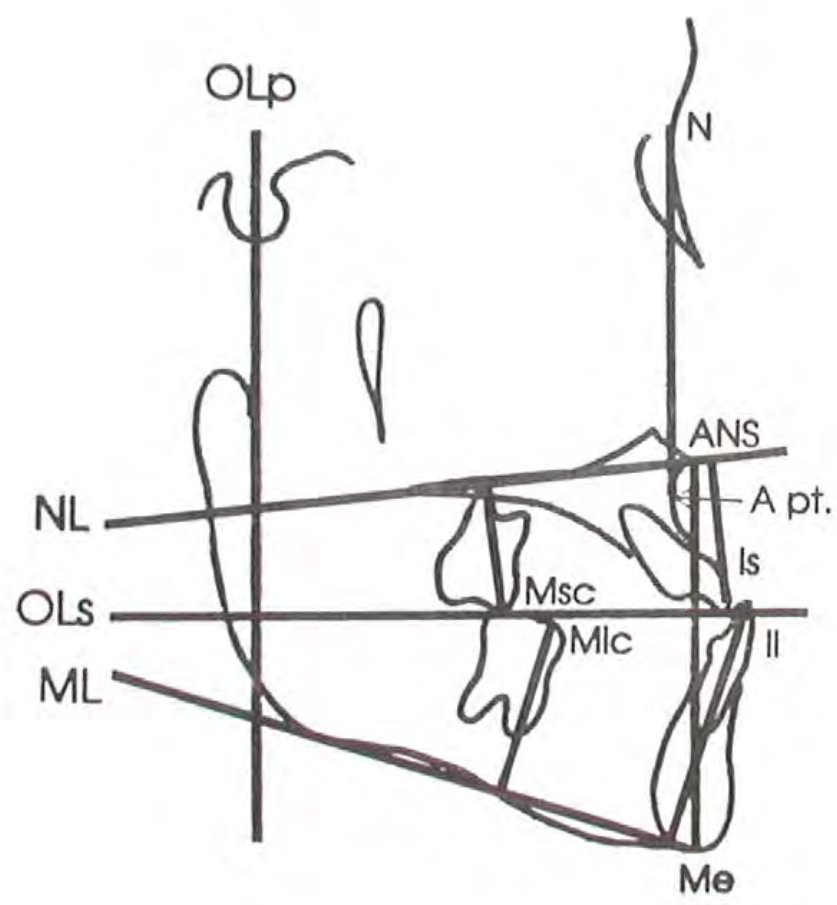

Figure 7. The Reference Lines and Measuring Points Used in the Vertical Cephalometric Analysis. 
Table 11. The vertical measurements of variables (10-16).

\begin{tabular}{|l|l|}
\hline \multicolumn{1}{|c|}{ Variable $(\mathrm{mm})$} & \multicolumn{1}{c|}{ Definition } \\
\hline Skeletal measuring points: & \\
\hline 10. N-A pt. & Maxillary vertical positioning \\
\hline 11. ANS-Me & Lower facial height \\
\hline Dental measuring points: & \\
\hline 12. Is-NL & Position of maxillary central incisor (measured Is $\perp$ NL) \\
\hline 13. Ii-ML & Position of mandibular central incisor (measured Ii $\perp$ ML) \\
\hline 14. Overbite & Distance from Ii $\perp$ OLs \\
\hline 15. Msc - NL & $\begin{array}{l}\text { Position of maxillary primary second or permanent first molar } \\
\text { (Msc } \perp \text { NL) }\end{array}$ \\
\hline 16. Mic - ML & $\begin{array}{l}\text { Position of mandibular primary second or permanent first } \\
\text { molar (Mic } \perp \text { ML) }\end{array}$ \\
\hline
\end{tabular}

\section{Measuring Procedure for Angular Changes.}

The reference lines and measuring points used for angular measurements are illustrated in Figure 8. The eight variables are listed in Table 12.

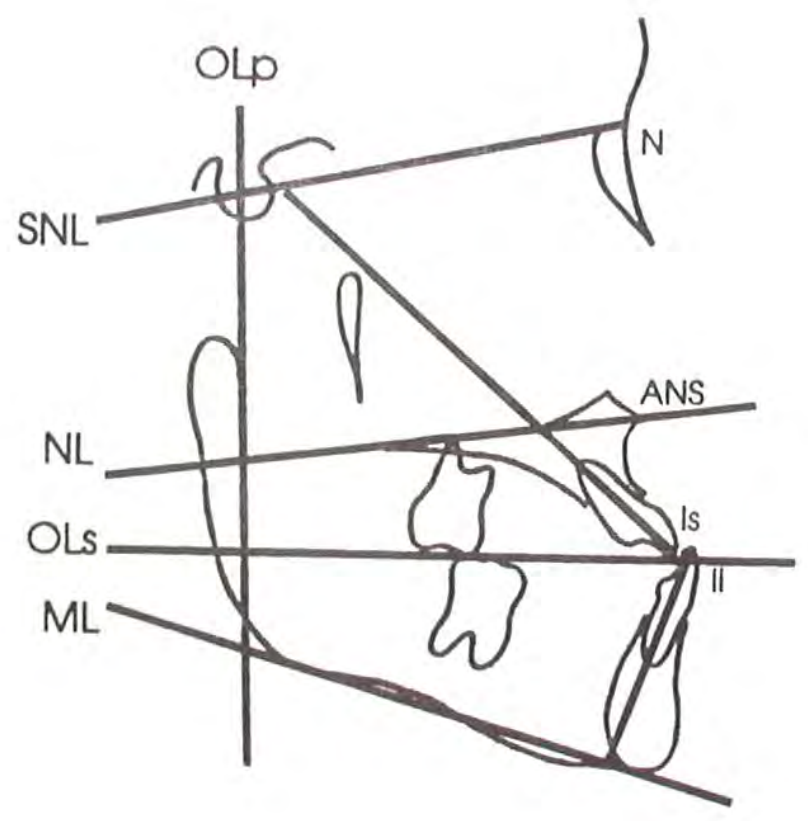

Figure 8. The Reference Lines and Measuring Points Used for the Angular Cephalometric Analysis 
Table 12. The angular measurements of variables (17-24).

\begin{tabular}{|l|l|}
\hline \multicolumn{1}{|c|}{ Variable $\left.^{\circ}{ }^{\circ}\right)$} & \multicolumn{1}{c|}{ Definition } \\
\hline Skeletal measuring points: & \\
\hline 17. SNA & Maxillary base relative to SNL \\
\hline 18. SNB & Mandibular base relative to SNL \\
\hline 19. ANB & SNA minus SNB \\
\hline 20. SNL - ML & Mandibular plane angle \\
\hline 21. SNL - OLs & Occlusal plane angle \\
\hline 22. SNL - NL & Palatal plane angle \\
\hline Dental measuring points: & \\
\hline 23. Is/SNL & Maxillary central incisor angle \\
\hline 24. Ii/ ML & Mandibular central incisor angle \\
\hline
\end{tabular}

\section{Evaluation of Overjet and Molar Relationship Correction}

The amount of dental changes that occurred within the maxilla and mandible was calculated in order to determine the amount of skeletal and dental contribution to the overjet and molar relationship correction. The calculation method is shown below in Table 13.

Table 13. Calculation of overjet and molar relationship changes.

\begin{tabular}{|l|l|}
\hline \multicolumn{1}{|c|}{ Overjet } & \multicolumn{1}{c|}{ Molar relationship } \\
\hline Skeletal contribution & Skeletal contribution: \\
\hline 1. OLp - A pt. & 1. OLp - A pt. \\
\hline 2. OLp - Pg & 2. OLp - Pg \\
\hline Dental contribution & Dental contribution \\
\hline 3. Is/OLp minus OLp - A pt. & 3. Ms/OLp minus OLp - A pt. \\
\hline 4. Ii/OLp minus OLp - Pg & 4. Mi/OLp minus OLp - Pg \\
\hline Overjet correction & Molar relationship correction \\
\hline Sum of $1,2,3$, and 4 & Sum of 1, 2, 3, and 4 \\
\hline
\end{tabular}




\section{STATISTICAL TREATMENT}

Arithmetic mean (mean) and standard deviation (SD) was calculated for each cephalometric variable. The JMP statistical software on a MacIntosh computer was used to analyze the data. To determine the reliability of cephalometric measurements, the Intraclass Correlation Coefficient of Reliability (I.C.C.R.) was used, in which MSA is the mean square among the variables, MSE is the mean square between the variables, and $\mathrm{k}$ is the number of repeated measures:

$$
\mathrm{R}=(\mathrm{MSA}-\mathrm{MSE}) / \mathrm{MSA}+[(\mathrm{k}-1) \mathrm{MSE}]
$$

The $\mathrm{R}$ value is a number between zero and one, and an $\mathrm{R}$ value greater than 0.90 indicates high reliability.

The 3x2 ANOVA was used to assess the statistical significance with regards to the differences in dentofacial morphology of the subjects in the three groups (e.g., Double-hinged group, Hyrax group, and Control group) at two different time periods (e.g., T1 and T2). The Tukey-Kramer Multiple Comparison Test was done to find the statistical significance when comparing two groups at a time (e.g., Control group vs. Hyrax expander group; Hyrax expander group vs. Double-hinged expander group; and Control group vs. Double-hinged expander group). A level of significance used include: $\mathrm{p}<0.05, \mathrm{p}<0.01$, and $\mathrm{p}<0.001$. However, $\mathrm{p}>0.05$ was designated as not significant (N.S.) 


\section{EQUIPMENT AND MATERIALS}

Hyrax 12 mm expander

(Summit Orthodontic Services, Inc. in Munroe Falls, OH 44262)

Double-hinged $12 \mathrm{~mm}$ expander

(Best Medical \& Dental International, Inc. in Kaohsiung, Taiwan)

Petit-Delaire Protraction face-mask

(Ormco Corporation in Glendora, CA 91740)

Fowler -Sylvac Ultra-Cal Mark III electronic caliper

(Salem Tools in Salem, Virginia)

Cephalometric acetate tracing paper

(3M Unitek in Monrovia, California)

Cephalometric protractor

(3M Unitek in Monrovia, California)

Bic mechanical pencil

(BIC Corporation in Shelton, CT 06484-6299 USA)

12 1/4” x 11 1/2” x 2 1/4" cephalometric tracing box and viewer.

(Henry Schein, 5 Harbor Park Drive, Port Washington, NY 11050)

JMP statistical software for MacIntosh computer 


\section{CHAPTER IV}

\section{RESULTS AND DISCUSSION}

\section{RESULTS}

This section presents the results and discussion of the study which investigated the quantitative difference, if any, between the two techniques of maxillary expansion and protraction. The traditional technique of using a Hyrax expander to expand the maxilla once prior to using the protraction facemask was compared to that of another technique which employs a double-hinged expansion appliance to expand and contract the maxilla multiple times prior to maxillary protraction. The results of the doublehinged expander group and the Hyrax expander group were compared to a matched control group.

Changes in the measurement points were assessed. The arithmetic mean, standard deviations, minimum, and maximum were calculated separately for both treated groups and the control group. The maxillary expansion and protraction facemask effects in the two treated groups were compared to one another as well as to that of the control group in order to find any statistical significant differences. The statistical results from this study are discussed in the following order:

1. Reliability of cephalometric measurements
a. Error of sagittal measurements
b. Error of vertical measurements
c. Error of angular measurements
d. Error of superimposition 
2. Statistical significance within the Double-hinged Expander group (DH) between $\mathrm{T} 1$ and $\mathrm{T} 2$

3. Statistical significance within the Hyrax Expander group $(\mathrm{H})$ between $\mathrm{T} 1$ and T2

4. Statistical significance within the Control group (C) between t1 and t2

5. Statistical significance among the three groups ( $\mathrm{DH}, \mathrm{H}$, and $\mathrm{C}$ ) for the time periods $\mathrm{T} 1$ and $\mathrm{T} 2$ in the treated groups and $\mathrm{t} 1$ and $\mathrm{t} 2$ in the control group.

\section{$\underline{\text { Reliability of Cephalometric Measurements }}$}

The Intraclass Correlation Coefficient of Reliability (I.C.C.R.) for sagittal, vertical, angular, and superimposition measurements are listed in TABLE 14. The errors made by one examiner (i.e., the intra-examiner error) when locating the different landmarks, superimposing the tracings, and measuring the changes of the landmarks, are illustrated in Appendix A through D. 
Table 14. Intraclass Correlation Coefficient of Reliability for Sagittal, Vertical, Angular Measurements, and Superimpositions

\begin{tabular}{|c|c|c|c|c|c|c|c|}
\hline & Variable & \multicolumn{2}{|c|}{ T1 } & \multicolumn{2}{|c|}{$\mathbf{T 2}$} & \multicolumn{2}{|c|}{ T2-T1 } \\
\hline & & $\begin{array}{c}\text { Mean } \\
\text { Difference }\end{array}$ & Reliability & $\begin{array}{c}\text { Mean } \\
\text { Difference }\end{array}$ & Reliability & $\begin{array}{c}\text { Mean } \\
\text { Difference }\end{array}$ & Reliability \\
\hline \multirow{11}{*}{ 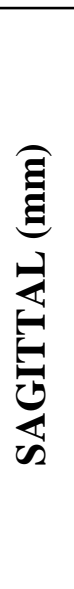 } & Skeletal & & & & & & \\
\hline & OLp - A pt. & 0.39 & 0.98979 & -0.07 & 0.99649 & -0.46 & 0.75415 \\
\hline & OLp - B pt. & -0.15 & 0.99929 & -0.19 & 0.99856 & -0.04 & 0.83303 \\
\hline & OLp - Pg & -0.09 & 0.99981 & -0.37 & 0.99650 & -0.28 & 0.83192 \\
\hline & Dental & & & & & & \\
\hline & Is / OLp & 0.10 & 0.99874 & -0.11 & 0.99943 & -0.21 & 0.98587 \\
\hline & Ii/ OLp & -0.01 & 0.99859 & -0.08 & 0.99896 & -0.07 & 0.98526 \\
\hline & Overjet & 0.12 & 0.98737 & -0.03 & 0.99490 & -0.15 & 0.95158 \\
\hline & Ms/OLp & -0.09 & 0.99982 & -0.24 & 0.99861 & -0.15 & 0.98521 \\
\hline & Mi/OLp & 0.05 & 0.99983 & -0.08 & 0.99945 & -0.13 & 0.73011 \\
\hline & $\begin{array}{c}\text { Molar } \\
\text { Relationship }\end{array}$ & -0.14 & 0.99819 & -0.16 & 0.93338 & -0.02 & 0.96216 \\
\hline \multirow{9}{*}{ 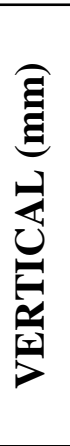 } & Skeletal & & & & & & \\
\hline & $\mathrm{N}-\mathrm{A} \mathrm{pt}$ & 0.05 & 0.99941 & -0.10 & 0.99874 & -0.05 & 0.97030 \\
\hline & ANS - Me & -0.32 & 0.99920 & -0.19 & 0.99754 & 0.13 & 0.98788 \\
\hline & Dental & & & & & & \\
\hline & Is - NL & 0.12 & 0.99560 & -0.13 & 0.99563 & -0.25 & 0.95383 \\
\hline & $\mathrm{Ii}-\mathrm{ML}$ & -0.16 & 0.99933 & 0.16 & 0.99780 & 0.24 & 0.94953 \\
\hline & Overbite & -0.42 & 0.99489 & -0.13 & 0.99960 & 0.21 & 0.99568 \\
\hline & Msc - NL & 0.35 & 0.98518 & 0.12 & 0.99346 & -0.24 & 0.89454 \\
\hline & Mic - ML & -0.01 & 0.99934 & 0.15 & 0.99832 & 0.16 & 0.99221 \\
\hline \multirow{10}{*}{ 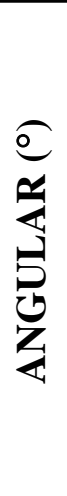 } & Skeletal & & & & & & \\
\hline & SNA & -0.3 & 0.99575 & 0.3 & 0.99183 & 0.6 & 0.95158 \\
\hline & SNB & 0.2 & 0.99527 & -0.1 & 0.99036 & -0.3 & 0.71981 \\
\hline & ANB & -0.5 & 0.99552 & 0.4 & 0.99754 & 0.9 & 0.96112 \\
\hline & SNL - ML & -0.1 & 0.99136 & -0.4 & 0.99991 & -0.4 & 0.99405 \\
\hline & SNL - OLs & 0.0 & 0.99732 & 0.1 & 0.99854 & -0.6 & 0.98337 \\
\hline & SNL - NL & 0.2 & 0.99553 & -0.4 & 0.88566 & 0.3 & 0.97119 \\
\hline & Dental & & & & & & \\
\hline & Is / SNL & 0.1 & 0.99964 & -0.4 & 0.99993 & -0.5 & 0.99357 \\
\hline & Ii / ML & 1.9 & 0.99394 & 0.4 & 0.89261 & -1.5 & 0.92210 \\
\hline
\end{tabular}


Error in Sagittal Measurements. The I.C.C.R. for all sagittal measurements and time periods were found to be greater than 0.93 , which indicates that the measurements are reliable. The greatest error measurements was found to be $0.39 \mathrm{~mm}$ for the maxillary base position (OLp - A pt.) measured at time T1. Appendix E lists the mean, standard deviation, minimum, and maximum of the sagittal measurements.

Error in Vertical Measurements. The I.C.C.R. for all the vertical measurements and time periods were found to be greater than 0.98 , which indicates that the measurements are reliable. The greatest error measurement was found to be $0.35 \mathrm{~mm}$ for the variable which measures the maxillary primary second or permanent first molar relative to the palatal plane (Msc - NL) at time T1. The mean, standard deviation, minimum, and maximum of the vertical measurements are listed in Appendix F.

Error in Angular Measurements. The I.C.C.R. for all except two of the angular measurements and time periods were found to be greater than 0.88 , which indicates that the measurements are reliable. The greatest mean error measurement was found to be $1.9^{\circ}$ for the maxillary central incisor angle (Ii/ML) measured at time T1. The mean, standard deviation, minimum, and maximum of the angular measurements are listed in Appendix G.

Error in Superimpostion. The I.C.C.R. for all superimposition measurements was found to be greater than 0.81 , which is considered to be reliable. The greatest mean error measurement was $0.90 \mathrm{~mm}$ for the ANB variable at T2-T1, but it had a reliability coefficient of 0.96. The mean, standard deviation, minimum, and maximum of the superimposition measurements are listed in Appendix $\mathrm{H}$. 


\section{Statistical Significance Within the Treated Group}

Cephalometric measurements at $\mathrm{T} 1$ and $\mathrm{T} 2$ with regards to the sagittal, vertical, and angular variables are listed in Appendices E through G.

Comparison of T1and T2 for the Double-Hinged Expansion Group. Statistically significant differences for sagittal, vertical, and angular changes for the Double-hinged expander group are listed in Tables 15, 16, and 17, respectively. The arithmetic mean, standard deviations, minimum, and maximum for the sagittal, vertical, and angular changes are also shown in Tables 15, 16, and 17.

Table 15. Sagittal measurements at $\mathrm{T} 1$ and $\mathrm{T} 2$ in the Double-hinged Expander Group

\begin{tabular}{|l|c|l|l|l|l|l|l|c|}
\hline Variables (mm) & \multicolumn{3}{|c|}{ T1 } & \multicolumn{3}{c|}{ T2 } & \multicolumn{2}{c|}{$\begin{array}{c}\text { Matched Pair } \\
\text { t-test* }\end{array}$} \\
\hline Sagittal & Min & Max & Mean & Min & Max & Mean & p-value & Sig. \\
\hline Skeletal & & & & & & & & \\
\hline 1. OLp - A pt. & 69.76 & 83.22 & 77.88 & 72.11 & 83.82 & 79.70 & 0.0003 & $* * *$ \\
\hline 2. OLp - B pt. & 79.97 & 92.10 & 85.12 & 79.54 & 91.28 & 83.75 & 0.0043 & N.S. \\
\hline 3. OLp - Pg & 81.59 & 95.00 & 87.19 & 79.44 & 95.57 & 86.13 & 0.1316 & N.S. \\
\hline Dental & & & & & & & & \\
\hline 4. Is/OLp & 75.56 & 90.86 & 83.89 & 80.74 & 94.99 & 87.19 & 0.0014 & $* *$ \\
\hline 5. Ii/ OLp & 79.77 & 91.25 & 84.64 & 78.96 & 90.27 & 82.77 & 0.0338 & $*$ \\
\hline 6. Overjet & -4.22 & 3.75 & -0.76 & 0.51 & 6.96 & 4.43 & 0.0001 & $* * *$ \\
\hline 7. Ms/OLp & 44.78 & 57.90 & 52.97 & 46.06 & 61.95 & 54.99 & 0.0008 & $* * *$ \\
\hline 8. Mi/OLp & 49.35 & 64.83 & 56.86 & 49.03 & 63.21 & 55.52 & 0.0245 & $*$ \\
\hline 9. Molar Rel. & -7.97 & 0.31 & -3.89 & -3.00 & 4.41 & -0.53 & 0.0003 & $* * *$ \\
\hline
\end{tabular}

NS = not significantly different

$*$ = significantly different at $\mathrm{p}<0.05$.

$* *=$ shows pairs of means that are significantly at $\mathrm{p}<0.01$

$* * *=$ shows pairs of means that are significantly at $\mathrm{p}<0.001$ 
With regards to the sagittal measurements, significant differences were found in all except two cephalometric variables tested as illustrated in Table 15. Skeletally, the position of the maxillary base (OLp - A pt.) increased from T1 to T2. Dentally, maxillary incisor (Is/OLp) had significant forward movement and mandibular incisor (Ii/OLp) had significant backward movement. Overjet improved significantly from -0.72 $\mathrm{mm}$ to $4.51 \mathrm{~mm}$, a $4.82 \mathrm{~mm}$ correction following maxillary expansion and protraction, while molar relationship had a significant correction from a Class III relationship of -4.01 $\mathrm{mm}$ to a minimal Class III relationship of $-0.66 \mathrm{~mm}$ following treatment.

Table 16 shows the vertical variables measured at times $\mathrm{T} 1$ and $\mathrm{T} 2$ for the Double-hinged expander group.

Table 16. Vertical measurements at T1and T2 in the Double-hinged Expander Group.

\begin{tabular}{|l|l|l|l|l|l|l|l|l|}
\hline Variables (mm) & \multicolumn{3}{|c|}{ T1 } & \multicolumn{3}{c|}{ T2 } & \multicolumn{2}{c|}{$\begin{array}{c}\text { Matched Pair t- } \\
\text { test* }\end{array}$} \\
\hline Vertical & Min & Max & Mean & Min & Max & Mean & p-value & Sig. \\
\hline Skeletal & & & & & & & & \\
\hline 10. N-A pt. & 50.07 & 63.18 & 55.57 & 49.18 & 64.03 & 55.96 & 0.2695 & N.S. \\
\hline 11. ANS - Me & 61.51 & 75.88 & 67.34 & 64.04 & 77.49 & 68.62 & 0.1362 & N.S. \\
\hline Dental & & & & & & & & \\
\hline 12. Is - NL & 25.64 & 32.25 & 27.91 & 24.95 & 30.63 & 27.42 & 0.8699 & N.S. \\
\hline 13. Ii - ML & 36.13 & 42.50 & 39.00 & 37.76 & 43.95 & 40.74 & 0.0013 & $* *$ \\
\hline 14. Overbite & -0.88 & 5.16 & 2.15 & -2.07 & 5.46 & 2.02 & 0.8171 & N.S. \\
\hline 15. Msc- NL & 14.98 & 23.98 & 18.96 & 16.37 & 24.28 & 19.00 & 0.9816 & N.S. \\
\hline 16. Mic - ML & 25.00 & 33.72 & 29.47 & 25.08 & 32.10 & 30.08 & 0.1769 & N.S. \\
\hline
\end{tabular}

NS = not significantly different

$*$ = significantly different at $\mathrm{p}<0.05$.

$* *=$ shows pairs of means that are significantly at $\mathrm{p}<0.01$

$* * *=$ shows pairs of means that are significantly at $\mathrm{p}<0.001$ 
Of the seven vertical variables, the one measuring the mandibular central incisor position (Ii $\perp$ ML) was the only variable that had a significant change, starting at 39.00 mm and becoming $40.74 \mathrm{~mm}$.

Table 17 shows the angular measurements for the Double-hinged expander group at times $\mathrm{T} 1$ and $\mathrm{T} 2$.

Table 17. Angular measurements at $\mathrm{T} 1$ and $\mathrm{T} 2$ in Double-hinged Expander Group

\begin{tabular}{|l|l|l|l|l|l|l|l|l|}
\hline Variables ( & \multicolumn{4}{l}{ T1 } & \multicolumn{3}{l|}{ T2 } & \multicolumn{2}{l|}{$\begin{array}{c}\text { Matched Pair } \\
\text { t-test* }\end{array}$} \\
\hline Angular & Min & Max & Mean & Min & Max & Mean & p-value & Sig. \\
\hline Skeletal & & & & & & & & \\
\hline 17. SNA & 72.0 & 82.5 & 79.3 & 74.5 & 88.6 & 80.8 & 0.0629 & N.S. \\
\hline 18. SNB & 72.5 & 81.5 & 79.2 & 71.5 & 81.5 & 78.1 & 0.0071 & $* *$ \\
\hline 19. ANB & -3.5 & 4.0 & 0.2 & -1.0 & -7.6 & 2.7 & 0.0038 & $* *$ \\
\hline 20. SNL - ML & 30.0 & 38.5 & 20.9 & 28.0 & 39.5 & 20.7 & 0.0071 & N.S. \\
\hline 21. SNL - OLs & 15.0 & 26.5 & 20.9 & 14.0 & 26.5 & 20.7 & 0.5862 & N.S. \\
\hline 22. SNL - NL & 2.0 & 11.5 & 5.8 & 1.5 & 10.0 & 5.8 & 1.0000 & N.S. \\
\hline Dental & & & & & & & & \\
\hline 23. Is/ SNL & 83.0 & 116.0 & 98.6 & 90.0 & 117.0 & 104.1 & 0.0172 & $*$ \\
\hline 24. Ii /ML & 72.0 & 94.0 & 84.9 & 76.0 & 91.0 & 83.6 & 0.5166 & N.S. \\
\hline
\end{tabular}

NS = not significantly different

$*$ = significantly different at $\mathrm{p}<0.05$.

** = shows pairs of means that are significantly at $\mathrm{p}<0.01$

$* * *=$ shows pairs of means that are significantly at $\mathrm{p}<0.001$

Significant differences were found with the variables: SNB, ANB, and maxillary incisor angle (Is / SNL). The SNB angle decreased from $79.17^{\circ}$ to $78.06^{\circ}$, whereas ANB 
significantly increased from $0.17^{\circ}$ to $2.73^{\circ}$ following treatment. The maxillary incisor angle also increased after treatment, going from $98.61^{\circ}$ to $104.11^{\circ}$.

Comparison of T1 and T2 for Hyrax Expansion Group. Statistical analyses to determine significant differences among the various time periods of the Hyrax expansion group with regards to the sagittal, vertical, and angular changes are listed in Tables 18, 19, and 20, respectively. Arithmetic mean, standard deviations, minimum, and maximum for the sagittal, vertical, and angular changes are shown in Appendices E-G.

Table 18. Sagittal measurements at $\mathrm{T} 1$ and $\mathrm{T} 2$ in Hyrax expander treatment group

\begin{tabular}{|l|c|l|l|l|l|l|l|l|}
\hline Variables (mm) & \multicolumn{3}{|c|}{ T1 } & \multicolumn{3}{c|}{ T2 } & \multicolumn{2}{c|}{$\begin{array}{c}\text { Matched Pair } \\
\text { t-test* }\end{array}$} \\
\hline Sagittal & Min & Max & Mean & Min & Max & Mean & p-value & Sig. \\
\hline Skeletal & & & & & & & & \\
\hline 1. OLp - A pt. & 62.66 & 70.45 & 67.65 & 66.03 & 73.59 & 70.49 & 0.0007 & $* * *$ \\
\hline 2. OLp - B pt. & 71.49 & 85.75 & 76.72 & 69.71 & 82.28 & 75.55 & 0.2570 & N.S. \\
\hline 3. OLp - Pg & 71.82 & 87.75 & 78.29 & 70.98 & 83.83 & 77.30 & 0.4480 & N.S. \\
\hline Dental & 71.30 & 77.73 & 74.97 & 74.07 & 84.61 & 79.49 & 0.0021 & $* *$ \\
\hline 4. Is/OLp & 74.40 & 80.59 & 77.74 & 70.04 & 80.96 & 75.98 & 0.1209 & N.S. \\
\hline 5. Ii/ OLp & -4.06 & -1.63 & -2.77 & 1.24 & 7.18 & 3.51 & 0.0014 & $* *$ \\
\hline 6. Overjet & 40.67 & 59.53 & 48.52 & 46.33 & 65.57 & 52.41 & 0.0012 & $* *$ \\
\hline 7. Ms/OLp & 45.76 & 65.19 & 51.65 & 45.24 & 65.16 & 52.41 & 0.1234 & N.S. \\
\hline 8. Mi/OLp & -6.90 & -1.00 & -3.12 & -2.77 & 1.09 & 0.01 & 0.0081 & $* *$ \\
\hline 9. Molar Rel. & & & & & & & & \\
\hline
\end{tabular}

NS = not significantly different

* = significantly different at $\mathrm{p}<0.05$.

$* *=$ shows pairs of means that are significantly at $\mathrm{p}<0.01$

$* * *=$ shows pairs of means that are significantly at $\mathrm{p}<0.001$ 
Table 18 lists the significant differences that were found in the sagittal variables. Significant changes skeletally in the position of maxillary base (OLp - A pt.). Dentally, there were significant sagittal changes in the position of the maxillary central incisor and overjet. Also, there were significant changes in the position of the maxillary second primary or first permanent molar position and thus in the molar relationship. The overjet started out at a mean of $-2.69 \mathrm{~mm}$ and corrected to a mean of $+1.99 \mathrm{~mm}$. Molar relationship was changed significantly from a Class III molar relationship, $-2.66 \mathrm{~mm}$, to a near Class I relationship of $-0.37 \mathrm{~mm}$, for total $2.29 \mathrm{~mm}$ correction following six months of treatment with protraction facemask.

Table 19. Vertical measurements at $\mathrm{T} 1$ and $\mathrm{T} 2$ in Hyrax Expander Group

\begin{tabular}{|l|l|l|l|l|l|l|l|c|}
\hline Variables (mm) & \multicolumn{3}{|c|}{ T1 } & \multicolumn{3}{c|}{ T2 } & \multicolumn{2}{c|}{$\begin{array}{c}\text { Matched Pair } \\
\text { t-test* }\end{array}$} \\
\hline Vertical & Min & Max & Mean & Min & Max & Mean & p-value & Sig. \\
\hline Skeletal & & & & & & & & \\
\hline 10. N-A pt. & 49.03 & 57.41 & 53.48 & 46.34 & 58.20 & 53.72 & 0.7913 & N.S. \\
\hline 11. ANS - Me & 57.44 & 62.68 & 60.50 & 59.74 & 69.07 & 63.57 & 0.0037 & $* *$ \\
\hline Dental & 21.63 & 27.87 & 25.78 & 23.07 & 27.80 & 26.24 & 0.0036 & $* *$ \\
\hline 12. Is - NL & & & & & & & & \\
\hline 13. Ii - ML & 35.02 & 39.87 & 37.51 & 36.88 & 41.53 & 39.07 & 0.0527 & $*$ \\
\hline 14. Overbite & -0.78 & 9.46 & 3.41 & 0.36 & 4.06 & 2.22 & 0.2547 & N.S. \\
\hline 15. Msc - NL & 15.47 & 21.09 & 18.48 & 17.88 & 21.84 & 19.77 & 0.0051 & $* *$ \\
\hline 16. Mic - ML & 25.45 & 31.13 & 28.04 & 26.33 & 32.18 & 29.42 & 0.0085 & $* *$ \\
\hline
\end{tabular}

NS = not significantly different

$*$ = significantly different at $\mathrm{p}<0.05$.

$* *$ = shows pairs of means that are significantly at $\mathrm{p}<0.01$

$* * *=$ shows pairs of means that are significantly at $\mathrm{p}<0.001$ 
Significant differences were found in five of the seven vertical variables, as illustrated in Table 19. No significant changes were observed with the maxillary vertical position (N-A pt.) and overbite. Skeletally, there were significant changes in lower facial height (ANS - Me). Dentally, there was not significant decrease in overbite, but there was a significant vertical change in position of the maxillary and mandibular central incisor as well as the maxillary and mandibular primary second or permanent first molar.

Statistically significant differences were found in only two of the eight angular variables, as illustrated in Table 20.

Table 20. Angular measurements at $\mathrm{T} 1$ and $\mathrm{T} 2$ in Hyrax Expander Group

\begin{tabular}{|l|l|l|l|l|l|l|l|l|}
\hline \multicolumn{1}{|c|}{ Variables ( } & \multicolumn{3}{c|}{ T1 } & \multicolumn{3}{c|}{ T2 } & \multicolumn{2}{c|}{$\begin{array}{c}\text { Matched Pair } \\
\text { t-test* }\end{array}$} \\
\hline Angular & Min & Max & Mean & Min & Max & Mean & p-value & Sig. \\
\hline Skeletal & & & & & & & & \\
\hline 17. SNA & 76.0 & 83.0 & 78.7 & 77.5 & 86.0 & 80.8 & 0.0001 & $* * *$ \\
\hline 18. SNB & 77.0 & 85.0 & 79.4 & 76.0 & 82.0 & 78.4 & 0.0633 & N.S. \\
\hline 19. ANB & -5.5 & 3.0 & -0.9 & 1.0 & 4.5 & 2.7 & 0.0011 & $* *$ \\
\hline 20. SNL - ML & 32.5 & 40.0 & 23.1 & 34.5 & 2.0 & 21.6 & 0.1185 & N.S. \\
\hline 21. SNL - OLs & 15.5 & 29.0 & 23.1 & 15.5 & 25.5 & 21.6 & 0.1185 & N.S. \\
\hline 22. SNL - NL & 2.0 & 12.5 & 8.1 & 2.5 & 11.0 & 7.6 & 0.3336 & N.S. \\
\hline Dental & & & & & & & & \\
\hline 23. Is/ SNL & 91.5 & 122.0 & 104.5 & 98.5 & 117.0 & 109.2 & 0.0653 & N.S. \\
\hline 24. Ii /ML & 73.0 & 106.5 & 91.3 & 76.5 & 105.5 & 88.1 & 0.1963 & N.S. \\
\hline
\end{tabular}

NS = not significantly different

* = significantly different at $\mathrm{p}<0.05$.

$* *$ = shows pairs of means that are significantly at $\mathrm{p}<0.01$

$* * *=$ shows pairs of means that are significantly at $\mathrm{p}<0.001$ 
Skeletally, SNA and ANB angles had a significant increase of over $2^{\circ}$ following treatment with maxillary expansion and protraction facemask. However, the SNB angle, palatal plane angle, occlusal plane angle, and mandibular plane angle did not decrease significantly following treatment. Otherwise, there were no significant changes dentally.

\section{Statistical Significance Within the Control Group}

The lateral cephalometric radiographs of the control group were measured and compared for the two different time intervals. The arithmetic mean, standard deviation (SD), minimum, and maximum of all variables are listed in Appendices E-G.

Comparison of t1 and t2. Statistical analyses for the control group's sagittal, vertical, and angular changes are shown in Tables 21, 22, and 23, respectively. Statistically significant differences between times $\mathrm{t} 1$ and $\mathrm{t} 2$ were found in five of the nine sagittal variables listed in Table 21. Skeletally, there were significant changes in the position of the mandibular base (OLp - B pt) and the position of the mandibular chin (OLp - Pg). Dentally, there was no significant change in the overjet, the molar relationship, and the maxillary incisor sagittal position (Is/OLp). The mandibular incisor edge, however, did have a significant forward movement relative to the occlusal plane perpendicular reference line (Ii/OLp). Other significant changes included forward movement of the maxillary molar (Ms/OLp) and the mandibular molar (Mi/OLp), all of which may be attributed to growth. 
Table 21. Sagittal Measurements at $\mathrm{t} 1$ and $\mathrm{t} 2$ for the Control Group

\begin{tabular}{|l|c|c|c|c|c|c|c|c|}
\hline Variables (mm) & \multicolumn{3}{|c|}{ t1 } & \multicolumn{3}{c|}{ t2 } & \multicolumn{2}{c|}{$\begin{array}{c}\text { Matched Pair } \\
\text { t-test* }\end{array}$} \\
\hline Sagittal & Min & Max & Mean & Min & Max & Mean & p-value & Sig. \\
\hline Skeletal & & & & & & & & \\
\hline 1. OLp - A pt. & 65.62 & 74.89 & 69.37 & 66.84 & 75.31 & 69.93 & 0.0699 & N.S. \\
\hline 2. OLp - B pt. & 70.76 & 88.05 & 76.73 & 72.92 & 89.40 & 78.22 & 0.0291 & $*$ \\
\hline 3. OLp - Pg & 71.43 & 90.00 & 78.35 & 73.28 & 91.51 & 80.31 & 0.0307 & $*$ \\
\hline Dental & & & & & & & & \\
\hline 4. Is/OLp & 71.63 & 83.72 & 75.12 & 71.51 & 85.47 & 76.34 & 0.0688 & N.S. \\
\hline 5. Ii/ OLp & 73.83 & 86.13 & 77.77 & 74.18 & 87.80 & 79.51 & 0.0271 & $*$ \\
\hline 6. Overjet & -4.56 & -1.87 & -2.67 & -4.62 & -2.34 & -3.17 & 0.1195 & N.S. \\
\hline 7. Ms/OLp & 42.63 & 56.57 & 47.87 & 44.88 & 58.09 & 49.38 & 0.0128 & $*$ \\
\hline 8. Mi/OLp & 43.90 & 61.99 & 50.92 & 47.48 & 63.81 & 52.96 & 0.0151 & $*$ \\
\hline 9. Molar Rel. & -7.45 & -0.04 & -3.05 & -8.48 & -1.21 & -3.58 & 0.1584 & N.S. \\
\hline
\end{tabular}

NS = not significantly different

$*$ = significantly different at $\mathrm{p}<0.05$.

$* *$ = shows pairs of means that are significantly at $\mathrm{p}<0.01$

$* * *=$ shows pairs of means that are significantly at $\mathrm{p}<0.001$

The control group subjects experienced significant increases in all seven vertical variables. Table 22 lists the vertical changes that had occurred in each variable. No significant changes in the angular variables for the control group subjects, as illustrated in Table 23. 
Table 22. Vertical measurements at t1 and t2 in Control Group

\begin{tabular}{|l|l|l|l|l|l|l|l|c|}
\hline $\begin{array}{l}\text { Variables } \\
\text { (mm) }\end{array}$ & \multicolumn{3}{|c|}{ t1 } & \multicolumn{3}{c|}{ t2 } & \multicolumn{2}{|c|}{$\begin{array}{l}\text { Matched Pair } \\
\text { t-test* }\end{array}$} \\
\hline Vertical & Min & Max & Mean & Min & Max & Mean & $\begin{array}{l}\text { p- } \\
\text { value }\end{array}$ & Sig. \\
\hline Skeletal & & & & & & & & \\
\hline 10. N-A pt. & 49.11 & 55.22 & 52.67 & 50.83 & 57.38 & 54.42 & 0.0027 & $* *$ \\
\hline 11. ANS - Me & 55.27 & 70.03 & 61.25 & 58.49 & 70.22 & 63.23 & 0.0097 & $* *$ \\
\hline Dental & & & & & & & & \\
\hline 12. Is - NL & 19.57 & 30.18 & 23.88 & 20.92 & 31.56 & 26.07 & 0.0031 & $* *$ \\
\hline 13. Ii - ML & 37.33 & 43.16 & 40.37 & 37.96 & 44.94 & 41.88 & 0.0002 & $* * *$ \\
\hline 14. Overbite & 1.79 & 7.02 & 3.46 & 3.72 & 7.33 & 5.25 & 0.0008 & $* * *$ \\
\hline 15. Msc - NL & 13.24 & 21.75 & 17.24 & 15.66 & 21.54 & 18.84 & 0.0038 & $* *$ \\
\hline 16. Mic - ML & 26.51 & 31.93 & 29.60 & 27.71 & 33.92 & 30.59 & 0.0081 & $* *$ \\
\hline
\end{tabular}

NS = not significantly different

$*$ = significantly different at $\mathrm{p}<0.05$.

$* *=$ shows pairs of means that are significantly at $\mathrm{p}<0.01$

$* * *=$ shows pairs of means that are significantly at $\mathrm{p}<0.001$ 
Table 23. Angular measurements at t1 and t2 in Control Group

\begin{tabular}{|l|l|l|l|l|l|l|l|l|}
\hline \multicolumn{1}{|c|}{ Variables ( } & \multicolumn{3}{|c|}{ t1 } & \multicolumn{3}{c|}{ t2 } & \multicolumn{2}{c|}{$\begin{array}{c}\text { Matched Pair } \\
\text { t-test* }\end{array}$} \\
\hline Angular & Min & Max & Mean & Min & Max & Mean & p-value & Sig. \\
\hline Skeletal & & & & & & & & \\
\hline 17. SNA & 75 & 83.5 & 80.3 & 74.5 & 84.5 & 79.7 & 0.3549 & N.S. \\
\hline 18. SNB & 75.5 & 85 & 79.6 & 76.5 & 86 & 79.9 & 0.5675 & N.S. \\
\hline 19. ANB & -3 & 2.5 & -0.1 & -3 & 4.5 & 0 & 0.8131 & N.S. \\
\hline 20. SNL - ML & 32 & 41.5 & 36.2 & 30.5 & 41 & 36.2 & 0.2389 & N.S. \\
\hline 21. SNL - OLs & 17 & 28 & 21.6 & 15 & 29.5 & 22.7 & 0.2389 & N.S. \\
\hline 22. SNL - NL & 4 & 12 & 8.4 & 4 & 12 & 8.2 & 0.8183 & N.S. \\
\hline Dental & & & & & & & & \\
\hline 23. Is/ SNL & 95.5 & 107 & 101 & 90 & 113 & 101.2 & 0.9377 & N.S. \\
\hline 24. Ii /ML & 81.5 & 96 & 89.2 & 81 & 100 & 88.9 & 0.9185 & N.S. \\
\hline
\end{tabular}

NS = not significantly different

\section{Comparison of Treated and Control Groups}

The effects with maxillary expansion and protraction facemask in the Doublehinged expansion group and the Hyrax expansion group were compared to one another other as well as to the control group. The comparison of the 24 variables at each time interval is illustrated in Tables 24. The ANOVA showed significant differences among the three groups for the following 12 variables: OLp- A pt., OLp-B pt., OLp-Pg, Ii/OLp, Overjet, Mi/OLp, Molar Relationship, N-A pt., Is-NL, Overbite, SNA, and ANB. Afterwards, the Tukey-Kramer procedure was used to analyze the difference among the paired groups. The results of the statistical analyses can also be found in Table 24 . 
Table 24. Comparison of the Mean Difference Among all Groups

\begin{tabular}{|c|c|c|c|c|c|c|c|c|c|c|}
\hline & \multirow[t]{2}{*}{ Variable Name } & \multicolumn{2}{|c|}{$\begin{array}{l}\text { Double-hinged } \\
\text { (DH) }\end{array}$} & \multicolumn{2}{|c|}{$\begin{array}{l}\text { Hyrax } \\
\text { (H) }\end{array}$} & \multicolumn{2}{|c|}{$\begin{array}{l}\text { Control } \\
\text { (C) }\end{array}$} & \multicolumn{2}{|c|}{ ANOVA } & \multirow{2}{*}{$\begin{array}{c}\text { Tukey-Kramer } \\
\text { (pairs showing } \\
\text { significant differences) }\end{array}$} \\
\hline & & Mean & SD & Mean & SD & \begin{tabular}{|l|} 
Mean \\
\end{tabular} & SD & p-value & Sig & \\
\hline \multirow{11}{*}{ 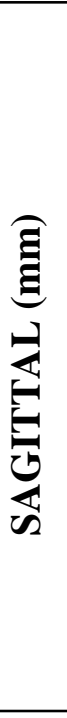 } & Skeletal & & & & & & & & & \\
\hline & OLp - A pt & 1.78 & 0.86 & 2.57 & 1.43 & 0.63 & 0.90 & 0.0038 & ** & $\mathrm{H}, \mathrm{C}$ \\
\hline & OLp - B pt & -1.23 & 1.74 & -0.60 & 1.47 & 1.53 & 1.73 & 0.0043 & $* *$ & $\begin{array}{c}\text { H, C } \\
\text { DH, C }\end{array}$ \\
\hline & OLp - Pg & -1.05 & 1.87 & -0.49 & 1.84 & 1.95 & 2.24 & 0.0089 & $* *$ & $\begin{array}{c}\mathrm{H}, \mathrm{C} \\
\mathrm{DH}, \mathrm{C}\end{array}$ \\
\hline & Dental & & & & & & & & & \\
\hline & Is / OLp & 3.28 & 2.07 & 3.18 & 2.15 & 1.32 & 1.88 & 0.0913 & N.S. & \\
\hline & Ii/ OLp & -1.95 & 2.28 & -1.50 & 2.59 & 1.83 & 2.04 & 0.0036 & $* *$ & $\begin{array}{l}\mathrm{H}, \mathrm{C} \\
\mathrm{DH}, \mathrm{C}\end{array}$ \\
\hline & Overjet & 5.22 & 2.08 & 4.68 & 2.93 & -0.51 & 0.88 & 0.0001 & $* * *$ & $\begin{array}{c}\mathrm{H}, \mathrm{C} \\
\mathrm{DH}, \mathrm{C}\end{array}$ \\
\hline & Ms/OLp & 2.10 & 1.22 & 3.40 & 2.08 & 1.57 & 1.48 & 0.0696 & N.S. & \\
\hline & Mi/OLp & -1.25 & 1.35 & 1.10 & 1.92 & 2.04 & 1.99 & 0.0019 & $* *$ & $\begin{array}{l}\mathrm{H}, \mathrm{DH} \\
\mathrm{DH}, \mathrm{C}\end{array}$ \\
\hline & \begin{tabular}{|l|} 
Molar \\
Relationship
\end{tabular} & 3.35 & 1.64 & 2.30 & 1.97 & -0.47 & 0.91 & 0.0001 & $* * *$ & $\begin{array}{c}\mathrm{H}, \mathrm{C} \\
\mathrm{DH}, \mathrm{C}\end{array}$ \\
\hline \multirow{9}{*}{ 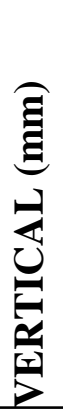 } & Skeletal & & & & & & & & & \\
\hline & $\mathrm{N}-\mathrm{A} p \mathrm{pt}$ & 0.54 & 1.37 & 0.10 & 1.11 & 1.63 & 1.14 & 0.0369 & * & $\mathrm{H}, \mathrm{C}$ \\
\hline & ANS - Me & 1.34 & 2.43 & 3.13 & 2.33 & 1.86 & 1.65 & 0.2157 & N.S. & \\
\hline & Dental & & & & & & & & & \\
\hline & Is - NL & 0.06 & 1.12 & 0.86 & 0.63 & 2.16 & 1.56 & 0.0031 & $* *$ & $\mathrm{DH}, \mathrm{C}$ \\
\hline & $\mathrm{Ii}-\mathrm{ML}$ & 1.89 & 1.17 & 2.62 & 3.46 & 1.50 & 0.70 & 0.5403 & N.S. & \\
\hline & Overbite & -0.13 & 1.65 & -1.25 & 3.05 & 1.88 & 1.09 & 0.0138 & * & $\mathrm{H}, \mathrm{C}$ \\
\hline & Msc - NL & -0.02 & 2.10 & 1.21 & 0.94 & 1.50 & 1.12 & 0.0899 & N.S. & \\
\hline & Mic-ML & 0.68 & 1.37 & 1.38 & 1.20 & 1.02 & 0.88 & 0.4545 & N.S. & \\
\hline \multirow{10}{*}{ 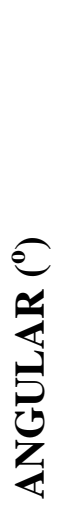 } & Skeletal & & & & & & & & & \\
\hline & SNA & 1.4 & 2.0 & 2.1 & 0.7 & -0.6 & 1.9 & 0.0054 & $* *$ & $\begin{array}{c}\mathrm{H}, \mathrm{C} \\
\mathrm{DH}, \mathrm{C}\end{array}$ \\
\hline & SNB & $\mid-1.1$ & 0.9 & -1.0 & 1.4 & 0.3 & 1.7 & 0.0630 & N.S. & \\
\hline & ANB & 2.6 & 1.9 & 3.6 & 2.2 & 0.1 & 1.4 & 0.0016 & ** & $\begin{array}{l}\text { H, C } \\
\text { DH, C }\end{array}$ \\
\hline & SNL - ML & 1.6 & 0.5 & 1.7 & 0.5 & -0.2 & 0.5 & 0.0297 & * & $\mathrm{H}, \mathrm{C}$ \\
\hline & SNL - OLs & -0.2 & 1.2 & -1.5 & 2.6 & 1.1 & 2.6 & 0.0637 & N.S & \\
\hline & SNL - NL & 0.0 & 2.7 & -0.5 & 1.5 & -0.2 & 2.8 & 0.9055 & N.S. & \\
\hline & Dental & & & & & & & & & \\
\hline & Is / SNL & 5.5 & 5.5 & 4.7 & 6.6 & 0.2 & 6.2 & 0.1588 & N.S. & \\
\hline & Ii / ML & $\mid-1.3$ & 5.9 & -3.2 & 6.8 & -0.2 & 6.3 & 0.6053 & N.S. & \\
\hline
\end{tabular}

DH $=$ Double-hinged $\quad \mathrm{H}=$ Hyrax $\quad \mathrm{C}=$ Control

NS $=$ not significantly different

$*$ = significantly different at $\mathrm{p}<0.05$.

$* *=$ shows pairs of means that are significantly at $\mathrm{p}<0.01$

$* * *=$ shows pairs of means that are significantly at $\mathrm{p}<0.001$ 
To summarize Table 24, significant skeletal and dental sagittal differences were found between the Hyrax expansion group $(\mathrm{H})$ and the control (C) group for the following variables: OLp-A pt., OLp-B pt., OLp-Pg, Ii/OLp, Overjet, Molar Relationship, N-A pt., Overbite, SNA, and ANB. The Double-hinged expansion group (DH) and the control group had statistically significant differences for the following variables: OLp-B pt., OLp-Pg, Ii/OLp, Overjet, Mi/OLp, Molar Relationship, Is-NL, SNA, and ANB. The Double-hinged expander group and the Hyrax group only had one statistically significant difference, which was related to the variable Mi/OLp.

The majority of the significant differences that were found between the treated groups and the control group were in the sagittal variables. Skeletally, both the Doublehinged and Hyrax expander groups display significant difference from the control group with regards to the position of the mandibular base (OLp-B pt.) and chin (OLp - Pg) only because the control group subjects experienced a significant change in the two aforementioned measurement variables. Although both treated groups had significant changes to the maxillary base position (OLp - A pt.), only the Hyrax group had a significant difference as compared to the control group.

Dentally, the Double-hinged expander group showed significant changes in all measurement variables but only had significant differences in four of the six measurement variables when compared to the control group. Although both treated groups had significant changes to the maxillary central incisor position (Is/OLp), it was not significantly different from the control group. The position of the mandibular incisor (Ii/OLp), however, was significantly different in the treated groups versus the control 
group. The Double-hinged expansion group had a -1.95 mm change and the Hyrax group had a $-1.50 \mathrm{~mm}$ change, compared to the control group’s $+1.83 \mathrm{~mm}$ change.

Furthermore, the position of the mandibular molar (Mi/OLp) in the Doublehinged expander group significantly differs that of the Hyrax expander group as well as that of the control group. The Double-hinged expander group and the control group experienced a significant change in the mandibular molar position (Mi/OLp). Doublehinged expander patients had $-1.25 \mathrm{~mm}$ of mean difference from time T1 to T2; whereas, the control group subjects had a +2.04 mm mean difference from time $\mathrm{t} 1 \mathrm{to} \mathrm{t} 2$. Note that all three groups (control and treated) had significant changes in the maxillary molar position (Ms/OLp) but there were no statistically significant differences among the three groups.

The use of maxillary expansion and protraction facemask affect both the skeletal and dental changes; therefore, they must be taken into consideration when referring to overjet and molar relationship corrections. In other words, the downward and backward movement of the mandible will in turn change the position of the measuring points associated with the sagittal variables OLp-Pg, Ii/OLp, and Mi/OLp, which will become more negative. As a result, the overjet and molar relationship will appear to have improved closer to a Class I relationship because the negative values will be added to the overjet and molar relationship. On the other hand, positive values of the aforementioned variables will be subtracted to determine the overjet and molar relationship. Method for calculating the overjet and molar relationship correction in the treated group was mentioned in Table 13. 
Diagrams of sagittal changes of the two treatment groups that occurred between times $\mathrm{T} 1$ and $\mathrm{T} 2$ as compared to that of the control group between times t1 and t2 are shown in Figures 9 and 10, respectively. In addition, calculations accounting for the skeletal and dental contributions to overjet and molar relationship are listed in Figures 9 and 10. Besides the skeletal and dental changes, one must take into consideration the contributions that growth may have in order to truly appreciate the treatment effects. Figures 9 and 10 also show the treatment effect (i.e., changes from the treatment minus changes due to growth). 
DOUBLE

HINGED
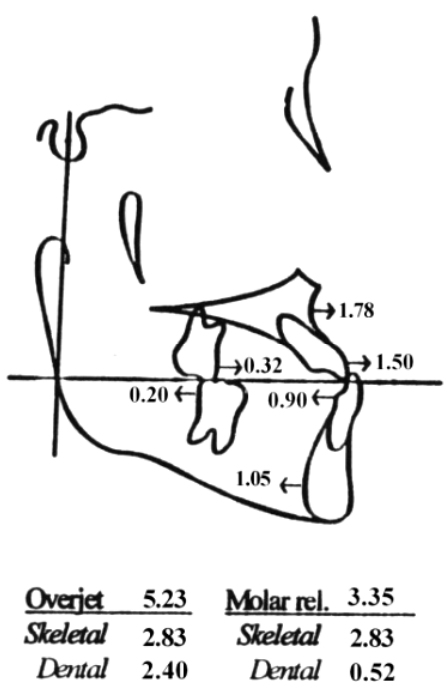

CONTROL

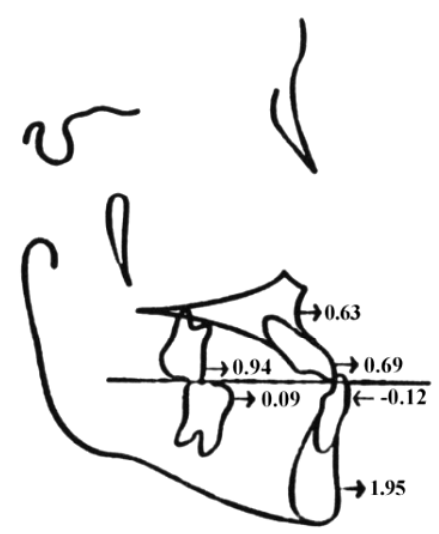

$\begin{array}{ccccc}\text { Overiet } & -0.51 & & \text { Molar rel. } & -0.47 \\ \text { Skeletal } & -1.32 & & \text { Sheletal } & -1.32 \\ \text { Dental } & 0.81 & & \text { Dental } & 0.85\end{array}$
DIFFERENCE

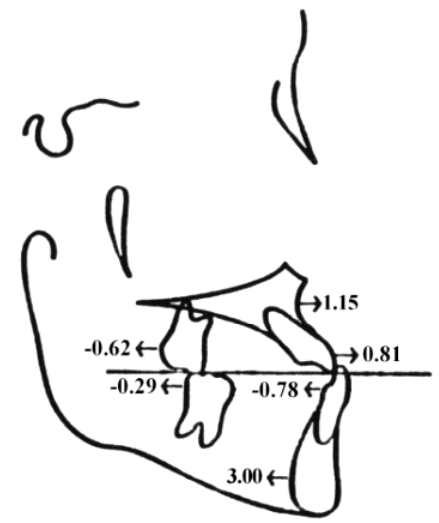

Overiet +5.74 Molar rel. +3.82

Skeletal $+4.15 \quad$ Skeletal +4.15

Derral $+\mathbf{1 . 5 9}$ Datal $-\mathbf{0 . 3 3}$

Figure 9. Total Observation (Double Hinged): Sagittal Changes

HYRAX

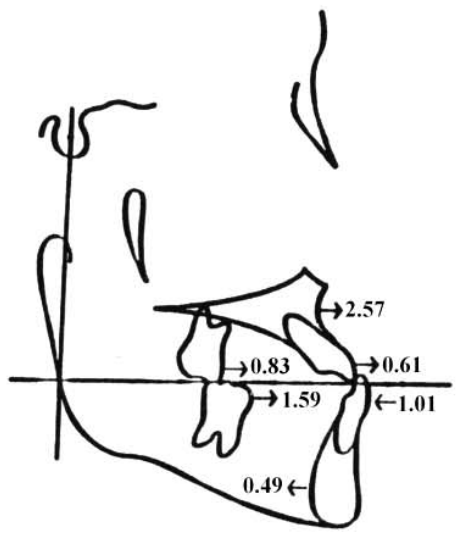

$\frac{\text { Overiet } 4.68}{\text { Skeletal }} 3.06$

Dental 1.62

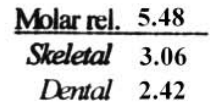

CONTROL
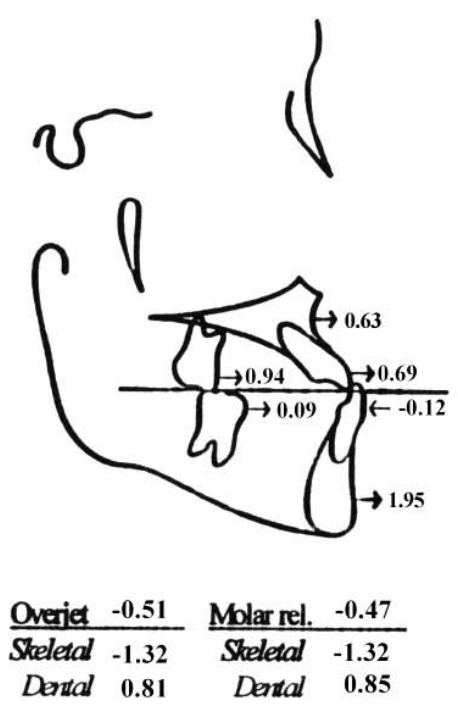

DIFFERENCE

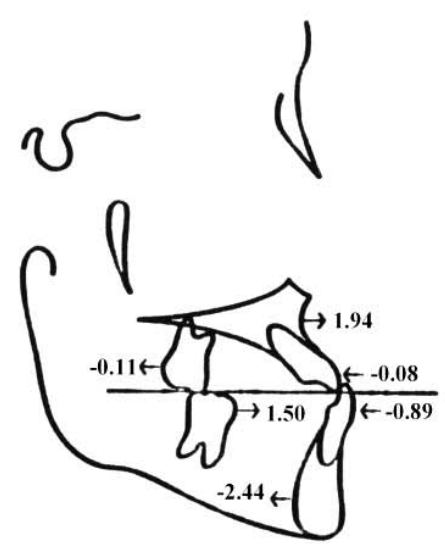

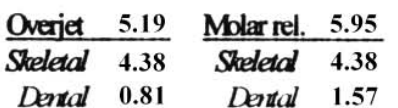

Figure 10. Total Observation (Hyrax): Sagittal Changes 
Both treated groups had significant changes to overjet and in turn were significantly different when compared to the control group's minimal change in overjet. However, upon closer examination once growth is accounted for, it is evident that the Double-hinged expander a greater change $(+5.74 \mathrm{~mm})$ to overjet as opposed to the Hyrax expansion group $(+5.19 \mathrm{~mm})$.

In addition, both treated groups had significant changes to molar relationship and were significantly different from the control group. Interestingly, the treatment effect (after subtracting growth) with regards to the molar relationship correction in the doublehinged expander subjects (+3.82 mm) was less than that of the Hyrax expander subjects (+5.95 mm) in molar relationship.

Diagrams of vertical and angular changes of the two treatment groups that occurred between times T1 and T2 as compared to that of the control group between times t1 and t2 are shown in Figures 11 and 12, respectively. Growth is also taken into account in order to get the actual treatment effects, and this is illustrated in Figures 11 and 12 . 


\section{DOUBLE-}

HINGED

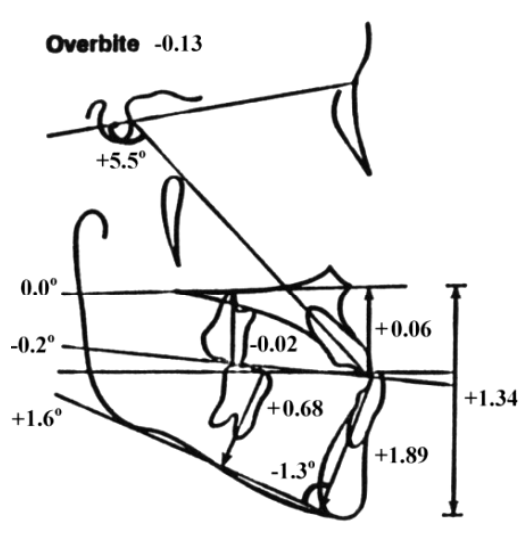

CONTROL

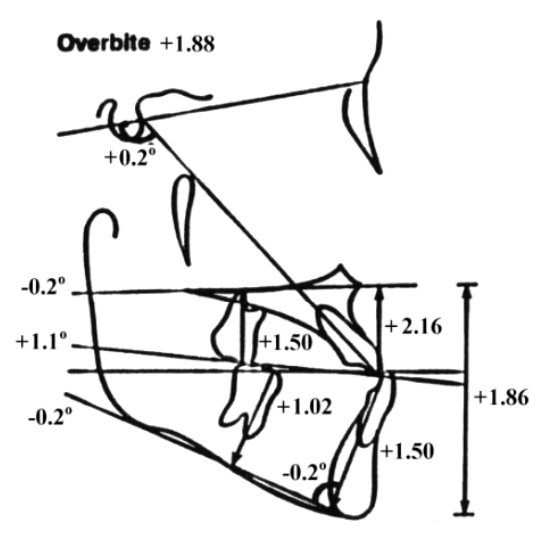

DIFFERENCE
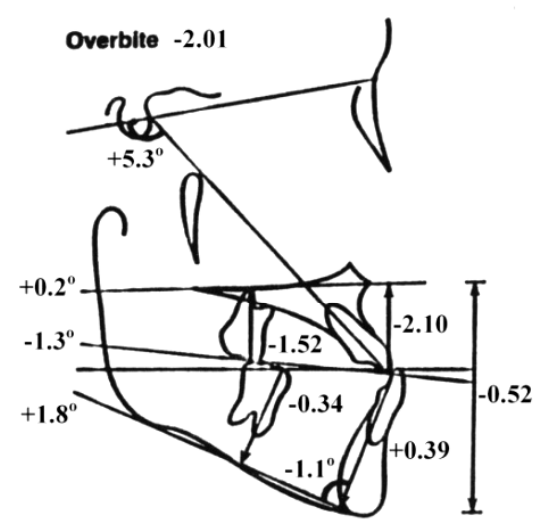

Figure 11. Total Observation (Double Hinged): Vertical and Angular Changes

HYRAX

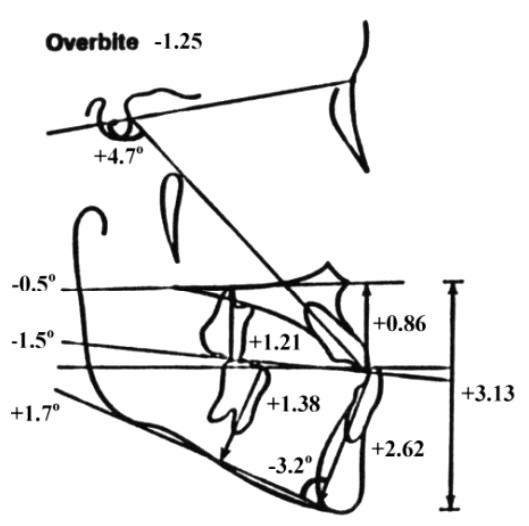

CONTROL

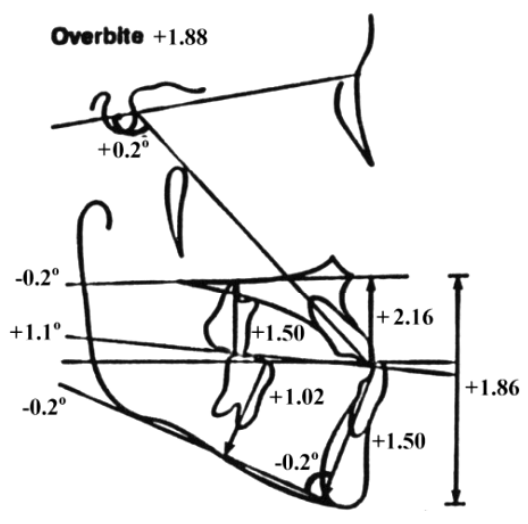

DIFFERENCE

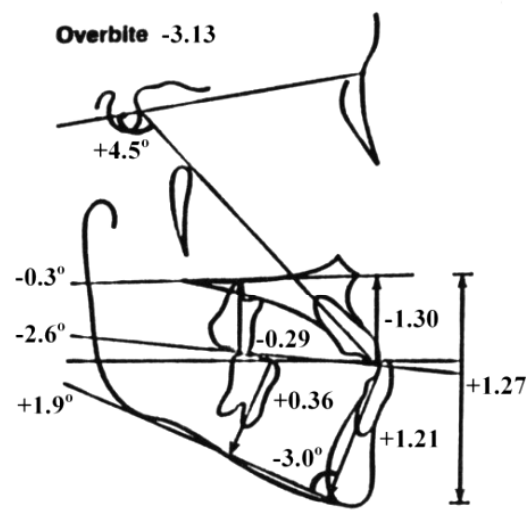

Figure 12. Total Observation (Hyrax): Vertical and Angular Changes 
Of the seven vertical variables, only three of the variables had significant differences amongst the control and treated groups. The control group had significant changes in all seven vertical variables but was only significantly different from the Hyrax group with respect to the N-A pt and the overbite. The control group’s N-A pt. increased significantly by $+1.63 \mathrm{~mm}$, and the control group's underbite increased by $+1.88 \mathrm{~mm}$. In contrast, the Hyrax group had significant changes in all measurement variables except the N-A pt. and overbite. The maxillary incisor vertical position relative to palatal plane (Is $\mathrm{NL}$ ) in the Double-hinged expander group measured only $0.06 \mathrm{~mm}$ more at time T2 than T1 and was significantly different from that of the control group, which had a significant change of $+2.16 \mathrm{~mm}$ to its vertical maxillary position.

Statistically significant differences between the three groups were found in two of the eight angular variables when reviewing the changes at time T2 in the treated groups and time t2 control group, respectively. The ANB angle showed a significant increase in the treated groups $\left(+2.57^{\circ}\right.$ for the Double-hinged group and $+3.61^{\circ}$ for the Hyrax group) and was significantly different from the control group. The Double-hinged expander group experienced a significant decrease in the angular measurement of SNB; whereas, the Hyrax expander group experienced a significant increase in the angular measurement of SNA. Furthermore, the Double-hinged expander group showed a significant increase in the maxillary central incisor angle (Is/ SNL), but when compared to the Hyrax expander group and the control group, there were no statistically significant differences among the three groups. 


\section{DISCUSSION}

\section{Reliability of Cephalometric Measurements}

The method of cephalometric analysis used in this study was based Pancherz's method of cephalometric analysis ${ }^{92}$. The error of most variables was within an acceptable limit for the treatment changes, as illustrated in Appendices A-D, and was therefore considered reliable.

It has been shown that identification error for different cephalometric landmarks can vary widely. However, Tng performed a study on human skulls in which he took a series of cephalograms with reference steel ball markers glued on the skulls to represent the "true" skeletal and dental landmarks and compared them to another series of cephalograms without steel ball markers to check the accuracy of the sagittal and vertical landmarks. Note that there was no steel ball markers were glued on the landmarks which represented the molar superius mesial cusp (Msc), molar inferius mesial cusp (Mic), and molar inferius (Mi), due to the overlapping right and left images on the cephalograms. Tng found no significant differences between the two series of cephalograms for sagittal and vertical landmarks. Thus, Pancherz’ method of analyzing the sagittal and vertical landmarks on a cephalogram can be considered accurate. ${ }^{93}$

\section{Comparison of All Groups}

For this study, the design of the appliance, anchorage device, treatment time, force magnitude and direction were standardized in order to minimize the number of variables to be interpreted when reviewing the data. Maxillary protraction was initiated on patients between the ages of 6 years 1 month to 10 years 1 month in this study. Takada $^{79}$ has shown that forward maxillary displacement with protraction is more favorable before or during acceleration of a child's pubertal growth spurt. 
Thus, the authors of this study reviewed the cervical vertebral maturation level in all treated and control group patients in order to assess the patient's skeletal age and to account for differences in treatment outcome that may be due to the pubertal growth spurt. The cervical maturation assessment used in this study was based on the new Cervical Vertebral Maturation (CVM) method developed and employed by Baccetti, Franchi, and McNamara. ${ }^{90}$ There were no statistically significant differences among any of the three groups (i.e., Double-hinged, Hyrax, and Control groups). Baik ${ }^{94}$ reported similar findings in that there were no statistical significant differences among the 47 subjects treated with rapid palatal expansion and protraction were divided into the following age groups: (1) less than ten years old; (2) between ten and 12 years; and (3) 12 years or older.

Statistically significant differences between the treated groups and control group were found in 12 of the 24 variables, as illustrated in Table 23. Majority of the significant changes in this study were found in the sagittal measurement variables of the treated groups which include OLp- A pt., OLp-B pt., OLp-Pg, Ii/OLp, Overjet, Mi/OLp, and Molar Relationship.

Haas has demonstrated that maxillary expansion alone to can produce a slight forward movement of point "A" along with a slight downward and forward movement of the maxilla. ${ }^{15}$ Furthermore, because the maxilla is articulated with nine other bones of the craniofacial complex palatal expansion can help to initiate a cellular response which will help to disarticulate the maxilla from the craniofacial complex. ${ }^{2}$ This will in turn ease maxillary protraction. 
The benefits of using rapid palatal expansion in conjunction with protraction were also reported in other studies. Ngan et al. ${ }^{95}$ reported $2.3 \mathrm{~mm}$ change with respect to "A" point in 20 Class III patients who were treated with rapid palatal expansion and protraction facemask for an average of six months. Similarly, Baik ${ }^{94}$ found $2.0 \mathrm{~mm}$ forward movement of "A" point in a sample of 47 subjects who were treated with rapid palatal expansion and protraction for a period of six months. Liou and Tsai ${ }^{1}$ were able to attain a stable overall $5.8 \pm 2.3 \mathrm{~mm}$ forward movement of "A" point through the use of an alternating rapid maxillary expansions and constrictions (Alt-RAMEC) protocol along with the use of a Double-hinged expander. Liou and Tsai attribute this success to the fact that the Alt-RAMEC group experienced "an orthopedic process of sutural expansion/protraction osteogenesis, which is similar, but less vigorous, than sutural distraction osteogenesis.” 1,2

In this study, the Hyrax and Double-hinged expander groups had significant forward movement of "A" point; however, only the Hyrax expander group was significantly different when compared to the control group. The Hyrax expander group had an average of $+2.57 \mathrm{~mm}$ advancement of "A" point, but the Double-hinged expander group had only $+1.78 \mathrm{~mm}$ advancement of " $\mathrm{A}$ " point possibly due to the fact that the Double-hinged expander subjects reported only wearing the protraction facemask for a period of 8-10 hours. Nanda ${ }^{77}$ and Ishii et al ${ }^{9}$ have reported similar "A" point changes of $1.5 \mathrm{~mm}$ and $2.1 \mathrm{~mm}$, respectively, following treatment with maxillary protraction and chincup therapy. Note that previous studies have found that the use of the chincup does not affect the anteroposterior growth of the maxilla. ${ }^{55,67}$ 
However, treatment using protraction facemask therapy could cause counterclockwise rotation of the palatal plane and extrusion of the maxillary molar which in turn may result in a downward and backward rotation of the mandible. ${ }^{9,12,17-19,71,94-97}$ This is a possible explanation for the skeletal changes seen in the control group where the position of the mandibular base (OLp-B pt.) and chin (OLp - Pg) showed significant forward movement whereas the treated groups did not.

Dentally, the Double-hinged expander group showed significant changes in all measurement variables but only had significant differences in four of the six measurement variables when compared to the control group. The Double-hinged expander subjects had a significant change of $-1.95 \mathrm{~mm}$ in the position of the mandibular incisor (Ii/OLp) as opposed to that of the control group’s significant change of +1.83 $\mathrm{mm}$. As previously mentioned, the control group's mandible continued forward growth contributed to the significant difference from the treated groups whose mandibles moved downward and backward as a result of treatment.

After accounting for mandibular skeletal and dental changes, the overjet correction in the treatment groups was not as much as shown in the initial results. Interestingly, the Double-hinged expansion group showed a significant mean change of $+5.22 \mathrm{~mm}$ overjet correction but actually only had $+0.13 \mathrm{~mm}$ of overjet correction. The Hyrax expansion group's significant change of $+4.68 \mathrm{~mm}$ was actually $+2.48 \mathrm{~mm}$ in overall overjet correction, which was more than the Double-hinged expansion group. This could be because the Hyrax expansion group had a more forward movement of "A" point and the Double-hinged expansion group had a more backward movement of the mandible. 
The position of the mandibular molar (Mi/OLp) in the Double-hinged expander group significantly differs that of the Hyrax expander group as well as that of the control group. This is due to the greater mandibular backward movement in the Double-hinged group. Again, when discussing the amount of molar correction, the skeletal and dental changes are taken into consideration because the downward and backward movement of the mandible will change the position of the measuring points associated with the sagittal variables OLp-Pg, Ii/OLp, and Mi/OLp, making them more negative.

The initial results show that the Double-hinged expander patients had $+3.35 \mathrm{~mm}$ molar relationship correction and the Hyrax expander patients had $+2.30 \mathrm{~mm}$ correction. However, after calculations were performed as described in Table 12, the amount of molar correction was $+0.61 \mathrm{~mm}$ in the Double-hinged expander group and $-0.34 \mathrm{~mm}$ in the Hyrax expander group. The greater molar correction in the Double-hinged expander group is possibly due to the significant backward movement of the mandibular molar related to the greater amount of downward and backward rotation of the mandible as compared to the Hyrax expander group.

Moreover, the treatment effect of maxillary expansion and protraction facemask therapy can only be appreciated once the changes related to growth have been taken into consideration. Figures 9 and 10 show the overall sagittal differences between the treated and control group for T2 - T1 and t2 - t1, respectively. Once growth is accounted for, the Double-hinged expander group actually had a decrease in overjet by $-1.88 \mathrm{~mm}$ as compared to the Hyrax expander group's increase of $+0.47 \mathrm{~mm}$. The treatment effect with regards to molar relationship correction was $-0.94 \mathrm{~mm}$ for the Double-hinged expander patients and $-1.89 \mathrm{~mm}$ for the Hyrax expander patients. This shows that growth 
can negatively affect the results of any correction that is attained through treatment using maxillary expansion and protraction facemask. Therefore, it is wise to consider overcorrecting the malocclusion in order to anticipate any potential changes due to growth.

Furthermore, it is important to keep in mind that the interpretation of any treatment changes involving the incisors and molars could be inaccurate due to the overlapping of the right and left images on cephalogram and due to the difficulty in identifying the mesial contact point of the upper molars that have bands on them. Although, bisecting of the right and left images were used in this study with consistency, results must be interpreted with care. This is especially true when interpreting the vertical dental changes due to transition between the deciduous and permanent dentition.

Of the seven vertical measurement points only N-A pt., Is - NL, and Overbite had significant changes. The Double-hinged expander group was significantly different from the control group, which had a significant vertical change of $+2.16 \mathrm{~mm}$ in the maxillary incisor position (Is - NL). A possible explanation is that the Double-hinged expander subjects experienced incisor proclination of $+5.5^{\circ}$ as opposed to the control group's incisor proclination of $0.17^{\circ}$. This may have been due to the difference in the design of the expander. The Double-hinged expander has a lingual bar that extends forward and touches the maxillary incisors’ cingulum area.

When compared to the control group, only the Hyrax expander group had significant differences with respect to the variables N-A pt. and overbite. In fact, the control group had a significant change in N-A pt (+1.63 mm). The Hyrax expander group had a minimal (+0.10 mm) downward movement of “A” point relative to Nasion. It can be concluded from this data that the Hyrax expansion group experienced more 
forward movement and less downward movement of the maxilla, which is the opposite pattern for the control group.

In addition, the Hyrax expansion group had a significantly different overbite than the control group. In fact, the Hyrax expander group had an openbite of $1.25 \mathrm{~mm}$; whereas the control group had a significant increase $1.88 \mathrm{~mm}$ in terms of an underbite. It is interesting to note that the Double-hinged expander patients did not experience a significant change in overbite (mean change of $-0.13 \mathrm{~mm}$ ). The protraction of the maxilla in combination with the significant vertical eruption of the maxillary and mandibular molars (Msc - NL and Mic -ML), may have contributed to the openbite seen in the Hyrax expansion group. There were no significant changes in Msc -NL and Mic - ML in the Double-hinged group.

Baik $^{94}$ reported $1.6 \mathrm{~mm}$ of maxillary molar extrusion and $1.7 \mathrm{~mm}$ of mandibular molar extrusion when a banded type rapid palatal expander was used in connection with protraction facemask over a period of six months. However, protraction treatment without expansion can also result in molar extrusion as noted by Takada ${ }^{79}$, who found significant molar extrusion greater than $1.8 \mathrm{~mm}$ in patients who were pre- and midpubertal stage.

Treatment was performed for nine months with the use of maxillary expansion at the start and then protraction facemask therapy after expansion was completed. Typically protraction of the maxillary arch will cause an anterior rotation and forward movement of the maxilla unless a downward vector of protraction force was also used, as shown by Hata et al. ${ }^{98}$ This was related to the point of force application on the maxilla. In the present study, protraction of the maxilla at the maxillary canine region with $30^{\circ}$ 
downward vector within a period of six months of protraction facemask therapy did not produce a significant change in the palatal plane.

The significant changes were evident in the SNA measurements. In reference to the cranial base, the protraction facemask therapy helped to displace the maxilla forward by an average of $1.44^{\circ}$ change in SNA for the Double-hinged expander group and by an average of $2.06^{\circ}$ change in SNA for the Hyrax expander group. Other investigators listed in Table 25 have found similar mean increase in SNA that range from 0.3 to 2.2 degrees.

Table 25. Mean Change in SNA Following Protraction Facemask Therapy

\begin{tabular}{|l|l|}
\hline References & Mean change in SNA \\
\hline Wisth et al. $^{78}, 1987$ & $0.3^{\circ}$ \\
\hline Tinlund $^{99}, 1989$ & $2.5^{\circ}$ \\
\hline Ngan et al. $^{71}, 1996$ & $1.3^{\circ}$ \\
\hline MacDonald $^{97}, 1999$ & $2.31^{\circ}$ \\
\hline Turley $^{100}, 2002$ & $2.35^{\circ}$ \\
\hline
\end{tabular}

Wisth et al ${ }^{78}$ studied 22 subjects with anterior crossbites who were treated for three to 12 months with a quad-helix and protraction facemask therapy, and the quadhelix was used for expansion only in children with anterior crossbite. The authors reported that the there were no significant forward displacement of the maxilla following protraction facemask therapy when comparing the treatment group to control group. However, in this study the treated groups had significant change in SNA as compared to the control group, which may an effect of orthopedic rapid palatal expansion prior to protraction therapy. 
Significant differences were present with regards to the ANB angle when comparing the treated groups to the control group. The large increase of $2.57^{\circ}$ in the Double-hinged expander group and a dramatic increase of $3.61^{\circ}$ in the Hyrax expander group occurred after six months of protraction facemask therapy. The significant increase in ANB angle is the result forward movement of the maxilla and the downward and backward rotation of the mandible.

Despite the significant change in Lop - B pt and OLp - Pg due to downward and backward rotation of the mandible, the lower anterior facial height (ANS-Me) did not significantly increase.

\section{Clinical Relevance.}

It can be concluded from the data gathered in this study that treatment of a skeletal Class III malocclusion at an early age when maxillary suture has not interlocked can be beneficial to the patient. Clinically both treatment groups showed improvement to the Class III malocclusion as compared to the control group. The Hyrax expander group appeared to have had a little more success possibly due to the fact that the Double-hinged expander patients' lack of compliance with regards to wearing the facemask for a requested period of 14-16 hours. The only statistically significant difference between the Double-hinged expansion group and the Hyrax expansion group, however, is related to the mandibular molar position (Mi/OLp) in which the Double-hinged expander group had a $-1.25 \mathrm{~mm}$ movement and the Hyrax expander group had a $+1.10 \mathrm{~mm}$ movement. This was because the Hyrax expander group had more vertical and mesial molar movement than the Double-hinged expander group. Hence, the Hyrax expander group also experienced more of an openbite than the Double-hinged expander group. 
A bonded type expander has the potential to reduce the tendency of posterior teeth extrusion, which has been observed when using the banded expanders. ${ }^{101}$ In addition, there have been less vertical changes reported with bonded expanders as compared to the banded expanders, possibly because of the splinting effect as well as the occlusal biteplate effect of the bonded expander. Therefore, it may be a good preventive measure to use bonded rapid palatal expander and protraction facemask therapy on patients who present with a Skeletal Class III openbite tendency.

\section{Consequences if Early Treatment is Not Rendered.}

The following lists the morphologic and functional changes that may occur if the Class III malocclusion is not treated early: increased loading of the teeth; disturbances in the functional equilibrium; impairment of the functions of chewing and speech, and even difficulties in prosthetic reconstruction. ${ }^{37}$ Other effects of delayed treatment of Class III malocclusions include psychosocial factors such as negative self-esteem and lower selfconfidence. Finally, the lack of early intervention for Class III patients will increase the likelihood of the need for orthognathic intervention at a later stage. ${ }^{9}$

\section{Individuality of Treatment Response.}

From this study, it can be concluded that success and failure of orthopedic treatment of children with skeletal Class III malocclusion is substantially dependent on the patient's compliance and the patient's growth potential. As observed, the Doublehinged expansion patients did not attain as much overjet correction as the Hyrax expansion patient, primarily due to the fact that the Double-hinged expansion patients reported only wearing the facemask for an average of 8-10 hours. However, it should be noted that the Double-hinged expansion patients showed marked improvement to the Class III malocclusion within the first few months of protraction. 
Furthermore, once growth was taken into consideration and subtracted from the treatment results to get the true amount of treatment effect, it was found that there was minimal change to overjet and molar correction. Therefore, one should consider overcorrecting the Class III malocclusion in order to anticipate any potential changes due to growth. 


\section{CHAPTER V}

\section{SUMMARY}

The purpose of this study is to evaluate the quantitative difference, if any, between the conventional protraction technique using the traditional Hyrax expander and the alternative protraction protocol with the Double-hinged expander as advocated by Liou. ${ }^{1}$ The differences between the two techniques were evaluated on lateral cephalometric radiographs, in which the skeletal and dental changes with maxillary expansion and protraction were measured.

Both treatment groups experienced statistically significant sagittal changes as compared to the control group. But the primary reason for the improvement of the Class III malocclusion is related to the downward and backward rotation of the mandible. The Hyrax expansion group had more "A" point forward movement, but the success may have been attributed to the higher level of compliance in this group compared to the Double-hinged expansion group. Future studies reviewing the length of time that protraction forces are placed on the maxilla can help to clarify the results of protraction facemask therapy. Finally, long-term follow-up studies are needed in order to evaluate the stability of this treatment modality. 


\section{REFERENCE LIST}

1. Liou, E. J. \& Tsai, W. C. A new protocol for maxillary protraction in cleft patients: repetitive weekly protocol of alternate rapid maxillary expansions and constrictions. Cleft Palate Craniofac. J 42, 121-127 (2005).

2. Liou, E. J. Effective maxillary orthopedic protraction for growing Class III patients: a clinical application simulates distraction osteogenesis. Prog. Orthod. 6, 154-171 (2005).

3. Liou, E. J. Toothborne orthopedic maxillary protraction in Class III patients. $J$ Clin. Orthod. 39, 68-75 (2005).

4. Riolo, M. \& Avery, J. Esentials for Orthodontic Practice. EFOP Press, Ann Arbor \& Grand Haven, MI (2003).

5. Guyer, E. C., Ellis, E. E., III, McNamara, J. A., Jr. \& Behrents, R. G. Components of class III malocclusion in juveniles and adolescents. Angle Orthod. 56, 7-30 (1986).

6. Ellis, E., III \& McNamara, J. A., Jr. Components of adult Class III malocclusion. J Oral Maxillofac. Surg. 42, 295-305 (1984).

7. Proffit, W. \& Fields Jr., H. Contemporary Orthodontics. Mosby, Inc., St. Louis, MO (2000).

8. Irie, M. \& Nakamura, S. Orthopedic approach to severe skeletal Class III malocclusion. Am. J Orthod. 67, 377-392 (1975).

9. Ishii, H., Morita, S., Takeuchi, Y. \& Nakamura, S. Treatment effect of combined maxillary protraction and chincap appliance in severe skeletal Class III cases. Am. J Orthod. Dentofacial Orthop. 92, 304-312 (1987).

10. McNamara, J. A., Jr. An orthopedic approach to the treatment of Class III malocclusion in young patients. J Clin. Orthod. 21, 598-608 (1987).

11. Turley, P. K. Orthopedic correction of Class III malocclusion with palatal expansion and custom protraction headgear. J Clin. Orthod. 22, 314-325 (1988).

12. Ngan, P. et al. Effect of protraction headgear on Class III malocclusion. Quintessence. Int. 23, 197-207 (1992). 
13. Staffenberg, D. A., Wood, R. J., McCarthy, J. G., Grayson, B. H. \& Glasberg, S. B. Midface distraction advancement in the canine without osteotomies. Ann. Plast. Surg. 34, 512-517 (1995).

14. Tung, T. H., Robertson, B. R., Winograd, J. M., Mullick, T. \& Manson, P. N. Successful distraction osteogenesis across a growing cranial suture without an osteotomy. Plast. Reconstr. Surg. 103, 362-370 (1999).

15. Haas, A. J. Palatal expansion: just the beginning of dentofacial orthopedics. Am. $J$ Orthod. 57, 219-255 (1970).

16. Movassaghi, K., Altobelli, D. E. \& Zhou, H. Frontonasal suture expansion in the rabbit using titanium screws. J Oral Maxillofac. Surg. 53, 1033-1042 (1995).

17. Williams, M. D., Sarver, D. M., Sadowsky, P. L. \& Bradley, E. Combined rapid maxillary expansion and protraction facemask in the treatment of Class III malocclusions in growing children: a prospective long-term study. Semin. Orthod. 3, 265-274 (1997).

18. Ngan, P. et al. Cephalometric and occlusal changes following maxillary expansion and protraction. Eur. J Orthod. 20, 237-254 (1998).

19. Vaughn, G. A., Mason, B., Moon, H. B. \& Turley, P. K. The effects of maxillary protraction therapy with or without rapid palatal expansion: a prospective, randomized clinical trial. Am. J Orthod. Dentofacial Orthop. 128, 299-309 (2005).

20. Melsen, B. Palatal growth studied on human autopsy material. A histologic microradiographic study. Am. J Orthod. 68, 42-54 (1975).

21. Huber RE \& Reynolds, J. A dentofacial study of male students at the University of Michigan in the physical hardening program. Am. J. Orthod. 32, 1-21 (1946).

22. Humphreys, H. F. \& Leighton, B. C. A survey of antero-posterior abnormalities of the jaws in children between the ages of 2 and $51 / 2$ years of age. Br. Dent $J$ 88, 3-15 (1950).

23. Massler, M. \& Frankel, J. M. Prevalence of malocclusion in children aged 14 to 18 years. Am. J Orthod. 37, 751-768 (1951).

24. Hill, I. N., Blayney, J. R. \& WOLF, W. The Evanston Dental Caries Study. XIX. Prevalence of malocclusion of children in a fluoridated and control area. J Dent Res 38, 782-794 (1959).

25. Newman, G. V. Prevalence of malocclusion in children six to fourteen years of age and treatment in preventable cases. J Am. Dent Assoc. 52, 566-575 (1956). 
26. Ast, D. B., Carlos, J. P. \& Cons, N. C. The Prevalence and Characteristics of Malocclusion among Senior High School Students in Upstate New York. Am. $J$ Orthod. 51, 437-445 (1965).

27. Ainsworth, N. J. Modern trends in the prevention of dental caries in children. Med. Press 227, 386-390 (1952).

28. Garner, L. D. \& Butt, M. H. Malocclusion in black Americans and Nyeri Kenyans. An epidemiologic study. Angle Orthod. 55, 139-146 (1985).

29. Iwagaki, H. Hereditary influence of malocclusion. Am. J. Orthod. Oral Surg 24, 328-338 (1938).

30. Allwright, W. \& Bundred, W. A survey of handicapping dentofacial anomalies among Chinese in Hong Kong. International Dent J 14, 505-519 (1964).

31. Bjork, A. The Face in Profile: An anthropological x-ray investigation of Swedish Children and Conscripts. Lund: Berlingska Boktrycheriet 40, 58 (1947).

32. Enrich, R. Prevalence of Class I, Class II, and Class III malocclusions (Angle) in an urban population. J Dent Res 44, 947 (1947).

33. Altemus LA Frequency of the incidence of malocclusion in American Negro children ages 12-16. Angle Orthod. 29, 189-200 (1964).

34. Horowitz, H. S. \& Doyle, J. Occlusal relations in children born and reared in an optimally fluoridated community. II. Clinical findings. Angle Orthod. 40, 104-111 (1970).

35. Litton, S. F., Ackermann, L. V., Isaacson, R. J. \& Shapiro, B. L. A genetic study of Class 3 malocclusion. Am. J Orthod. 58, 565-577 (1970).

36. Harris, J. E., Kowalski, C. J. \& Watnick, S. S. Genetic factors in the shape of the craniofacial complex. Angle Orthod. 43, 107-111 (1973).

37. Rakosi, T. \& Schilli, W. Class III anomalies: a coordinated approach to skeletal, dental, and soft tissue problems. J Oral Surg. 39, 860-870 (1981).

38. Enlow, D. Facial Growth. WB Saunders Co., Philadelphia, PA (1990).

39. Singh, G. D. Morphologic determinants in the etiology of class III malocclusions: a review. Clin. Anat. 12, 382-405 (1999).

40. Hopkin, G. B., Houston, W. J. \& James, G. A. The cranial base as an aetiological factor in malocclusion. Angle Orthod. 38, 250-255 (1968). 
41. Jarvinen, S. Saddle angle and maxillary prognathism: a radiological analysis of the association between the NSAr and SNA angles. Br. J Orthod. 11, 209-213 (1984).

42. Kasai, K., Moro, T., Kanazawa, E. \& Iwasawa, T. Relationship between cranial base and maxillofacial morphology. Eur. J Orthod. 17, 403-410 (1995).

43. Kerr, W. J. \& Adams, C. P. Cranial base and jaw relationship. Am. J Phys. Anthropol. 77, 213-220 (1988).

44. Hong, S. X. \& Yi, C. K. A classification and characterization of skeletal class III malocclusion on etio-pathogenic basis. Int. J Oral Maxillofac. Surg 30, 264-271 (2001).

45. McNamara, J. Jr. \& Brodudon, J. Orthodontic and Orthopedic Treatment in the Mixed Dentition. Needham Press, Inc., Ann Arbor, MI (1993).

46. Lew, K. K. \& Foong, W. C. Horizontal skeletal typing in an ethnic Chinese population with true Class III malocclusions. Br. J Orthod. 20, 19-23 (1993).

47. Kao, C. T., Chen, F. M., Lin, T. Y. \& Huang, T. H. The craniofacial morphologic structures of the adult with Class III malocclusion. Int. J Adult. Orthodon. Orthognath. Surg 10, 285-293 (1995).

48. Battagel, J. M. The aetiological factors in Class III malocclusion. Eur. J Orthod. 15, 347-370 (1993).

49. Baccetti, T., Antonini, A., Franchi, L., Tonti, M. \& Tollaro, I. Glenoid fossa position in different facial types: a cephalometric study. Br. J Orthod. 24, 55-59 (1997).

50. Battagel, J. M. \& Orton, H. S. Class III malocclusion: the post-retention findings following a non-extraction treatment approach. Eur. J Orthod. 15, 45-55 (1993).

51. Murakami, C., Hiyama, S. \& Ohyama, K. Craniofacial morphology of skeletal class III patients before treatment and growth-related changes during treatment with a maxillary protraction appliance: a comparison of orthodontic and surgical cases. World J Orthod. 6, 51-60 (2005).

52. McIntyre, G. T. Treatment planning in Class III malocclusion. Dent Update. 31, 13-20 (2004).

53. Joondeph, D. R. Early orthodontic treatment. Am. J Orthod. Dentofacial Orthop. 104, 199-200 (1993). 
54. Turpin, I. M., Furnas, D. W. \& Amlie, R. N. Craniofacial duplication (diprosopus). Plast. Reconstr. Surg. 67, 139-142 (1981).

55. Sugawara, J., Asano, T., Endo, N. \& Mitani, H. Long-term effects of chincap therapy on skeletal profile in mandibular prognathism. Am. J Orthod. Dentofacial Orthop. 98, 127-133 (1990).

56. Robertson, N. R. An examination of treatment changes in children treated with the function regulator of Frankel. Am. J Orthod. 83, 299-310 (1983).

57. Macey-Dare, L. V. The early management of Class III malocclusions using protraction headgear. Dent Update. 27, 508-513 (2000).

58. Hagg, U., Tse, A., Bendeus, M. \& Rabie, A. B. A follow-up study of early treatment of pseudo Class III malocclusion. Angle Orthod. 74, 465-472 (2004).

59. Frankel, R. Maxillary retrusion in Class 3 and treatment with the function corrector 3. Rep. Congr. Eur. Orthod. Soc. 249-259 (1970).

60. Loh, M. K. \& Kerr, W. J. The Function Regulator III: effects and indications for use. Br. J Orthod. 12, 153-157 (1985).

61. Ulgen, M. \& Firatli, S. The effects of the Frankel's function regulator on the Class III malocclusion. Am. J Orthod. Dentofacial Orthop. 105, 561-567 (1994).

62. Petit, H. Adaptations following accelerated facial mask therapy, in clinical alteration of the growing face. Craniofacial Growth Series . 1983. University of Michigan, Ann Arbor, Center for Human Growth and Development and Development.

63. McNamara, J. A., Jr. \& Huge, S. A. The functional regulator (FR-3) of Frankel. Am. J Orthod. 88, 409-424 (1985).

64. Graber, L. W. Chin cup therapy for mandibular prognathism. Am. J Orthod. 72, 23-41 (1977).

65. Mitani, H. \& Sakamoto, T. Chin cap force to a growing mandible. Long-term clinical reports. Angle Orthod. 54, 93-122 (1984).

66. Mitani, H. \& Fukazawa, H. Effects of chincap force on the timing and amount of mandibular growth associated with anterior reversed occlusion (Class III malocclusion) during puberty. Am. J Orthod. Dentofacial Orthop. 90, 454-463 (1986). 
67. Ritucci, R. \& Nanda, R. The effect of chin cup therapy on the growth and development of the cranial base and midface. Am. J Orthod. Dentofacial Orthop. 90, 475-483 (1986).

68. Allen, R. A., Connolly, I. H. \& Richardson, A. Early treatment of Class III incisor relationship using the chincap appliance. Eur. J Orthod. 15, 371-376 (1993).

69. Turley, P. K. Guidance of the Developing Class III Malocclusion. McNamara, J. A., Jr. Craniofacial Growth Series 35. 1999. Ann Arbor, Center for Human Growth and Development, The University of Michigan

70. Delaire, J. [Manufacture of the "orthopedic mask"]. Rev. Stomatol. Chir Maxillofac. 72, 579-582 (1971).

71. Ngan, P., Hagg, U., Yiu, C., Merwin, D. \& Wei, S. H. Soft tissue and dentoskeletal profile changes associated with maxillary expansion and protraction headgear treatment. Am. J Orthod. Dentofacial Orthop. 109, 38-49 (1996).

72. Mermigos, J., Full, C. A. \& Andreasen, G. Protraction of the maxillofacial complex. Am. J Orthod. Dentofacial Orthop. 98, 47-55 (1990).

73. Jackson, G. W., Kokich, V. G. \& Shapiro, P. A. Experimental and postexperimental response to anteriorly directed extraoral force in young Macaca nemestrina. Am. J Orthod. 75, 318-333 (1979).

74. Kambara, T. Dentofacial changes produced by extraoral forward force in the Macaca irus. Am. J Orthod. 71, 249-277 (1977).

75. Nanda, R. Protraction of maxilla in rhesus monkeys by controlled extraoral forces. Am. J Orthod. 74, 121-141 (1978).

76. Dellinger, E. L. A preliminary study of anterior maxillary displacement. Am. $J$ Orthod. 63, 509-516 (1973).

77. Nanda, R. Biomechanical and clinical considerations of a modified protraction headgear. Am. J Orthod. 78, 125-139 (1980).

78. Wisth, P. J., Tritrapunt, A., Rygh, P., Boe, O. E. \& Norderval, K. The effect of maxillary protraction on front occlusion and facial morphology. Acta Odontol. Scand. 45, 227-237 (1987).

79. Takada, K., Petdachai, S. \& Sakuda, M. Changes in dentofacial morphology in skeletal Class III children treated by a modified maxillary protraction headgear and a chin cup: a longitudinal cephalometric appraisal. Eur. J Orthod. 15, 211221 (1993). 
80. Nartallo-Turley, P. E. \& Turley, P. K. Cephalometric effects of combined palatal expansion and facemask therapy on Class III malocclusion. Angle Orthod. 68, 217-224 (1998).

81. Keles, A., Tokmak, E. C., Erverdi, N. \& Nanda, R. Effect of varying the force direction on maxillary orthopedic protraction. Angle Orthod. 72, 387-396 (2002).

82. Kokich, V. G., Shapiro, P. A., Oswald, R., Koskinen-Moffett, L. \& Clarren, S. K. Ankylosed teeth as abutments for maxillary protraction: a case report. Am. $J$ Orthod. 88, 303-307 (1985).

83. Smalley, W. M., Shapiro, P. A., Hohl, T. H., Kokich, V. G. \& Branemark, P. I. Osseointegrated titanium implants for maxillofacial protraction in monkeys. Am. $J$ Orthod. Dentofacial Orthop. 94, 285-295 (1988).

84. Singer, S. L., Henry, P. J. \& Rosenberg, I. Osseointegrated implants as an adjunct to facemask therapy: a case report. Angle Orthod. 70, 253-262 (2000).

85. Sherwood, K. H., Burch, J. G. \& Thompson, W. J. Closing anterior open bites by intruding molars with titanium miniplate anchorage. Am. J Orthod. Dentofacial Orthop. 122, 593-600 (2002).

86. Umemori, M., Sugawara, J., Mitani, H., Nagasaka, H. \& Kawamura, H. Skeletal anchorage system for open-bite correction. Am. J Orthod. Dentofacial Orthop. 115, 166-174 (1999).

87. Beyza, H., Zafer, O. \& Sina, U. Orthopedic Protraction with Skeletal Anchorage in Patient with Maxillary Hypoplasia and Hypodontia. Angle Orthod. 76, 156-163 (2005).

88. Alcan, T., Keles, A. \& Erverdi, N. The effects of a modified protraction headgear on maxilla. Am. J Orthod. Dentofacial Orthop. 117, 27-38 (2000).

89. Wang, Y. C., Chang, P. M. \& Liou, E. J. Opening of circumaxillary sutures by alternate rapid maxillary expansions and constrictions. Angle Orthod. 79, 230-234 (2009).

90. Baccetti, T., Franchi, L. \& McNamara, J. A., Jr. An improved version of the cervical vertebral maturation (CVM) method for the assessment of mandibular growth. Angle Orthod. 72, 316-323 (2002).

91. Bjork, A. The principle of the Andresen method of orthodontic treatment a discussion based on cephalometric x-ray analysis of treated cases. Am. J. Orthod. 37, 437-458 (1951). 
92. Pancherz, H. The mechanism of Class II correction in Herbst appliance treatment. A cephalometric investigation. Am. J. Orthod. 82, 104-113 (1982).

93. Tng, T. T., Chan, T. C., Hagg, U. \& Cooke, M. S. Validity of cephalometric landmarks. An experimental study on human skulls. Eur. J Orthod. 16, 110-120 (1994).

94. Baik, H. S. Clinical results of the maxillary protraction in Korean children. Am. $J$ Orthod. Dentofacial Orthop. 108, 583-592 (1995).

95. Ngan, P., Hagg, U., Yiu, C., Merwin, D. \& Wei, S. H. Treatment response to maxillary expansion and protraction. Eur. J Orthod. 18, 151-168 (1996).

96. Ngan, P. W., Hagg, U., Yiu, C. \& Wei, S. H. Treatment response and long-term dentofacial adaptations to maxillary expansion and protraction. Semin. Orthod. 3, 255-264 (1997).

97. Macdonald, K. E., Kapust, A. J. \& Turley, P. K. Cephalometric changes after the correction of class III malocclusion with maxillary expansion/facemask therapy. Am. J Orthod. Dentofacial Orthop. 116, 13-24 (1999).

98. Hata, S. et al. Biomechanical effects of maxillary protraction on the craniofacial complex. Am. J. Orthod. Dentofacial Orthop. 91, 305-311 (1987).

99. Tindlund, R. S. Orthopaedic protraction of the midface in the deciduous dentition. Results covering 3 years out of treatment. J Craniomaxillofac. Surg. 17 Suppl 1, 17-19 (1989).

100. Turley, P. K. Managing the developing Class III malocclusion with palatal expansion and facemask therapy. Am. J Orthod. Dentofacial Orthop. 122, 349352 (2002).

101. Sarver, D. M. \& Johnston, M. W. Skeletal changes in vertical and anterior displacement of the maxilla with bonded rapid palatal expansion appliances. Am. J. Orthod. Dentofacial Orthop. 95, 462-466 (1989). 
APPENDICES 


\section{APPENDIX A}

Intraclass Correlation Coefficient of Reliability for Sagittal Measurements

\begin{tabular}{|c|c|c|}
\hline Variable Name & Time & Reliability \\
\hline \multicolumn{3}{|l|}{ Skeletal } \\
\hline OLp - A pt. & $\mathrm{T} 1$ & 0.98979 \\
\hline OLp - B pt. & $\mathrm{T} 1$ & 0.99929 \\
\hline OLp - Pg & $\mathrm{T} 1$ & 0.99981 \\
\hline \multicolumn{3}{|l|}{ Dental } \\
\hline Is / OLp & $\mathrm{T} 1$ & 0.99874 \\
\hline Ii/ OLp & $\mathrm{T} 1$ & 0.99859 \\
\hline Overjet & $\mathrm{T} 1$ & 0.98737 \\
\hline Ms/OLp & $\mathrm{T} 1$ & 0.99982 \\
\hline Mi/OLp & $\mathrm{T} 1$ & 0.99983 \\
\hline Molar Relationship & $\mathrm{T} 1$ & 0.99819 \\
\hline \multicolumn{3}{|l|}{ Skeletal } \\
\hline OLp - A pt. & $\mathrm{T} 2$ & 0.99649 \\
\hline OLp - B pt. & $\mathrm{T} 2$ & 0.99856 \\
\hline OLp - Pg & $\mathrm{T} 2$ & 0.99650 \\
\hline \multicolumn{3}{|l|}{ Dental } \\
\hline Is / OLp & $\mathrm{T} 2$ & 0.99943 \\
\hline $\mathrm{Ii} / \mathrm{OLp}$ & $\mathrm{T} 2$ & 0.99896 \\
\hline Overjet & $\mathrm{T} 2$ & 0.99490 \\
\hline Ms/OLp & $\mathrm{T} 2$ & 0.99861 \\
\hline Mi/OLp & $\mathrm{T} 2$ & 0.99945 \\
\hline Molar Relationship & $\mathrm{T} 2$ & 0.93338 \\
\hline
\end{tabular}




\section{APPENDIX B}

Intraclass Correlation Coefficient of Reliability for Vertical Measurements

\begin{tabular}{|l|c|c|}
\hline Variable Name & Time & Reliability \\
\hline Skeletal & & \\
\hline N - A pt & T1 & 0.99941 \\
\hline ANS - Me & T1 & 0.99920 \\
\hline Dental & & \\
\hline Is - NL & T1 & 0.99560 \\
\hline Ii - ML & T1 & 0.99933 \\
\hline Overbite & T1 & 0.99489 \\
\hline Msc - NL & T1 & 0.98518 \\
\hline Mic - ML & T1 & 0.99934 \\
\hline & & \\
\hline Skeletal & & \\
\hline N - A pt & T2 & 0.99874 \\
\hline ANS - Me & T2 & 0.99754 \\
\hline Dental & & \\
\hline Is - NL & T2 & 0.99563 \\
\hline Ii - ML & T2 & 0.99780 \\
\hline Overbite & T2 & 0.99960 \\
\hline Msc - NL & T2 & 0.99346 \\
\hline Mic - ML & T2 & 0.99832 \\
\hline
\end{tabular}




\section{APPENDIX C}

Intraclass Correlation Coefficient of Reliability for Angular Measurements

\begin{tabular}{|l|c|c|}
\hline Variable Name & Time & Reliability \\
\hline Skeletal & & \\
\hline SNA & $\mathrm{T} 1$ & 0.99183 \\
\hline SNB & $\mathrm{T} 1$ & 0.99036 \\
\hline ANB & $\mathrm{T} 1$ & 0.99754 \\
\hline SNL - ML & $\mathrm{T} 1$ & 0.99991 \\
\hline SNL - OLs & $\mathrm{T} 1$ & 0.99854 \\
\hline SNL - NL & $\mathrm{T} 1$ & 0.88566 \\
\hline Dental & & \\
\hline Is / SNL & $\mathrm{T} 1$ & 0.99993 \\
\hline Ii / ML & $\mathrm{T} 1$ & 0.89261 \\
\hline & & \\
\hline Skeletal & & \\
\hline SNA & $\mathrm{T} 2$ & 0.99575 \\
\hline SNB & $\mathrm{T} 2$ & 0.99527 \\
\hline ANB & $\mathrm{T} 2$ & 0.99552 \\
\hline SNL - ML & $\mathrm{T} 2$ & 0.99136 \\
\hline SNL - OLs & $\mathrm{T} 2$ & 0.99732 \\
\hline SNL - NL & $\mathrm{T} 2$ & 0.99553 \\
\hline Dental & & \\
\hline Is / SNL & $\mathrm{T} 2$ & 0.99964 \\
\hline Ii / ML & $\mathrm{T} 2$ & 0.99394 \\
\hline & & \\
\hline
\end{tabular}




\section{APPENDIX D}

Intraclass Correlation Coefficient of Reliability for Superimpositions

\begin{tabular}{|c|c|c|c|}
\hline & Variable Name & Time & Reliability \\
\hline \multirow{11}{*}{ 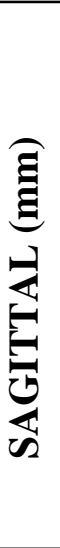 } & Skeletal & & \\
\hline & OLp - A pt. & $\mathrm{T} 2-\mathrm{T} 1$ & 0.81099 \\
\hline & OLp - B pt. & $\mathrm{T} 2-\mathrm{T} 1$ & 0.83303 \\
\hline & $\mathrm{OLp}-\mathrm{Pg}$ & $\mathrm{T} 2-\mathrm{T} 1$ & 0.83192 \\
\hline & Dental & & \\
\hline & Is / OLp & $\mathrm{T} 2-\mathrm{T} 1$ & 0.98587 \\
\hline & $\mathrm{Ii} / \mathrm{OLp}$ & $\mathrm{T} 2-\mathrm{T} 1$ & 0.98526 \\
\hline & Overjet & $\mathrm{T} 2-\mathrm{T} 1$ & 0.95158 \\
\hline & Ms/OLp & $\mathrm{T} 2-\mathrm{T} 1$ & 0.98521 \\
\hline & Mi/OLp & $\mathrm{T} 2-\mathrm{T} 1$ & 0.93664 \\
\hline & Molar Relationship & $\mathrm{T} 2-\mathrm{T} 1$ & 0.96216 \\
\hline \multirow{9}{*}{ 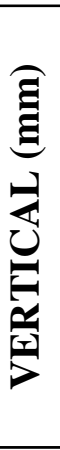 } & Skeletal & & \\
\hline & $\mathrm{N}-\mathrm{A} p \mathrm{t}$ & $\mathrm{T} 2-\mathrm{T} 1$ & 0.97030 \\
\hline & ANS - Me & $\mathrm{T} 2-\mathrm{T} 1$ & 0.98788 \\
\hline & Dental & & \\
\hline & Is - NL & $\mathrm{T} 2-\mathrm{T} 1$ & 0.95383 \\
\hline & $\mathrm{Ii}-\mathrm{ML}$ & $\mathrm{T} 2-\mathrm{T} 1$ & 0.94953 \\
\hline & Overbite & $\mathrm{T} 2-\mathrm{T} 1$ & 0.99568 \\
\hline & Msc - NL & $\mathrm{T} 2-\mathrm{T} 1$ & 0.89454 \\
\hline & Mic - ML & $\mathrm{T} 2-\mathrm{T} 1$ & 0.99221 \\
\hline \multirow{10}{*}{ 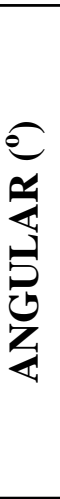 } & Skeletal & & \\
\hline & SNA & $\mathrm{T} 2-\mathrm{T} 1$ & 0.95158 \\
\hline & SNB & $\mathrm{T} 2-\mathrm{T} 1$ & 0.9759 \\
\hline & ANB & $\mathrm{T} 2-\mathrm{T} 1$ & 0.96112 \\
\hline & SNL - ML & $\mathrm{T} 2-\mathrm{T} 1$ & 0.99405 \\
\hline & SNL - OLs & $\mathrm{T} 2-\mathrm{T} 1$ & 0.98337 \\
\hline & SNL - NL & $\mathrm{T} 2-\mathrm{T} 1$ & 0.97119 \\
\hline & Dental & & \\
\hline & Is / SNL & $\mathrm{T} 2-\mathrm{T} 1$ & 0.99357 \\
\hline & $\mathrm{Ii} / \mathrm{ML}$ & $\mathrm{T} 2-\mathrm{T} 1$ & 0.92210 \\
\hline
\end{tabular}


APPENDIX E

Error of Sagittal Measurements

\begin{tabular}{|c|c|c|c|c|c|c|c|c|c|}
\hline & Variables (mm) & \multicolumn{4}{|c|}{$\mathbf{T 1}$} & \multicolumn{4}{|c|}{$\mathbf{T} 2$} \\
\hline \multirow{12}{*}{ 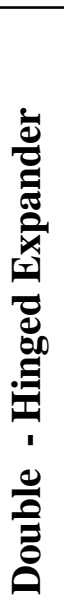 } & Sagittal & Min & Max & Mean & S.D. & Min & Max & Mean & S.D. \\
\hline & Skeletal & & & & & & & & \\
\hline & 1. OLp - A pt. & 69.76 & 83.22 & 77.88 & 3.86 & 72.11 & 83.82 & 79.70 & 3.58 \\
\hline & 2. OLp - B pt. & 79.97 & 92.10 & 85.12 & 3.71 & 79.54 & 91.28 & 83.75 & 3.66 \\
\hline & 3. OLp - Pg & 81.59 & 95.00 & 87.19 & 4.13 & 79.44 & 95.57 & 86.13 & 4.87 \\
\hline & Dental & & & & & & & & \\
\hline & 4. Is/OLp & 75.56 & 90.86 & 83.89 & 4.57 & 80.74 & 94.99 & 87.19 & 3.89 \\
\hline & 5. $\mathrm{Ii} / \mathrm{OLp}$ & 79.77 & 91.25 & 84.64 & 3.28 & 78.96 & 90.27 & 82.77 & 3.39 \\
\hline & 6. Overjet & -4.22 & 3.75 & -0.76 & 2.38 & 0.51 & 6.96 & 4.43 & 2.02 \\
\hline & 7. $\mathrm{Ms} / \mathrm{OLp}$ & 44.78 & 57.90 & 52.97 & 4.05 & 46.06 & 61.95 & 54.99 & 4.67 \\
\hline & 8. $\mathrm{Mi} / \mathrm{OLp}$ & 49.35 & 64.83 & 56.86 & 4.65 & 49.03 & 63.21 & 55.52 & 4.37 \\
\hline & 9. Molar Rel. & -7.97 & 0.31 & -3.89 & 2.73 & -3.00 & 4.41 & -0.53 & 2.27 \\
\hline \multirow{12}{*}{ 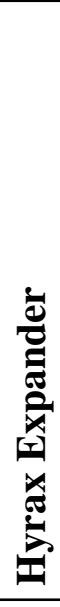 } & Sagittal & Min & Max & Mean & S.D. & Min & Max & Mean & S.D. \\
\hline & Skeletal & & & & & & & & \\
\hline & 1. OLp - A pt. & 62.66 & 70.45 & 67.65 & 2.92 & 66.03 & 73.59 & 70.49 & 2.95 \\
\hline & 2. OLp - B pt. & 71.49 & 85.75 & 76.72 & 4.33 & 69.71 & 82.28 & 75.55 & 4.10 \\
\hline & 3. OLp - Pg & 71.82 & 87.75 & 78.29 & 4.71 & 70.98 & 83.83 & 77.30 & 4.22 \\
\hline & Dental & & & & & & & & \\
\hline & 4. Is/OLp & 71.30 & 77.73 & 74.97 & 2.57 & 74.07 & 84.61 & 79.49 & 3.58 \\
\hline & 5. $\mathrm{Ii} / \mathrm{OLp}$ & 74.40 & 80.59 & 77.74 & 2.73 & 70.04 & 80.96 & 75.98 & 4.42 \\
\hline & 6. Overjet & -4.06 & -1.63 & -2.77 & 0.98 & 1.24 & 7.18 & 3.51 & 1.88 \\
\hline & 7. $\mathrm{Ms} / \mathrm{OLp}$ & 40.67 & 59.53 & 48.52 & 5.79 & 46.33 & 65.57 & 52.41 & 6.08 \\
\hline & 8. $\mathrm{Mi} / \mathrm{OLp}$ & 45.76 & 65.19 & 51.65 & 6.35 & 45.24 & 65.16 & 52.41 & 6.59 \\
\hline & 9. Molar Rel. & -6.90 & -1.00 & -3.12 & 2.08 & -2.77 & 1.09 & 0.01 & 1.11 \\
\hline \multirow{12}{*}{$\stackrel{\bar{O}}{\grave{B}}$} & Sagittal & Min & Max & Mean & S.D. & Min & $\operatorname{Max}$ & Mean & S.D. \\
\hline & Skeletal & & & & & & & & \\
\hline & 1. OLp - A pt. & 65.62 & 74.89 & 69.37 & 2.95 & 66.84 & 75.31 & 69.93 & 2.49 \\
\hline & 2. OLp - B pt. & 70.76 & 88.05 & 76.73 & 5.97 & 72.92 & 89.40 & 78.22 & 6.02 \\
\hline & 3. OLp - Pg & 71.43 & 90.00 & 78.35 & 6.49 & 73.28 & 91.51 & 80.31 & 7.04 \\
\hline & Dental & & & & & & & & \\
\hline & 4. Is/OLp & 71.63 & 83.72 & 75.12 & 3.97 & 71.51 & 85.47 & 76.34 & 4.73 \\
\hline & 5. $\mathrm{Ii} / \mathrm{OLp}$ & 73.83 & 86.13 & 77.77 & 4.38 & 74.18 & 87.80 & 79.51 & 4.67 \\
\hline & 6. Overjet & -4.56 & -1.87 & -2.67 & 0.88 & -4.62 & -2.34 & -3.17 & 0.68 \\
\hline & 7. Ms/OLp & 42.63 & 56.57 & 47.87 & 5.32 & 44.88 & 58.09 & 49.38 & 5.16 \\
\hline & 8. $\mathrm{Mi} / \mathrm{OLp}$ & 43.90 & 61.99 & 50.92 & 6.38 & 47.48 & 63.81 & 52.96 & 6.40 \\
\hline & 9. Molar Rel. & -7.45 & -0.04 & -3.05 & 2.46 & -8.48 & -1.21 & -3.58 & 2.30 \\
\hline
\end{tabular}




\section{APPENDIX F}

Error of Vertical Measurements

\begin{tabular}{|c|c|c|c|c|c|c|c|c|c|}
\hline \multirow{11}{*}{ 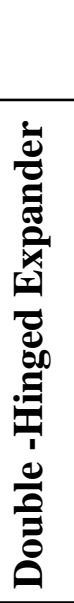 } & Variables (mm) & \multicolumn{4}{|c|}{$\mathbf{T 1}$} & \multicolumn{4}{|c|}{$\mathbf{T} 2$} \\
\hline & Vertical & Min & Max & Mean & S.D. & Min & Max & Mean & S.D. \\
\hline & Skeletal & & & & & & & & \\
\hline & 10. N-A pt. & 49.84 & 63.02 & 55.51 & 4.17 & 49.18 & 64.03 & 55.96 & 4.55 \\
\hline & 11. ANS - Me & 61.19 & 75.90 & 67.08 & 4.69 & 64.04 & 77.49 & 68.62 & 3.92 \\
\hline & Dental & & & & & & & & \\
\hline & 12. Is $-\mathrm{NL}$ & 25.39 & 31.90 & 27.66 & 2.13 & 24.95 & 30.63 & 27.42 & 1.89 \\
\hline & 13. Ii - ML & 35.84 & 42.07 & 38.76 & 2.58 & 37.76 & 43.95 & 40.74 & 2.18 \\
\hline & 14. Overbite & -0.76 & 4.96 & 2.03 & 2.17 & -2.07 & 5.46 & 2.02 & 2.38 \\
\hline & 15. Msc - NL & 15.03 & 24.01 & 18.95 & 2.52 & 16.37 & 24.28 & 19.00 & 2.67 \\
\hline & 16. Mic-ML & 24.67 & 34.09 & 29.45 & 2.74 & 25.08 & 32.10 & 30.08 & 2.25 \\
\hline \multirow{10}{*}{ 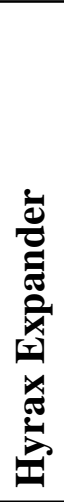 } & Vertical & Min & Max & Mean & S.D. & Min & Max & Mean & S.D. \\
\hline & Skeletal & & & & & & & & \\
\hline & 10. N-A pt. & 49.03 & 57.41 & 53.48 & 2.88 & 46.34 & 58.20 & 53.72 & 3.50 \\
\hline & 11. ANS - Me & 57.44 & 62.68 & 60.50 & 1.68 & 59.74 & 69.07 & 63.57 & 3.19 \\
\hline & Dental & & & & & & & & \\
\hline & 12. Is - NL & 21.63 & 27.87 & 25.78 & 1.86 & 23.07 & 27.80 & 26.24 & 1.65 \\
\hline & 13. Ii - ML & 35.02 & 39.87 & 37.51 & 1.65 & 36.88 & 41.53 & 39.07 & 1.21 \\
\hline & 14. Overbite & -0.78 & 9.46 & 3.41 & 3.42 & 0.36 & 4.06 & 2.22 & 1.44 \\
\hline & 15. Msc - NL & 15.47 & 21.09 & 18.48 & 1.86 & 17.88 & 21.84 & 19.77 & 1.51 \\
\hline & 16. Mic - ML & 25.45 & 31.13 & 28.04 & 2.02 & 26.33 & 32.18 & 29.42 & 1.66 \\
\hline \multirow{10}{*}{ 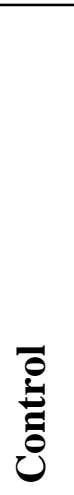 } & Vertical & Min & Max & Mean & S.D. & Min & Max & Mean & S.D. \\
\hline & Skeletal & & & & & & & & \\
\hline & 10. N-A pt. & 49.11 & 55.22 & 52.67 & 2.43 & 50.83 & 57.38 & 54.42 & 2.17 \\
\hline & 11. ANS - Me & 55.27 & 70.03 & 61.25 & 5.31 & 58.49 & 70.22 & 63.23 & 5.03 \\
\hline & Dental & & & & & & & & \\
\hline & 12. Is $-\mathrm{NL}$ & 19.57 & 30.18 & 23.88 & 3.58 & 20.92 & 31.56 & 26.07 & 3.42 \\
\hline & 13. Ii - ML & 37.33 & 43.16 & 40.37 & 2.24 & 37.96 & 44.94 & 41.88 & 2.44 \\
\hline & 14. Overbite & 1.79 & 7.02 & 3.46 & 1.84 & 3.72 & 7.33 & 5.25 & 1.56 \\
\hline & 15. Msc - NL & 13.24 & 21.75 & 17.24 & 2.81 & 15.66 & 21.54 & 18.84 & 2.10 \\
\hline & 16. Mic - ML & 26.51 & 31.93 & 29.60 & 1.70 & 27.71 & 33.92 & 30.59 & 2.14 \\
\hline
\end{tabular}




\section{APPENDIX G}

Error of Angular Measurements

\begin{tabular}{|c|c|c|c|c|c|c|c|c|c|}
\hline & Variables $\left({ }^{0}\right)$ & \multicolumn{4}{|c|}{ T1 } & \multicolumn{4}{|c|}{$\mathbf{T 2}$} \\
\hline \multirow{11}{*}{ 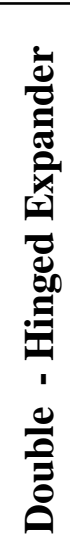 } & Angular & Min & Max & Mean & S.D. & Min & Max & Mean & S.D. \\
\hline & Skeletal & & & & & & & & \\
\hline & 17. SNA & 72.5 & 82.5 & 79.3 & 3.0 & 75.3 & 88.6 & 80.8 & 3.6 \\
\hline & 18. SNB & 73.0 & 81.75 & 79.2 & 2.6 & 72.0 & 81.3 & 78.1 & 3.1 \\
\hline & 19. ANB & -3.4 & 3.8 & 0.1 & 2.4 & -1.5 & 7.6 & 2.7 & 3.1 \\
\hline & 20. SNL - ML & 29.8 & 38 & 35.0 & 2.8 & 27.8 & 39.3 & 36.5 & 3.6 \\
\hline & 21. SNL - OLs & 15.0 & 26.5 & 21.0 & 3.9 & 14 & 26.5 & 19.8 & 5.2 \\
\hline & 22. SNL - NL & 1.8 & 11.5 & 5.7 & 3.1 & 1.3 & 9.5 & 5.9 & 2.8 \\
\hline & \multicolumn{9}{|c|}{ Dental } \\
\hline & 23. Is/ SNL & 83.3 & 116 & 98.8 & 12.5 & 90.3 & 117.5 & 104.1 & 10.1 \\
\hline & 24. Ii /ML & 72 & 94 & 84.8 & 6.7 & 75.5 & 91.5 & 83.4 & 5.4 \\
\hline \multirow{11}{*}{ 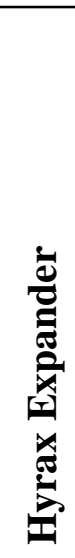 } & Angular & Min & Max & Mean & S.D. & Min & Max & Mean & S.D. \\
\hline & Skeletal & & & & & & & & \\
\hline & 17. SNA & 76.3 & 83.0 & 79.3 & 2.8 & 78.0 & 86.8 & 81.7 & 3.2 \\
\hline & 18. SNB & 77.0 & 85.5 & 80.3 & 2.8 & 76.5 & 82.3 & 78.9 & 1.9 \\
\hline & 19. ANB & -5.5 & 3.0 & -1.0 & 2.7 & 1.0 & 4.8 & 2.8 & 1.5 \\
\hline & 20. SNL - ML & 32.3 & 40.3 & 36.3 & 2.6 & 34.8 & 41.8 & 38.0 & 2.2 \\
\hline & 21. SNL - OLs & 15.3 & 29.0 & 23.3 & 4.1 & 15.5 & 25.3 & 21.2 & 2.8 \\
\hline & 22. SNL - NL & 1.8 & 12.0 & 8.3 & 3.2 & 2.5 & 10.8 & 7.3 & 2.6 \\
\hline & Dental & & & & & & & & \\
\hline & 23. Is/ SNL & 91.5 & 121 & 104.3 & 8.8 & 98.5 & 117 & 109 & 5.5 \\
\hline & 24. Ii /ML & 73 & 106.3 & 91.1 & 10.4 & 75.8 & 105.3 & 87.9 & 11.4 \\
\hline \multirow{11}{*}{$\begin{array}{l}\overline{0} \\
\bar{\theta} \\
0\end{array}$} & Angular & Min & Max & Mean & S.D. & Min & Max & Mean & S.D \\
\hline & Skeletal & & & & & & & & \\
\hline & 17. SNA & 75.0 & 83.5 & 79.8 & 3.3 & 74.3 & 84 & 79.7 & 3.8 \\
\hline & 18. SNB & 75.5 & 85.3 & 79.8 & 2.9 & 76.5 & 86.3 & 79.8 & 3.0 \\
\hline & 19. ANB & -3.0 & 3.0 & 0.1 & 2.2 & -3.0 & 4.8 & -0.1 & 3.0 \\
\hline & 20. SNL - ML & 31.8 & 42 & 36.4 & 3.5 & 31 & 40.8 & 36.2 & 4.2 \\
\hline & 21. SNL - OLs & 17 & 27.8 & 21.4 & 3.9 & 15.3 & 29.3 & 22.5 & 5.4 \\
\hline & 22. SNL - NL & 3.5 & 12.0 & 8.1 & 3.1 & 3.8 & 12.3 & 7.9 & 2.6 \\
\hline & Dental & & & & & & & & \\
\hline & 23. Is/ SNL & 96.0 & 107.5 & 101.1 & 4.9 & 89.5 & 112.3 & 101.0 & 9.5 \\
\hline & 24. Ii /ML & 81.3 & 95.0 & 89.0 & 3.6 & 81.0 & 100.0 & 88.9 & 7.9 \\
\hline
\end{tabular}




\section{APPENDIX H}

Error of Superimpositions

\begin{tabular}{|c|c|c|c|c|c|c|}
\hline & Variable Name & Time & Min & Max & $\begin{array}{c}\text { Mean } \\
\text { Difference }\end{array}$ & S.D. \\
\hline \multirow{11}{*}{ 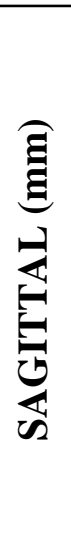 } & Skeletal & & & & & \\
\hline & OLp - A pt. & $\mathrm{T} 2-\mathrm{T} 1$ & 1.14 & 1.87 & -0.46 & 0.66 \\
\hline & OLp - B pt. & $\mathrm{T} 2-\mathrm{T} 1$ & -1.10 & -0.66 & -0.04 & 0.17 \\
\hline & OLp - Pg & $\mathrm{T} 2-\mathrm{T} 1$ & -0.70 & -0.45 & -0.28 & 0.32 \\
\hline & Dental & & & & & \\
\hline & Is / OLp & $\mathrm{T} 2-\mathrm{T} 1$ & 3.41 & 3.62 & -0.21 & 0.18 \\
\hline & Ii/ OLp & $\mathrm{T} 2-\mathrm{T} 1$ & -1.24 & -1.18 & -0.07 & 0.07 \\
\hline & Overjet & $\mathrm{T} 2-\mathrm{T} 1$ & 4.58 & 4.86 & -0.15 & 0.16 \\
\hline & Ms/OLp & $\mathrm{T} 2-\mathrm{T} 1$ & 1.94 & 2.04 & -0.15 & 0.16 \\
\hline & Mi/OLp & $\mathrm{T} 2-\mathrm{T} 1$ & -1.38 & -0.87 & -0.13 & 0.25 \\
\hline & Molar Relationship & $\mathrm{T} 2-\mathrm{T} 1$ & 2.81 & 3.43 & -0.02 & 0.26 \\
\hline \multirow{9}{*}{ 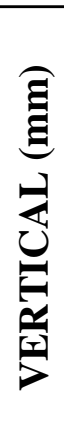 } & Skeletal & & & & & \\
\hline & $\mathrm{N}-\mathrm{Apt}$ & $\mathrm{T} 2-\mathrm{T} 1$ & 0.64 & 1.51 & -0.05 & 0.23 \\
\hline & ANS - Me & $\mathrm{T} 2-\mathrm{T} 1$ & 2.46 & 3.21 & 0.13 & 0.22 \\
\hline & Dental & & & & & \\
\hline & Is - NL & $\mathrm{T} 2-\mathrm{T} 1$ & -0.15 & 0.08 & -0.25 & 0.15 \\
\hline & $\mathrm{Ii}-\mathrm{ML}$ & $\mathrm{T} 2-\mathrm{T} 1$ & 1.86 & 1.90 & 0.24 & 0.13 \\
\hline & Overbite & $\mathrm{T} 2-\mathrm{T} 1$ & -0.11 & 0.44 & 0.21 & 0.13 \\
\hline & Msc - NL & $\mathrm{T} 2-\mathrm{T} 1$ & -0.65 & 1.11 & -0.24 & 0.50 \\
\hline & Mic - ML & $\mathrm{T} 2-\mathrm{T} 1$ & 0.05 & 0.29 & 0.16 & 0.14 \\
\hline \multirow{10}{*}{ 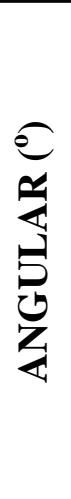 } & Skeletal & & & & & \\
\hline & SNA & $\mathrm{T} 2-\mathrm{T} 1$ & 0.8 & 1.5 & 0.6 & 0.24 \\
\hline & SNB & $\mathrm{T} 2-\mathrm{T} 1$ & -1.5 & -0.7 & -0.3 & 0.37 \\
\hline & ANB & $\mathrm{T} 2-\mathrm{T} 1$ & 2.2 & 2.3 & 0.9 & 0.19 \\
\hline & SNL - ML & $\mathrm{T} 2-\mathrm{T} 1$ & 1.1 & 1.3 & -0.4 & 0.35 \\
\hline & SNL - OLs & $\mathrm{T} 2-\mathrm{T} 1$ & -2.8 & -1.9 & -0.6 & 0.41 \\
\hline & SNL - NL & $\mathrm{T} 2-\mathrm{T} 1$ & -1.5 & -1.3 & 0.3 & 0.29 \\
\hline & Dental & & & & & \\
\hline & Is / SNL & $\mathrm{T} 2-\mathrm{T} 1$ & 5.2 & 6.7 & -0.5 & 0.16 \\
\hline & Ii / ML & $\mathrm{T} 2-\mathrm{T} 1$ & -3.3 & -1.3 & -1.5 & 2.26 \\
\hline
\end{tabular}

